Portland State University

PDXScholar

Dissertations and Theses

Dissertations and Theses

Spring 5-20-2014

\title{
Health and Well-being of Young Adults with Cerebral Palsy
}

Susan Elizabeth Sienko

Portland State University

Follow this and additional works at: https://pdxscholar.library.pdx.edu/open_access_etds

Part of the Physiology Commons

Let us know how access to this document benefits you.

\section{Recommended Citation}

Sienko, Susan Elizabeth, "Health and Well-being of Young Adults with Cerebral Palsy" (2014).

Dissertations and Theses. Paper 1819.

https://doi.org/10.15760/etd.1818

This Dissertation is brought to you for free and open access. It has been accepted for inclusion in Dissertations and Theses by an authorized administrator of PDXScholar. Please contact us if we can make this document more accessible: pdxscholar@pdx.edu. 
Health and Well-being of Young Adults with Cerebral Palsy

by

Susan Elizabeth Sienko

A dissertation submitted in partial fulfillment of the requirements for the degree of

Doctor of Philosophy

in

Systems Science

Dissertation Committee:

Wayne Wakeland, Chair

Paula Carder

Donald Lollar

Laurie Powers

Portland State University

2014 
(C) 2014 Susan Elizabeth Sienko 


\begin{abstract}
Health is a multidimensional, holistic, concept integrating physical and mental health. In childhood, the most common cause of physical disability is Cerebral Palsy (CP). For individuals with $\mathrm{CP}$, health and well-being is impacted by the complex interactions among their physical impairments, activity, participation and environmental barriers. Although CP is considered non-progressive, secondary conditions (pain and fatigue) and their functional consequences have been found to worsen as the individual with $\mathrm{CP}$ ages. While preliminary evidence shows that many of the physical impairments (pain, fatigue, depression) reported in adults with $\mathrm{CP}$ begin during late adolescence, there is little information about the role personal and environmental factors, impairments, activity limitations, and participation restrictions have on health and well-being of young adults with $\mathrm{CP}$.
\end{abstract}

To understand the health and well-being of young adults with $\mathrm{CP}$, the International Classification of Functioning, Disability and Health (ICF), a World Health Organization framework, guided the selection of survey instruments for this study. Surveys were sent to 610 young adults (18-30 years) with CP. 95 surveys were returned, 55 were selfreported and 40 were completed by proxies. Increasing severity of impairment was associated with decreased participation in daily activities and social roles, while loss of ambulatory ability, pain, fatigue, depression, and activity level did not differ by severity Abstract 
of impairment. Environmental barriers restricted the level of participation only for the self-report participants. Health status was decreased in those who self-reported increased pain, fatigue, and depression; offset by emotional support. Life satisfaction was decreased by depression and poor health; offset by emotional support.

Addressing the physical impairments, activity limitations, participation restrictions, personal factors and environmental barriers impacting young adults with $\mathrm{CP}$ requires coordinated efforts among the medical, educational and vocational systems. These efforts need to begin early with appropriate assessment and treatment of impairments, provision of assistive technologies and augmentative communication, and adaptation of the environment to facilitate participation in activities and social roles. The health and well-being in young adults with CP can also be improved with enhanced emotional support beyond the family unit through peer support groups, mentors, and other adult role models. 


\section{Acknowledgements}

Although it is not possible to thank everyone who supported me throughout my academic journey, I would like to express my heartfelt thanks the following people:

My husband, Jim, for being my "rock" and taking on many additional household and parenting duties during the many years it took me to complete my degree. My daughters, Morgan and Sydney, for understanding that my classes and homework often took away from the time I had to spend with them. My parents, who taught me that you are never too old to learn and that an education provides you with opportunities that you may never get otherwise. My siblings: Sharon, who provided the inspiration to begin this journey and Stephanie and Stephen, who supported me along the way.

My committee: Wayne Wakeland, for his ability to navigate me through the roadblocks along my path to my PhD and seeing me through to the end. Paula, Don and Laurie for their guidance and constructive feedback on the many drafts of my proposal, and articles, all of which enhanced this final dissertation.

My systems science professors: George Lendaris for his insight into multiple perspectives and Martin Zwick for teaching about reconstructability analysis as a method for looking at big data and the complex relationships among multiple variables. 
My systems science classmates: Teresa and Rajesh, whom without their support and continual study sessions, I would not have made it through my comprehensive exams. Robin for being my statistics and modeling study partner and providing me with a step by step guide to completing my comp proposal, dissertation proposal and graduation requirements.

Dr Michael Aiona, Dr Michael Sussman, Dr Peter Blasco and my work colleagues Cathleen and Kirsten, for supporting me during my classwork and my dissertation process, especially Cathleen for listening to me over the many years of my schooling and for reading the many iterations of my dissertation proposal and articles. Susan Labhard, the Shriners Hospitals for Children transition nurse who always believed in my research and the potential of the data. The Shriners Hospitals for Children and the Child Development and Rehabilitation Center (CDRC) of Oregon Health and Sciences University, Institute on Development \& Disability for providing me access to their patient databases for recruitment. My professional colleagues in the American Academy of Cerebral Palsy and Developmental Medicine (AACPDM) who inspire me through their research endeavors and their passion for enhancing the health and well-being of individuals with childhood-onset disabilities throughout the lifespan. To, Daniel Coleman, for his statistical consultations. 
I would like to thank all of my friends who have been there during my "rants", kept me on track and provided me with good wine to get through the rough times. Finally, I would like to thank the parents and youth with CP that I have worked with over the past 30 years for providing me with the inspiration for my dissertation and to all of the young adults with $\mathrm{CP}$ who took the time to complete their surveys. Without them, this dissertation would not be possible. As Hillary would say, "It takes a village" and I thank each and everyone who contributed to this journey. 


\section{Table of Contents}

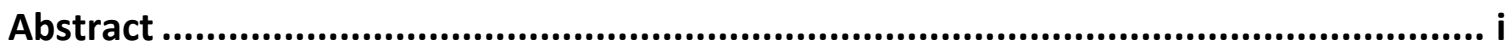

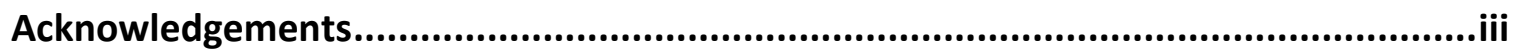

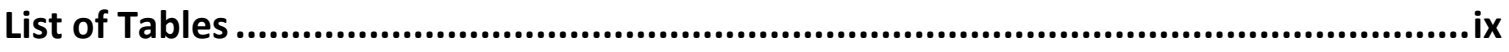

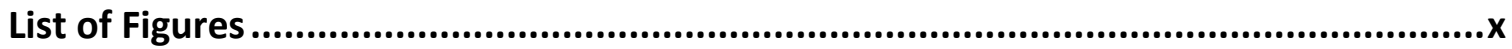

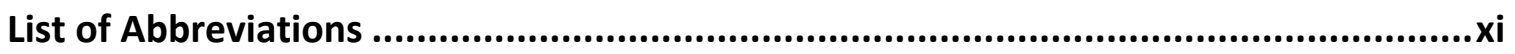

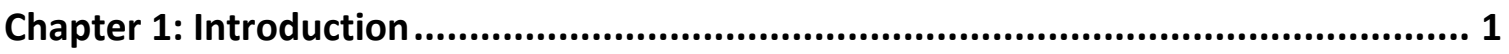

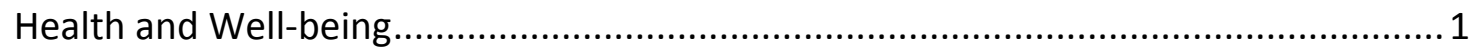

International Classification of Functioning, Disability and Health (ICF) ....................... 1

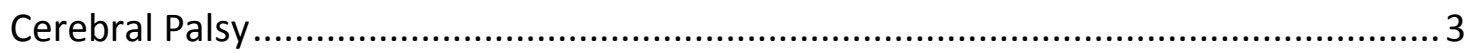

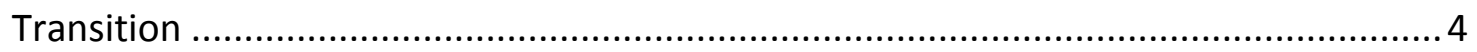

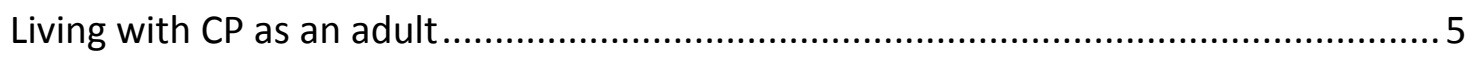

Theoretical lens and aims of this research ........................................................... 7

Chapter 2: Methods and Statistical Analysis ......................................................11

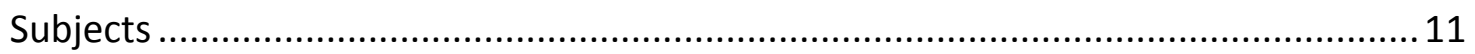

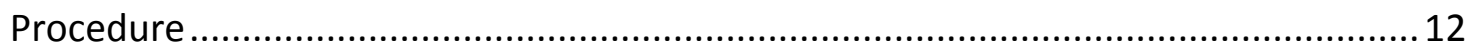

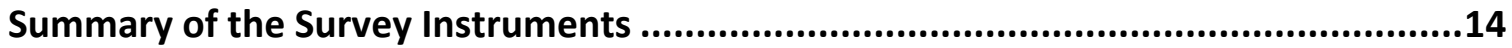

Impairments of body structure and function ........................................................ 14

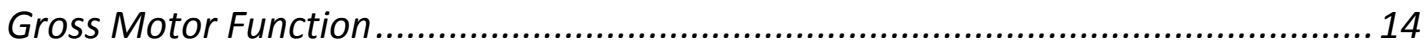

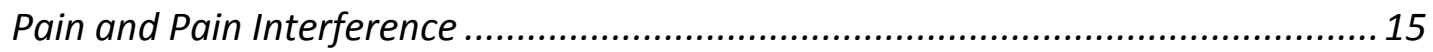

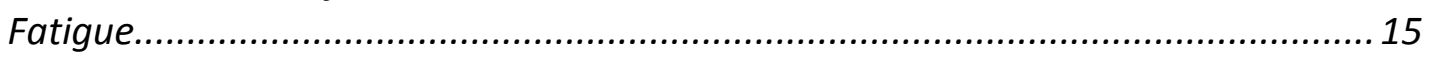

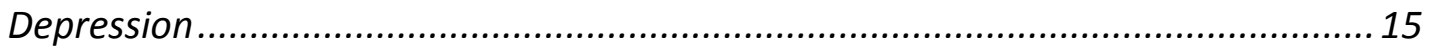

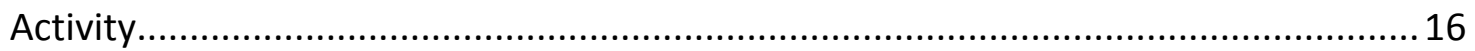

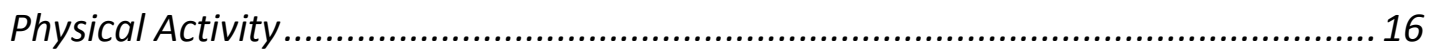

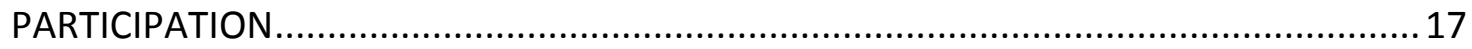

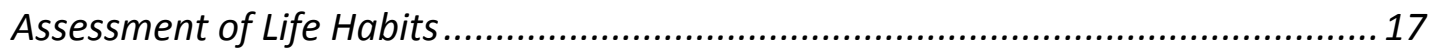

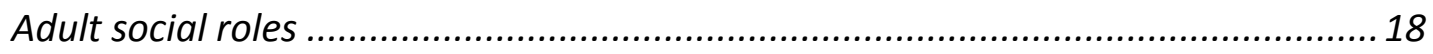

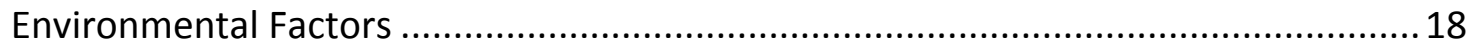

Environmental Barriers................................................................................. 18

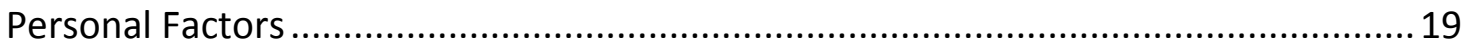

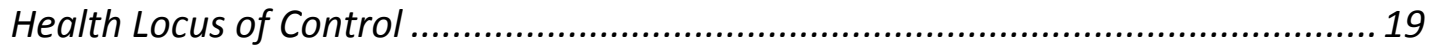

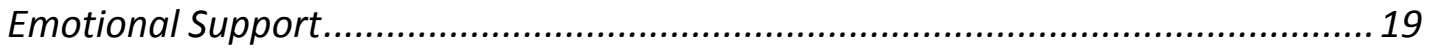

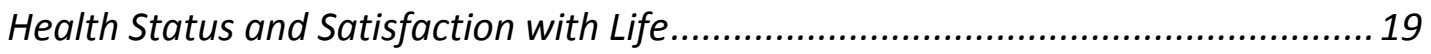

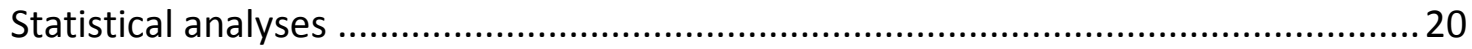

Chapter 3: Article 1 .....................................................................................21

An exploratory study investigating the multidimensional factors impacting the health and well-being of young adults with cerebral palsy. 


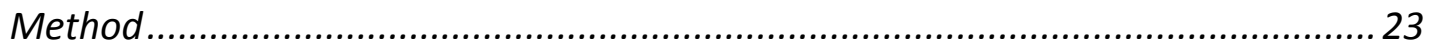

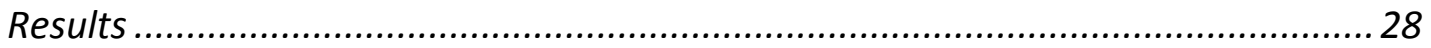

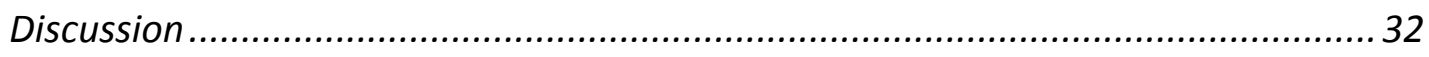

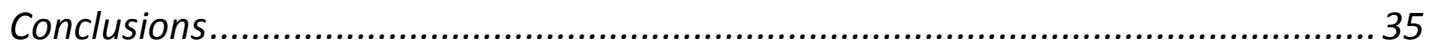

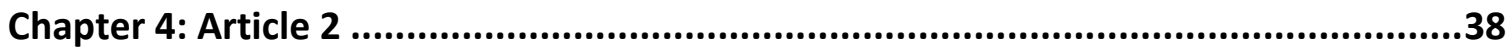

Participation in physical activity and recreation in young adults with cerebral palsy: an exploratory study into the role of functional motor impairment and environmental

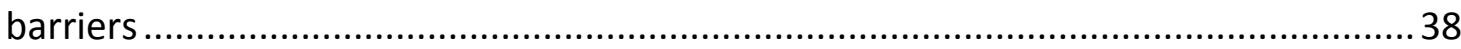

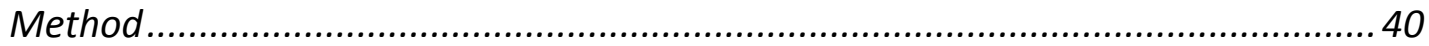

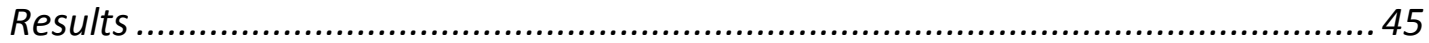

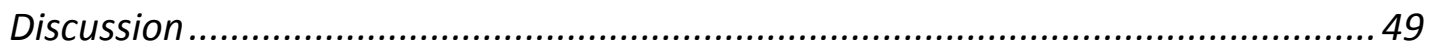

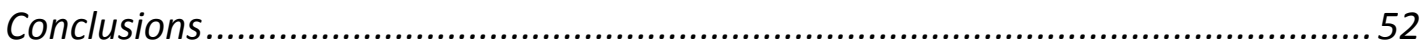

Chapter 5: Article 3 ...............................................................................................54

The role of functional motor level and environmental barriers on participation and satisfaction with life in young adults with cerebral palsy: an exploratory analysis .....54

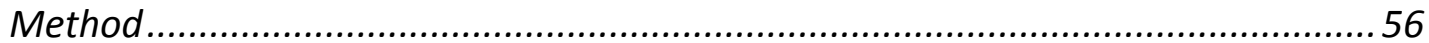

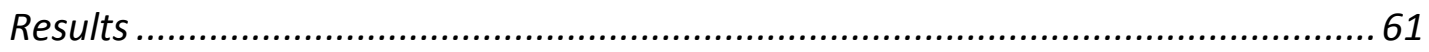

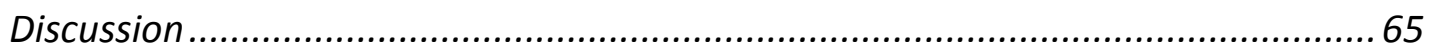

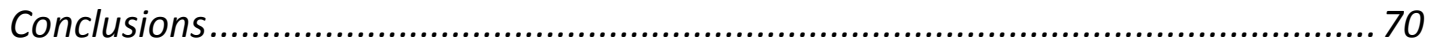

Chapter 6: Article 4 .......................................................................................71

Proxy report of functional impairments, activity limitations and participation restrictions in young adults with cerebral palsy: an exploratory study of the role of functional motor level and environmental barriers ................................................. 71

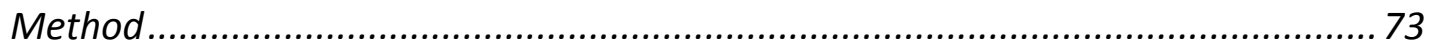

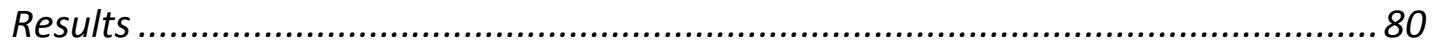

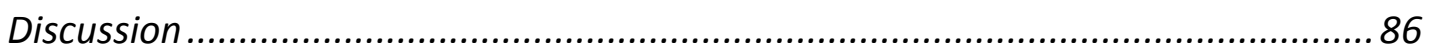

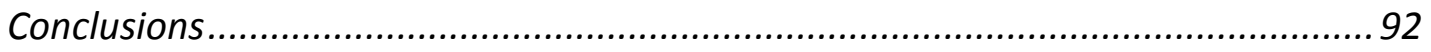

Chapter 7: Methodological Considerations and Potential limitations .......................93

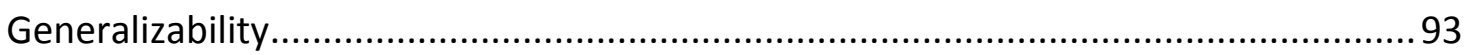

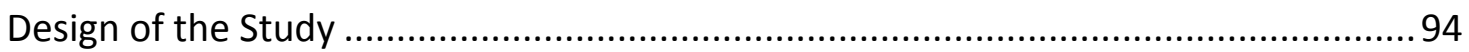

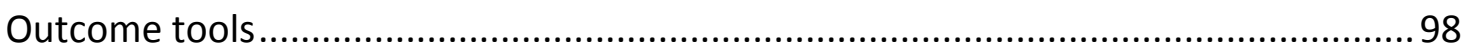

Chapter 8: Synthesis and Discussion ..............................................................100

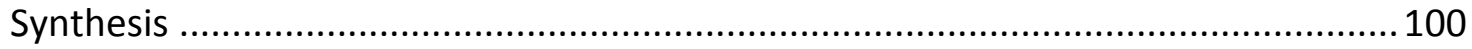

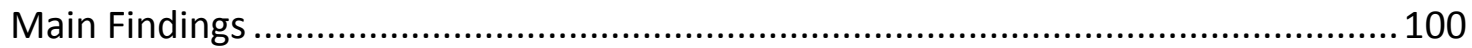

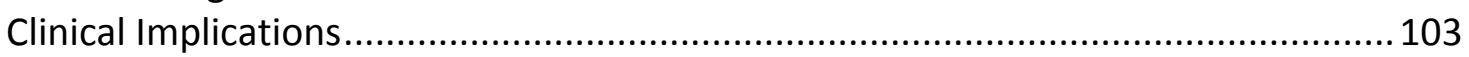

Coordination among medical professionals, services, companies, families and young adults with CP to address impairments in body structure and function................. 104 Coordination among medical professionals, services, companies, families and young adults with $C P$ to address activity limitations. 
Coordination among medical professionals, services, companies, families and young adults with CP to address participation restrictions...................................... 107

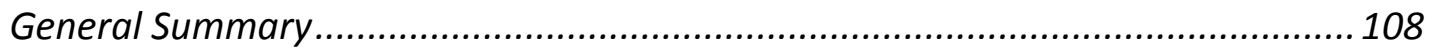

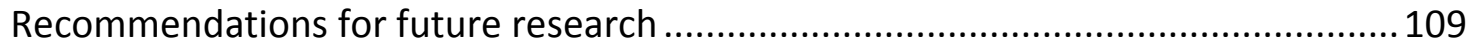

Research to reduce the impact of impairments in body and structure ..................109

Research to improve physical activity .......................................................... 109

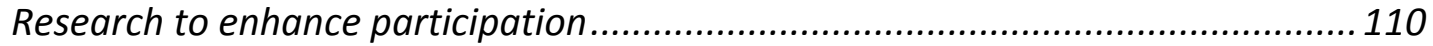

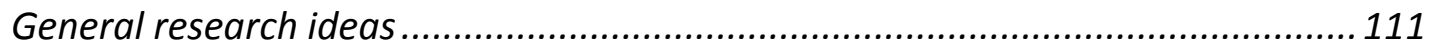

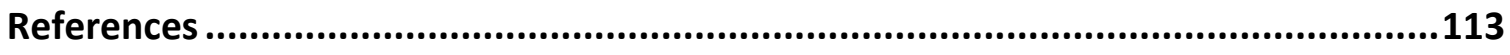




\section{List of Tables}

TABLE 1: DEMOGRAPHICS OF THE TOTAL GROUP AND FOR SELF AND PROXY RESPONDENTS BY FUNCTIONAL

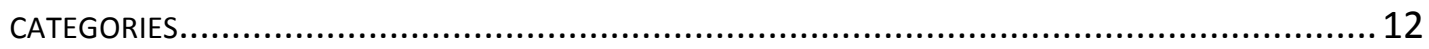

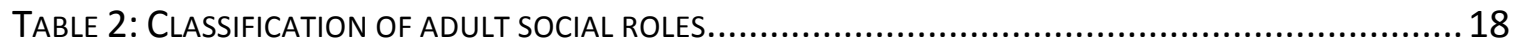

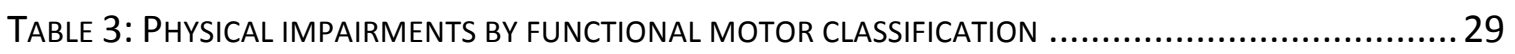

TABLE 4: TIME AND MAGNITUDE OF PHYSICAL ACTIVITY AND PARTICIPATION IN FITNESS AND RECREATIONAL

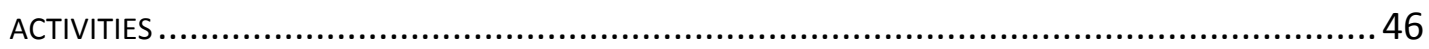

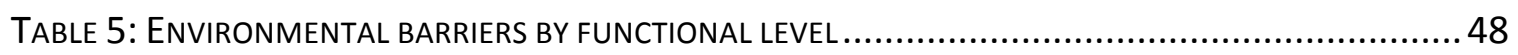

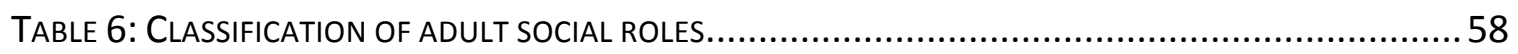

TABLE 7: ENVIRONMENTAL BARRIERS AND LIFE-H DOMAINS BY FUNCTIONAL LEVEL ............................ 64

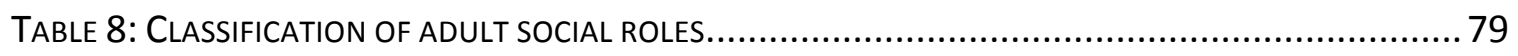

TABLE 9: IMPAIRMENTS, ACTIVITIES AND PARTICIPATION BY FUNCTIONAL LEVEL (PROXY-REPORT)........... 82

TABLE 10: ENVIRONMENTAL BARRIERS BY FUNCTIONAL LEVEL AND ASSOCIATIONS (PEARSON CORRELATION COEFFICIENTS) AMONG ENVIRONMENTAL BARRIERS AND PARTICIPATION IN DAILY ACTIVITIES AND

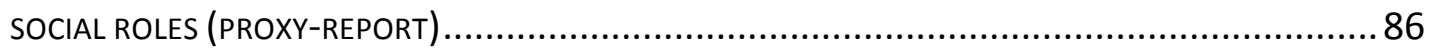




\section{List of Figures}

Figure 1: International Classification of Functioning, Disability and Health $(\text { ICF })^{6} \ldots \ldots \ldots \ldots . . . . . . .3$

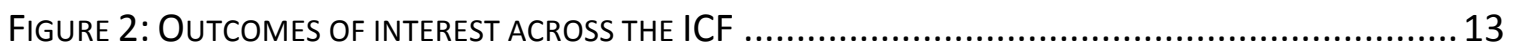

FIGURE 3: MAGNITUDE OF THE INTERFERENCE OF PAIN ON SPECIFIC ACTIVITIES BY FUNCTIONAL MOTOR

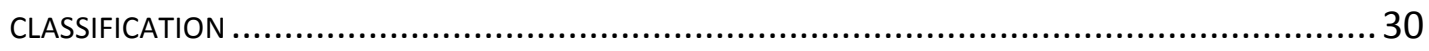

FIGURE 4: HEALTH LOCUS OF CONTROL AND EMOTIONAL SUPPORT BY FUNCTIONAL MOTOR CLASSIFICATION

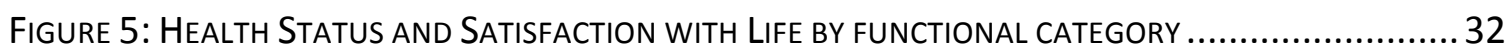

FIGURE 6: NUMBER OF HOURS PER DAY AND NUMBER OF DAYS PER WEEK SPENT PARTICIPATING IN

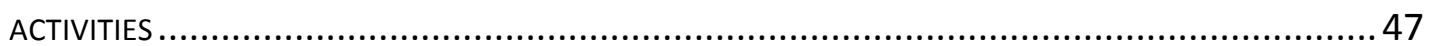

FIGURE 7: LIFE-H PARTICIPATION IN DAILY ACTIVITIES AND SOCIAL ROLES BY FUNCTIONAL LEVEL .............62

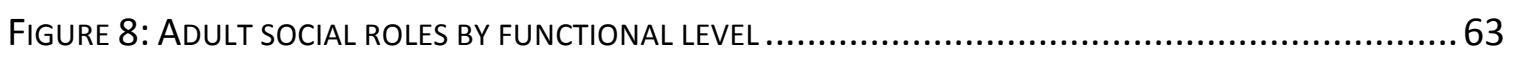

FIGURE 9: NUMBER OF HOURS PER DAY AND DAYS PER WEEK SPENT PARTICIPATING IN ACTIVITIES (PROXY-

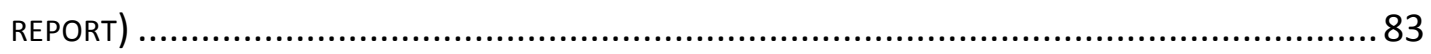

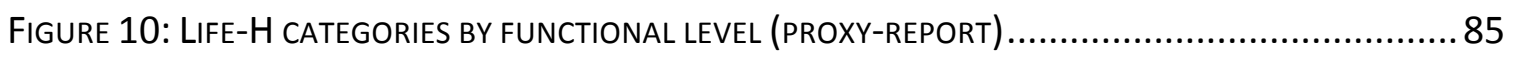

Figure 11: Representation of the Complex Relationships that exist among Professionals, SERVICES, COMPANIES, AND FAMILIES, WHICH IMPACT THE HEALTH AND WELL-BEING OF YOUNG ADULTS WITH CP 


$\begin{array}{ll}\text { List of Abbreviations } \\ \text { ANOVA } & \text { Analysis of Variance } \\ \text { BPI } & \text { Brief Pain Inventory } \\ \text { BRFSS } & \text { Behavioral Risk Factor Surveillance System } \\ \text { CHIEF } & \text { Craig Hospital Inventory of Environmental Factors } \\ \text { CP } & \text { Cerebral Palsy } \\ \text { CDRC } & \text { Child Development and Rehabilitation Center (CDRC) of Oregon Health and } \\ & \text { Sciences University, Institute on Development \& Disability } \\ \text { FAS } & \text { Fatigue Assessment Scale } \\ \text { GMFCS } & \text { Gross Motor Function Classification System } \\ \text { HSRRC } & \text { Human Subjects Research Review Committee } \\ \text { ICF } & \text { International Classification of Functioning, Disability and Health } \\ \text { Life-H } & \text { The Assessment of Life Habits short version 3.0 } \\ \text { MHLC } & \text { Multidimensional Health Locus of Control } \\ \text { PASIPD } & \text { Physical Activity Scale for Individuals with Physical Disabilities } \\ \text { PHQ-9 } & \text { Patient Health Questionnaire-9 } \\ \text { SHC-P } & \text { Shriners Hospitals for Children, Portland } \\ \text { WHO } & \text { World Health Organization }\end{array}$




\section{Chapter 1: Introduction}

\section{HEALTH AND WELL-BEING}

Health is a multidimensional, holistic, complex concept integrating not only physical health, but mental health or the balance among physical, emotional, social, and spiritual components. ${ }^{1 ; 2}$ For individuals with childhood onset disabilities a holistic approach to health is often overshadowed by the imperative to address the medical problems that arise as a result of their primary disability. ${ }^{3}$ Due to the connections among physical, mental, personal and environmental factors, the assessment of health in individuals with disabilities is a complex task. It has been reported in the literature that for some individuals with disabilities, the absence of illness or disability is not a prerequisite for health, but rather it is a function of the interaction of the person with the environment that influences overall health. ${ }^{4 ; 1}$

\section{INTERNATIONAL CLASSIFICATION OF FUNCTIONING, DISABILITY AND HEALTH (ICF)}

A model is a description, pattern, plan, or representation designed to show the structure or workings of an object, system, process or concept. ${ }^{5}$ Models are often used to represent complex structures and relationships or to help explain or understand difficult or multi-dimensional concepts. The International Classification of Functioning, Disability and Health (ICF) is a multi-purpose classification system of health and healthrelated domains, approved by the World Health Organization (WHO) in $2001 .^{6}$ The ICF is a multivariable and interconnected framework where functioning and disability are a 
multidimensional phenomenon experienced at the level of the body, the person and society. Over the past 10 years, the ICF framework (Figure 1) has been used to understand the complex interactions that influence personal health and well-being, including factors that either constrain or enhance functional possibilities. Similar to a "dynamic system", the ICF recognizes that interventions or changes in one element of the system will very likely have an impact on other aspects of an individuals life. ${ }^{7}$ From a systems perspective, the center of the model has three functional dimensions: body functions and structures, activities, and participation. ${ }^{8}$ The ICF also includes personal and environment contextual factors, acknowledging the pivotal role they have on impairment, activity and participation.

At the organ level, body functions and structures refers to the physiological and psychological functions of the various body systems (cardiovascular system or structures related to movement); while recognizing the impairments of body structure or the alterations from the norm in the functioning of these systems and typically are the anatomical manifestation of the underlying pathology. ${ }^{9}$ At the personal level, activity refers to the execution of a task or action by an individual, ${ }^{10 ; 6}$ recognizing the limitations in activities or the challenges and/or difficulties that an individual may experience in performing particular tasks. ${ }^{9}$ Finally, at the societal level, participation is the involvement of a person in life situations acknowledging the challenges in the ability of the individual to be involved or engaged in particular life roles, such as learning and 
applying knowledge, mobility in different environments, or interpersonal interactions and relationships. ${ }^{9}$

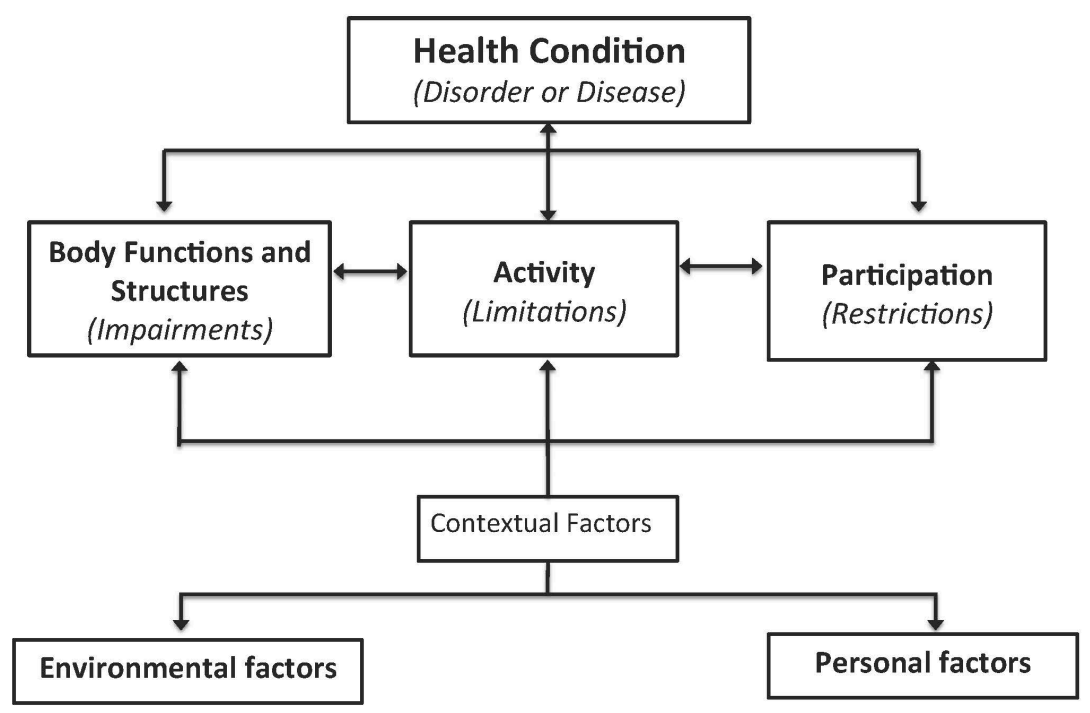

Figure 1: International Classification of Functioning, Disability AND HeAlth (ICF) ${ }^{6}$ CEREBRAL PALSY

Cerebral palsy (CP) is defined as "a group of permanent disorders of the development of movement and posture, causing activity limitation, that are attributed to nonprogressive disturbances that occurred in the developing fetal or infant brain. The motor disorders of $\mathrm{CP}$ are often accompanied by disturbances in sensation, perception, cognition, communication, and behavior; by epilepsy, and by secondary musculoskeletal problems." ${ }^{11}$

$\mathrm{CP}$ is considered the most common cause of physical disability in childhood. Recent 
reports suggest that the prevalence of $\mathrm{CP}$ among children is 2.0-2.5 children per 1000 live births or approximately 1 in every 500 children born has CP. ${ }^{12}$ While the prevalence of CP has remained fairly stable over time, there has been a slight increase in the prevalence of CP since the 1980 's. ${ }^{13}$ Improvements in treatment and care for individuals with $\mathrm{CP}$ over the last 20 years have contributed to a life expectancy that is similar to the general population. ${ }^{14-16}$ It is now estimated that there are approximately $400,000-$ 500,000 adults with CP living in the United States. ${ }^{17}$

Although the diagnostic categorization of $\mathrm{CP}$ is homogenous, differences in functional ability and cognitive involvement contribute to heterogeneity in activities and participation for individuals with CP. In the 1990's, the Gross Motor Function Classification System (GMFCS) was created to classify individuals with CP using the constructs of disability and functional limitations. ${ }^{18}$ During childhood, the GMFCS is often used as a prognostic tool for functional ambulation ${ }^{19}$ and as a tool to help explain differences in outcomes following treatment. More recently, as researchers begin to evaluate the health and function of adults with CP, the GMFCS has provided a classification system to discriminate among health outcomes. ${ }^{20 ; 21}$

\section{TRANSITION}

Transition to adulthood is a dynamic, complex, multidimensional, multidisciplinary and multiagency phenomenon requiring a systematic approach to the complex interactions between the person and environment. ${ }^{22 ;} 23$ During the course of a lifetime, individuals Chapter 1 
experience numerous transitions, with the transition to adulthood being one of the most momentous. ${ }^{24}$ While, the transition from adolescence to adulthood is a normal developmental stage, young adults with CP find themselves needing to fulfill adult roles and responsibilities such as moving from dependent to independent living, furthering their education, finding employment and becoming financially independent. ${ }^{25}$ Encompassed by changes in physical, psychological, and social development, transition to adulthood is often a difficult developmental phase for many young adults with $\mathrm{CP}$, impacting both their health and well-being. ${ }^{26 ; 27}$

\section{LIVING WITH CP AS AN ADULT}

While cerebral palsy is considered a static condition, adults with cerebral palsy perceive that deterioration in function and development of secondary conditions such as musculoskeletal deformity, fatigue and pain occur at an earlier age than reported for the general population. ${ }^{28-31}$ Adults with $\mathrm{CP}$ report that they experience pain daily, with prevalence rates ranging from $67-84 \%,{ }^{32-36 ; 31}$ rendering pain as one of the most common secondary conditions. ${ }^{33 ; 36}$ In addition to pain, co-occurring impairments of fatigue and decreased balance contribute to the loss in ambulation experienced by adults with $\mathrm{CP} .{ }^{33 ; 37}$ The pain and fatigue that occur with aging with $\mathrm{CP}$, in conjunction with the deterioration in functional abilities are associated with depression and decreased quality of life. ${ }^{38 ; 34 ; 35 ; 31}$ 
Decreases in flexibility, muscular strength and endurance, increased fatigue and low levels of physical activity cause a cycle of deconditioning, restrict functional independence and increase the risk for chronic disease. ${ }^{39 ; 30 ; 40 ; 41}$ Participation in regular exercise has been promoted as an effective way to improve strength and cardiovascular fitness, reduce pain, and have a positive influence in the prevention of secondary conditions, $^{42 ; 43}$ yet most adults with CP do not adhere to a regular exercise program of stretching, strengthening and aerobics, leading to further decline in functional ability. ${ }^{32}$ While $75 \%$ of young adults with CP between the ages of $21-31$ years report independence in activities of daily living, young adults with CP are poorly integrated socially, in education, paid employment and sports activities. ${ }^{38 ; 44}$ In order to determine potential avenues for improving health and well-being during adulthood, it is necessary to understand the complex relationships that exist between the young adult with cerebral palsy and the personal and environmental contextual factors, which either constrain or enhance their functional abilities, participation and quality of life.

While the decline in function and increased impairments that occur with aging with $\mathrm{CP}$ play a role in activity and participation; personal factors, such as education, income, motivation, ability, self-worth, and social support, in addition to the physical, social and attitudinal contextual factors wielded by the environmental exert additional influences on functioning and may increase the gap between capacity and performance for adults with $\mathrm{CP} .{ }^{9}$ Therefore, the utilization of the ICF model provides the paradigm shift towards 
a holistic view of health and well-being for individuals with $\mathrm{CP}$, seeing them as a whole person rather than an individual defined by their impairments. ${ }^{1}$ By utilizing the ICF framework to understand the complex relationships that encompass all aspects of health and disability for the young adult with cerebral palsy as they transition into adulthood, leverage points for change within the system can be identified and a holistic approach to the improvement in overall health and well-being can be provided to individuals with cerebral palsy. ${ }^{45}$

\section{Theoretical lens and aims of this research}

Over the last 10 years, there has been a proliferation of research on the health status and quality of life of adults with CP. For the adult with CP, the normative aging process interacts with the motor disorder, contributing to an increase incidence in pain, fatigue

and depression. ${ }^{30 ; 31}$ It has been found that the ability of adults with CP to participate in fitness programs, activities of daily living and social roles is influenced by level of impairment, personal factors and environmental barriers. While the short-term goal of pediatric health care is to minimize the impairments to maximize function, the longterm goal of treatment is to ensure that adults with CP lead healthy and productive lives. Little information exists about whether the onset of pain, fatigue and depression begins with the transition to adulthood; little is known about the role impairments, personal factors and environmental barriers have on the ability of the young adult with $\mathrm{CP}$ to 
participate in fitness and activities of daily living and begin the acquisition of adult social roles.

I have worked with individuals with CP for more than 30 years. Only recently however, have I thought more about the overall health and well-being of young adults with $\mathrm{CP}$, especially as they transition out of the familiar healthcare and educational systems provided during their pediatric years. The aim of this dissertation is to investigate whether the impairments, activity limitations and participation restrictions found in adults with $\mathrm{CP}$ are present in young adults with $\mathrm{CP}$ and to identify the influence impairments, personal and environmental factors have on the ability to participate in activity and social roles. By understanding the complex relationships between health and disability for the young adult with $\mathrm{CP}$ as they transition into adulthood, potential leverage points for change within the pediatric system can be identified in order to lessen the impact of impairments and increase activity and participation during adulthood, providing a holistic approach to improving health and well-being of adults with CP. Chapter 2 describes the methods, tools and statistical approach used to examine the impact, independently or in combination, that impairments, activity limitations, participation restrictions, environmental barriers and personal factors have on the health and well-being of young adults with CP. The next four chapters are organized to each stand alone, and present a portion of the findings. Each includes appropriate background, methods, results, and discussion. 
While individuals with CP have disorders of movement and posture that cause activity limitations, additional disturbances in sensation, perception, cognition, communication, behavior and secondary musculoskeletal problems may impose additional impairments that contribute to decreased activity and participation and greater environmental barriers. The manifestations of the motor disorders and the consequences of additional impairments vary across the spectrum of the condition. In this study, young adults with $\mathrm{CP}$ were encouraged to self-report; however if they were unable a proxy could respond on their behalf. The proxy respondents all reported the presence of additional impairments, primarily physical, cognitive and communication that prevented the young adult from completing the survey independently or with assistance. As a result, responses from the young adults who self-reported and those completed by proxy were analyzed separately. Chapters $\mathbf{3}, \mathbf{4}$, and $\mathbf{5}$ focus on the impairments of body structure and function, activity limitations and participation restrictions of the group of young adults with CP who self-reported. Chapter 6 summarizes the responses from proxies of young adults with $\mathrm{CP}$ and additional physical, cognitive or communication impairments that prevented them from completing the survey independently.

Chapter $\mathbf{3}$ explores the relationship among functional ability and the presence of pain, fatigue and depression and examines the role personal factors may have on mediating the relationship among functional impairments, health and well-being. Chapter 4 
examines the influence functional level and environmental barriers have on the intensity and type of physical activity and participation in recreation in young adults with CP. Chapter 5 examines the impact personal factors and environmental barriers have on participation and satisfaction with life in young adults with CP. Chapter 6 utilizes the reports from proxy respondents to examine the impact functional motor level has on physical impairments, activity limitations and participation restrictions in young adults with $\mathrm{CP}$ with additional physical, cognitive and communication impairments; and the role environmental barriers have on participation in daily activities and social roles. Chapter 7 describes the limitations of this study in terms of the methodology and the outcome tools and provides insight for future studies. Finally, Chapter 8 summarizes the findings of the research, discusses the implications and provides suggestions for future research. 


\section{Chapter 2: Methods and Statistical Analysis}

\section{SUBJECTS}

A convenience sample of 668 potential subjects was identified from the databases of Shriners Hospitals for Children-Portland (SHC-P) and the Child Development and Rehabilitation Center (CDRC) of Oregon Health and Sciences University, Institute on Development \& Disability. Inclusion criteria included: 1) diagnosis of $C P, 2$ ) between the ages of 18-30 years (January 1, 1982-December 31, 1994), and 3) last known address in Oregon or Washington. Exclusion criteria included living in a foster home. 58 subjects were deemed ineligible as they did not have a diagnosis of CP or they lived in foster home, yielding 610 eligible subjects. Approval for this study was obtained from the Portland State University, Human Subjects Research Review Committee (HSRRC).

Of the 610 potential subjects, 15 subjects had died and 153 surveys were returned as unable to deliver. Of the remaining 442 surveys, a total of 95 surveys were returned, yielding a $21.5 \%$ response rate. 55 participants self-reported, while 40 surveys were completed by a proxy respondent. A summary of the demographics of the respondents is found in Table 1. 


\begin{tabular}{|l|c|c|c|c|c|c|c|}
\hline \multicolumn{1}{|c|}{ Variable } & Total & \multicolumn{3}{|c|}{ Independent } & \multicolumn{3}{c|}{ Proxy } \\
\cline { 3 - 8 } & $\mathrm{N}=95$ & GMFCS & GMFCS & GMFCS & GMFCS & GMFCS & GMFCS \\
& & I & II & III, IV, V & I, II, III & IV & V \\
& & $\mathrm{N}=24$ & $\mathrm{~N}=16$ & $\mathrm{~N}=15$ & $\mathrm{~N}=9$ & $\mathrm{~N}=14$ & $\mathrm{~N}=17$ \\
\hline Age (years) & 23.79 & 23.18 & 25.43 & 24.61 & 20.81 & 24.46 & 23.41 \\
& $(3.58)$ & $(3.24)$ & $(3.29)$ & $(4.21)$ & $(1.98)$ & $(3.91)$ & $(3.27)$ \\
\hline Gender & $\mathrm{M}=45$ & $\mathrm{M}=9$ & $\mathrm{M}=4$ & $\mathrm{M}=8$ & $\mathrm{M}=6$ & $\mathrm{M}=8$ & $\mathrm{M}=10$ \\
& $\mathrm{~F}=50$ & $\mathrm{~F}=15$ & $\mathrm{~F}=12$ & $\mathrm{~F}=7$ & $\mathrm{~F}=3$ & $\mathrm{~F}=6$ & $\mathrm{~F}=7$ \\
\hline Ethnicity & $\mathrm{NH}=84$ & $\mathrm{NH}=22$ & $\mathrm{NH}=16$ & $\mathrm{NH}=15$ & $\mathrm{NH}=7$ & $\mathrm{NH}=11$ & $\mathrm{NH}=13$ \\
& $\mathrm{H}=11$ & $\mathrm{H}=2$ & & & $\mathrm{H}=2$ & $\mathrm{H}=3$ & $\mathrm{H}=4$ \\
\hline
\end{tabular}

TABLE 1: DEMOGRAPHICS OF THE TOTAL GROUP AND FOR SELF AND PROXY RESPONDENTS BY FUNCTIONAL CATEGORIES

Age=means (standard deviations), Gender and ethnicity=\# of individuals in each category. $\mathrm{M}=$ male, $\mathrm{F}=$ female, $\mathrm{NH}=$ non-Hispanic, $\mathrm{H}=$ Hispanic

PROCEDURE

In order to ensure a holistic understanding of the complex relationships that impact the health and well-being of individuals with CP, the ICF framework was used as a model to help guide the selection of outcomes of interest (Figure 2) and the survey instruments used in this dissertation. A survey approach was used to assess impairments in body structure and function, activity limitations and participation restrictions, and contextual factors that impact the ability of young adults with CP to achieve optimal health and well-being. 


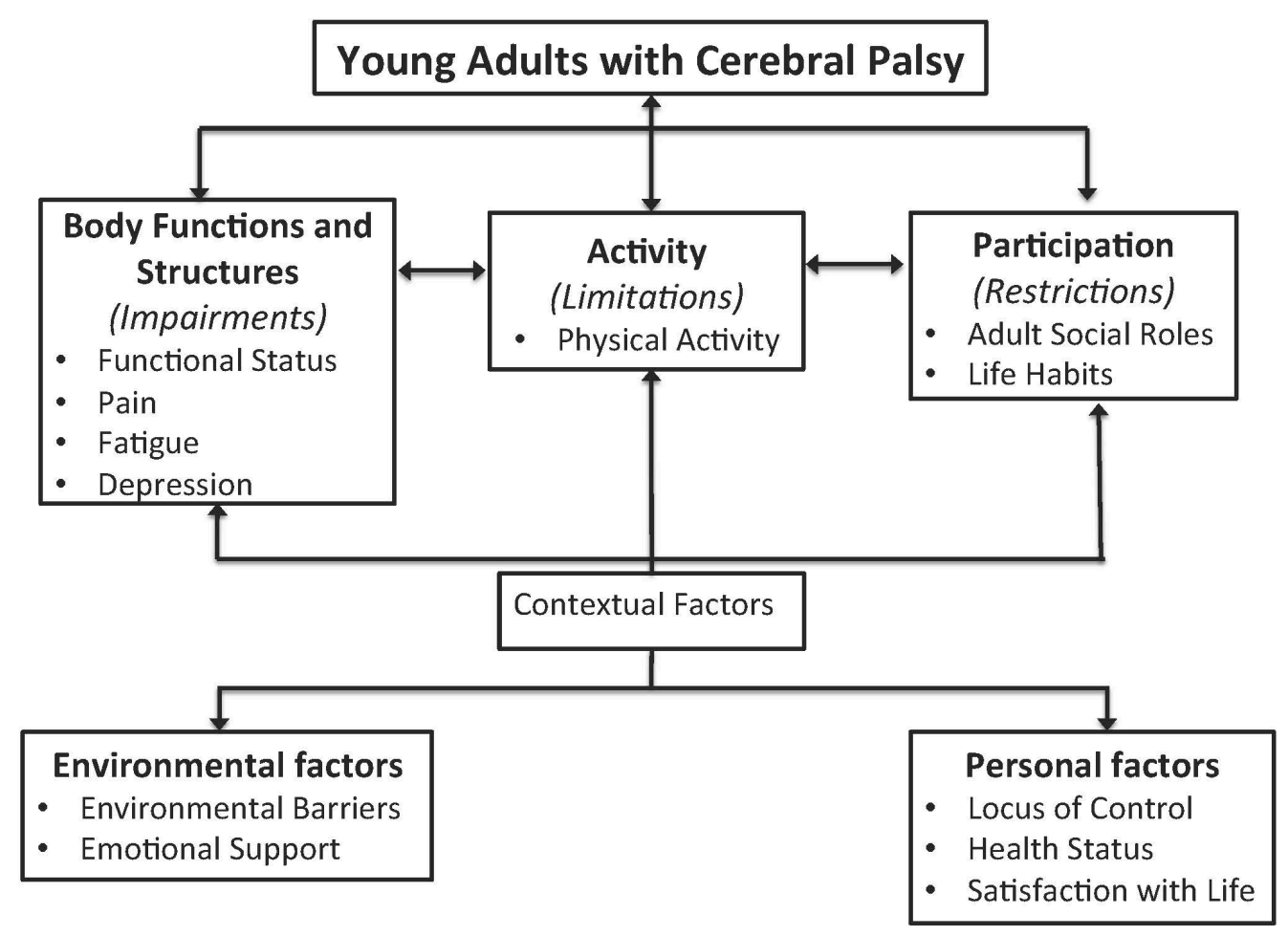

FIGURE 2: OUTCOMES OF INTEREST ACROSS THE ICF

Survey packages were addressed and mailed to 610 young adults with CP identified through the SHC-P/CDRC database search. Survey packages included a letter of introduction, a background information letter describing their rights as a research participant and the two survey booklets. All questionnaires, except the life habit (Life-H), were incorporated into one booklet to provide continuity between the questionnaires and a standardized appearance. Potential subjects were instructed to complete both surveys and return completed questionnaires in the stamped, self-addressed envelope. Subjects were encouraged to self-report, however could solicit assistance in completing the questionnaires. While self-report is considered the "gold standard," specifically for 
subjective measures i.e. pain, fatigue, depression, health status and quality of life, individuals with $\mathrm{CP}$ and impairments that prevented them from interpreting the questions or completing the survey independently, could engage a proxy to complete the survey on their behalf. Follow-up reminder cards were sent three and six weeks later to encourage return of the survey. In order to increase the number of respondents, a repeat mailing of the survey package was sent to non-responders two months following the initial mailing. Individuals who returned the surveys were sent a $\$ 5$ gift card.

\section{Summary of the Survey Instruments}

IMPAIRMENTS OF BODY STRUCTURE AND FUNCTION

\section{Gross Motor Function}

Gross Motor Function Classification System (Expanded and Revised)-GMFCS (E\&R)- SelfReport Questionnaire for Young People Aged $12-18$ years $^{46}$ was used both as a classification system and a measure of deterioration in motor ability between childhood and young adulthood. The GMFCS is a five level classification system that distinguishes among levels of motor function that are clinically meaningful. ${ }^{47 ; 18}$ Individuals classified as GMFCS level I walk without limitations; GMFCS level II walk with limitations; GMFCS level III walk using a hand-held mobility device; GMFCS level IV possess self-mobility with limitations and may use powered mobility , and GMFCS level V are transported in a manual wheelchair. ${ }^{46}$ It has been shown that adults with CP can accurately self-report 
their level of function. ${ }^{20}$ Change in functional motor ability was assessed by the difference in functional motor ability at the age of 12 years to current.

\section{Pain and Pain Interference}

The magnitude of pain was assessed with the pain question from the 2011 Behavioral Risk Factor Surveillance System (BRFSS), ${ }^{48}$ while pain interference was assessed with the Impact of Pain on Functioning and Well-being Scale of the Brief Pain Inventory (BPI). ${ }^{49}$ The BRFSS pain question assesses the level of bodily pain present on a five-point scale. ${ }^{50}$ The pain interference scale of the $\mathrm{BPI}^{49}$ uses a five-point scale to measure the extent to which pain interferes with general activity, mood, walking ability, normal work, relations with people, sleep and enjoyment in life. Scores from the specific activities can be evaluated independently or summed to yield a total pain interference score. The BPI has been found to be a reliable pain measure in non cancer patients. ${ }^{49}$

\section{Fatigue}

Fatigue was assessed with the Fatigue Assessment Scale (FAS), ${ }^{51}$ a 10 -item selfadministered questionnaire designed to measure chronic fatigue. Fatigue is rated on a five-point scale ranging from, never to always. ${ }^{51}$ The FAS has been shown to have high internal consistency and correlates strongly with other fatigue scales. ${ }^{51}$

\section{Depression}

The presence and severity of depression were assessed with the Patient Health Questionnaire-9 (PHQ-9). ${ }^{52}$ The PHQ-9 is a brief self-report questionnaire that assesses 
the levels of depression on the nine key symptoms. The amount to which each symptom bothers the individual is rated on a scale from not at all to nearly every day. ${ }^{52}$ Five distinct categories of depression severity are determined based on the total score. ${ }^{52}$

\section{ACTIVITY}

\section{Physical Activity}

Participation in physical activity was assessed with the Physical Activity Scale for Individuals with Physical Disabilities (PASIPD). ${ }^{53 ; 41}$ The PASIPD is a 7-day physical activity recall questionnaire designed to evaluate physical activity levels in persons with disabilities. ${ }^{41}$ The PASIPD consists of 13 items that assess leisure, household and work activities. Only the six leisure time activity items were assessed: 1) stationary activity, 2) walking and wheeling outside, 3) light sport, 4) moderate sport, 5) strenuous sport and 6) exercises to increase muscle strength and endurance. ${ }^{41}$ The metabolic equivalent (MET) value for each activity is created by multiplying the average hours per day (based on the number of days per week and the number of hours per day they report participating in the activity) by a MET value associated with the intensity of the activity. The summation of the five activity items created the PASIPD score. ${ }^{41}$ The PASIPD has been shown to have strong construct and criterion validity for individuals with CP. ${ }^{54}$ 


\section{PARTICIPATION}

\section{Assessment of Life Habits}

The Assessment of Life Habits (LIFE-H) ${ }^{55}$ was used to evaluate the level of participation in daily activities and social roles. The Life-H was developed to evaluate the social participation of people with disabilities, regardless of the type of underlying impairments. ${ }^{56}$ The LIFE-H (short form) has 69 items in 12 categories: 1) nutrition, 2) fitness, 3) personal care, 4) communication, 5) housing, 6) mobility, 7) responsibilities, 8) interpersonal relationships, 9) community life, 10) education, 11) employment and 12) recreation. ${ }^{55}$ The LIFE-H evaluates the level of participation in daily activities and social roles by considering both the degree of difficulty and the type of assistance used on a scale of $0-9$, where 0 indicates total handicap and 9 indicates optimal participation. ${ }^{55}$ Scores for both the accomplishment and satisfaction scales are calculated for each of the 12 categories. While each category can be examined independently, overall participation in daily activities includes the categories of nutrition, fitness, personal care, communication, housing and mobility, while participation in social roles includes responsibilities, interpersonal relationships, community life, education, employment and recreation. The Life-H has been shown to have good test-retest reliability in older adults with disabilities. ${ }^{56 ; 55}$ 
Adult social roles

\begin{tabular}{|l|l|}
\hline \multirow{4}{*}{ Residential Status } & Category \\
\hline \multirow{4}{*}{ Financial Independence } & $\begin{array}{l}\text { Dependent- Living in the parental home or adult care } \\
\text { center }\end{array}$ \\
\cline { 2 - 2 } & $\begin{array}{l}\text { Independent- Living independently alone or with a } \\
\text { spouse, partner of friend }\end{array}$ \\
\cline { 2 - 2 } Status & Income between $\$ 0-10,000$ \\
\cline { 2 - 2 } & Income between $\$ 10,000-34,999$ \\
\hline & Income greater than 35,000 \\
\cline { 2 - 2 } & Not working or going to school \\
\cline { 2 - 2 } & Volunteering or working in a sheltered workshop \\
\cline { 2 - 2 } & $\begin{array}{l}\text { Student only (high school or post secondary) } \\
\text { Working (full time or part time) or working part time and } \\
\text { pursuing secondary education }\end{array}$ \\
\hline
\end{tabular}

TABLE 2: CLASSIFICATION OF ADULT SOCIAL ROLES

ENVIRONMENTAL FACTORS

\section{Environmental Barriers}

The Craig Hospital Inventory of Environmental Factors (CHIEF) $)^{57 ; 58}$ was used to examine the role environmental barriers have on participation. The questionnaire consists of 25 questions that are divided into five subscales: 1) physical and structural, 2) work and school, 3) attitudes and support, 4) services and support and 5) policies. ${ }^{58}$ Each question has two types of response scales: one for the frequency that the identified barrier occurs and one for the magnitude of the barrier as a problem. ${ }^{58}$ The frequency scale uses a 5-point Likert scale ranging from never to daily, while the magnitude scale was dichotomized as either a big problem or little problem. ${ }^{58} \mathrm{~A}$ magnitude frequency product score is computed to indicate the overall impact of the barrier, with higher scores indicating greater barriers. While the five subscales can be examined separately 
to determine the role a specific type of barrier has on participation, a total CHIEF score can be used to examine the role of all environmental barriers evaluated by the CHIEF. The CHIEF has good test-retest reliability and evidence of content, construct, and discriminant validity. ${ }^{59}$

PERSONAL FACTORS

\section{Health Locus of Control}

The extent to which young adults with $\mathrm{CP}$ have, internal or external, control over their health decisions was assessed with Form C of the Multidimensional Health Locus of Control (MHLC). ${ }^{60}$ The MHLC has been shown to be reliable (Cronbach alphas in the .60.75 range) ${ }^{60}$ and valid, with internal consistency of form $C$ ranging from $.70-.87 .^{61}$

\section{Emotional Support}

Emotional support was assessed with a single question from the 2011 Behavioral Risk Factor Surveillance System (BRFSS) Questionnaire. ${ }^{50}$ How often individuals received the social and emotional support needed was rated on a scale from $1=$ always to $5=$ never.

\section{Health Status and Satisfaction with Life}

Health status and satisfaction with life were each assessed with a single question from the 2011 BRFFS Questionnaire. ${ }^{50}$ Health status was defined as excellent, very good, good, fair or poor, with lower scores indicating greater health status. ${ }^{50}$ Satisfaction with life was assessed on a four point scale, ranging from very satisfied to very dissatisfied. ${ }^{50}$ 


\section{STATISTICAL ANALYSES}

In this study, data were evaluated for normality, linearity, and equality of variance with SPSS, version 21 (Chicago, IL) prior to performing statistical analysis; the appropriate parametric or non-parametric statistics were used in the analysis. Categorical variables were expressed as frequencies and percentages, while data for continuous variables were described as means and standard deviations. One-way ANOVA's were used to determine differences among functional groups for interval and ratio data, while Kruskal-Wallis were used for ordinal data. Pearson correlation coefficients were used to examine the associations among variables and to identify significant associations for use in the regression analysis. Hierarchical and linear regressions were used to determine the role that functional impairments, personal factors and environmental barriers had on activity, participation, health status and satisfaction with life. Due to the small sample size, statistical significance was set conservatively at $p<.01$. Data were analyzed and reported separately based on responder type because of the potential bias between proxy and self-report for subjective measures such as pain, fatigue, and depression. 


\section{Chapter 3: Article 1}

\section{AN EXPLORATORY STUDY INVESTIGATING THE MULTIDIMENSIONAL FACTORS}

IMPACTING THE HEALTH AND WELL-BEING OF YOUNG ADULTS WITH CEREBRAL PALSY

Health is a multidimensional, complex concept integrating not only physical health, but the balance among physical, emotional, and social components. ${ }^{1 ; 2}$ For individuals with childhood onset disabilities a holistic approach to health is often overshadowed by the imperative to address the medical problems that arise as a result of their primary disability. ${ }^{3}$ Cerebral Palsy (CP) is the most common cause of physical disability in childhood, affecting 2.0-2.5 children per 1000 live births. ${ }^{12}$ Defined as "a group of permanent disorders of the development of movement and posture, causing activity limitation, that are attributed to non-progressive disturbances that occurred in the developing fetal or infant brain," ${ }^{11}$ the medical interventions offered during childhood focus on diminishing motor impairments to optimize functional mobility.

Although CP is considered non-progressive, evolving medical co-morbidities and their functional consequences have been found to change as the individual with $\mathrm{CP}$ ages. ${ }^{62}$ Recent reports have identified that aging with $\mathrm{CP}$ is accompanied by increased falling and worsening gait, ${ }^{63 ; 64}$ pain, ${ }^{32-36 ; 31}$ fatigue ${ }^{65 ; 31}$ and depression. ${ }^{66 ; 37}$ For young adults with $\mathrm{CP}$, changes in psychological and social development, in conjunction with the progression of musculoskeletal deformities and the onset of secondary conditions, make 
the transition to adulthood a difficult developmental phase. ${ }^{26 ; 27}$ While medical interventions aim to address the physical impairments that emerge during adolescence and young adulthood, psychological and social factors such as emotional support and locus of control have been reported to decrease the impact of impairments on health and well-being during this transitional phase. ${ }^{40}$ While preliminary evidence shows that many of the physical impairments reported in adults with CP begin during late adolescence, ${ }^{29 ; 67 ; 68}$ there is little information about prevalence of impairments and the combined role impairments, psychological and social factors have on the health and well-being of young adults with CP.

In 2001, the World Health Organization approved the International Classification of Functioning, Disability and Health (ICF) ${ }^{6}$ a multidimensional framework to examine the complex interactions among the health condition, impairments, activity limitations, participation restrictions and the personal and environmental factors that influence personal health and well-being. ${ }^{62}$ As young adults with CP transition into adulthood, the ICF provides a holistic approach to understanding the multidimensional factors that encompass all aspects of health and well-being. The purpose of this exploratory study was twofold: 1) to examine whether functional motor ability influences physical impairments (ambulatory decline, pain, pain interference, depression, fatigue), psychological (health locus of control) and social (emotional support) factors, overall health status and satisfaction with life and 2) to examine the combined roles that these 
physical impairments, psychological and social factors have on overall health status and satisfaction with life. By understanding the complex relationships between health and disability for young adults with $\mathrm{CP}$ as they transition into adulthood, potential leverage points for change can be identified and a holistic approach to the improvement in health and well-being can be provided. ${ }^{45}$

\section{Method}

\section{PARTICIPANTS}

Young adults were recruited from the databases of Shriners Hospitals for ChildrenPortland (SHC-P) and the Child Development and Rehabilitation Center (CDRC) of Oregon Health and Sciences University Institute on Development \& Disability. Inclusion criteria included: 1) diagnosis of $\mathrm{CP}, 2$ ) between the ages of $18-30$ years, and 3) last known address in Oregon or Washington, while living in a foster home was an exclusion criteria. 688 potential subjects were identified; 58 subjects were ineligible for this study as they did not have a diagnosis of CP or lived in foster home, yielding 610 eligible subjects. The Portland State University, Human Subjects Research Review Committee (HSRRC) approved this study.

\section{PROCEDURES}

In order to assess all factors that impact the health and well-being of young adults with $\mathrm{CP}$, a cross-sectional, multidimensional survey approach was used. Survey packages 
were addressed and mailed to 610 young adults. Potential subjects were instructed to complete and return the surveys in the stamped, self-addressed envelope. Subjects were encouraged to self-report; however if necessary they could solicit assistance in completing the questionnaires from another individual. While self-report is considered the "gold standard," specifically for subjective measures i.e. pain, fatigue, depression, health status and quality of life, proxy reporting was permitted for individuals with CP and impairments that prevented them from completing the survey independently. Follow-up reminder cards were sent three and six weeks later to encourage return of the survey. A repeat mailing of the survey package was sent to non-responders two months following the initial mailing. Individuals who returned the surveys were sent a $\$ 5$ gift card. Of the 610 potential subjects, 15 subjects had died and 153 surveys were returned as unable to deliver. Of the remaining 442 surveys, a total of 95 surveys were returned, yielding a $21.5 \%$ response rate. 55 participants self-reported, while 40 surveys were completed by a proxy respondent.

Although all components of the $\mathrm{ICF}^{6}$ were examined in the complete survey, only physical impairments and the psychological and social factors reported to influence the overall health status and satisfaction with life of young adults with CP will be reported in this study. Recently differences in functional motor ability have been reported to discriminate among health outcomes in adults with $\mathrm{CP},{ }^{20 ; 21}$ and therefore the Gross Motor Function Classification System (Expanded and Revised)-GMFCS (E\&R)- Self-Report 
Questionnaire for Young People Aged $12-18$ years ${ }^{46}$ was used both as a classification system and a measure of deterioration in motor ability between childhood and young adulthood. The GMFCS is a five level classification system that distinguishes among levels of motor function that are clinically meaningful. ${ }^{47 ; 18}$ Individuals classified as GMFCS level I walk without limitations; GMFCS level II walk with limitations; GMFCS level III walk using a hand-held mobility device; GMFCS level IV possess self-mobility with limitations and may use powered mobility, and GMFCS level V are transported in a manual wheelchair. ${ }^{46}$

In addition to the deterioration of functional mobility, pain, fatigue and depression are associated with perceived health and satisfaction with life. ${ }^{37}{ }^{31}$ The magnitude of pain was assessed with the pain question from the 2011 Behavioral Risk Factor Surveillance System (BRFSS), ${ }^{48}$ while pain interference was assessed with the Impact of Pain on Functioning and Well-being Scale of the Brief Pain Inventory (BPI). ${ }^{49}$ The BRFSS pain question assesses the level of bodily pain present on a five-point scale. ${ }^{50}$ The pain interference scale of the $\mathrm{BPI}^{49}$ uses a five-point scale to measure the extent to which pain interferes with general activity, mood, walking ability, normal work, relations with people, sleep and enjoyment in life. Scores from the specific activities can be evaluated independently or summed to yield a total pain interference score. 
Fatigue was assessed with the Fatigue Assessment Scale (FAS), ${ }^{51}$ a 10 -item selfadministered questionnaire designed to measure chronic fatigue. Fatigue is rated on a five-point scale ranging from never to always. ${ }^{51}$ The FAS has been shown to have high internal consistency and correlates strongly with other fatigue scales. ${ }^{51}$ The presence and severity of depression were assessed with the Patient Health Questionnaire-9 (PHQ9). ${ }^{52}$ The PHQ-9 is a brief self-report questionnaire that assesses the levels of depression on the nine key symptoms. The amount to which each symptom bothers the individual is rated on a scale from not at all to nearly every day. ${ }^{52}$ Five distinct categories of depression severity are determined based on the total score. ${ }^{52}$

The extent to which young adults with $\mathrm{CP}$ have, internal or external, control over their health decisions (psychological factor) was assessed with Form C of the Multidimensional Health Locus of Control (MHLC). ${ }^{60}$ The MHLC has been shown to be both reliable ${ }^{60}$ and valid. ${ }^{61}$ The determination of how often individuals received the social and emotional support needed (social factor), was assessed with a single question from the BRFSS Questionnaire. ${ }^{50}$

As the goal of this study was to determine the role physical, psychological and social factors have on health and well being of young adults with $\mathrm{CP}$, health status and satisfaction with life were each assessed with a single question from the 2011 BRFFS 
Questionnaire. ${ }^{50}$ Overall health status and how satisfied the individual was with life were assessed using a four point scale. ${ }^{50}$

\section{Statistical Analysis}

Due to the potential bias between self and proxy report for assessments of pain ${ }^{69}$ and quality of life, ${ }^{70-73}$ only individuals who self-reported $(N=55)$ were included in this analysis. Statistical analysis of the data was carried out with SPSS, version 21 (Chicago, IL). Data were evaluated for normality, linearity and equality of variance and the appropriate parametric or non-parametric statistics were used in the analysis. Frequencies and percentages were used for categorical variables, while means and standard deviations were used for continuous variables. Kruskal-Wallis and one-way ANOVA's were used to determine differences among motor function levels.

Hierarchical linear regression was used to determine the role physical, psychological and social factors have on both the health and well-being of young adults with CP. As a result of the low response rate $(\mathrm{N}=55)$ and the large number of potential contributing factors, Pearson correlations were used to identify the factors significantly associated with health status and satisfaction with life. Only predictive variables with a significant correlation at the $p<.01$ level were used in the regression analysis; however due to the known association between gender, pain and depression, ${ }^{74}$ gender was also included in 
the analysis. As this study is exploratory, significance was set conservatively at $p<.01$ to account for multiple comparisons.

\section{$\underline{\text { Results }}$}

GROUP CHARACTERSITICS

The mean age of the 55 participants who self-reported was 24.23 years ( \pm 3.61 years) with females representing $62 \%$ of the sample. The majority $(96.4 \%)$ of the participants were Caucasian and only $4.6 \%$ were Hispanic. Due to the small sample size and the limited number of individuals in GMFCS levels III ( $N=7)$ IV $(N=7$ and $V(N=1)$, the group was divided into three subgroups according to functional motor ability. These groupings were chosen to provide similar subject numbers in each group. Individuals classified as GMFCS levels I ( $\mathrm{N}=24)$ and II ( $\mathrm{N}=16)$ were considered separate groups, while individuals classified as GMFCS levels III, IV, and V ( $\mathrm{N}=15)$ were grouped together.

\section{PHYSICAL, PSYCHOLOGICAL AND SOCIAL PREDITCTIVE FACTORS}

Changes in function, pain, pain interference, fatigue and depression scores are summarized in Table 1. Despite a majority of young adults in GMFCS level I reporting an improvement in motor ability over time, there were no significant differences found by functional classification. Pain was reported in approximately $85 \%$ of the young adults with $\mathrm{CP}$, with $51 \%$ reporting greater than moderate pain. No significant differences were found among functional levels for pain or pain interference. Pain interfered with all 
activities to a greater extent for young adults in GMFCS levels III, IV and V than for young adults in GMFCS level I's and II's (Table 3). For young adults in GMFCS levels I and II, pain interfered most with walking, while pain interfered most with sleep for young adults in GMFCS level's III, IV, and V. No significant differences were seen among functional levels for fatigue or depression (Figure 3). $42 \%$ of young adults with CP reported depression, ranging from mild (25\%) to moderate (13\%) and severe (4\%).

\begin{tabular}{|l|c|c|c|c|}
\hline \multicolumn{5}{|c|}{ Physical Impairments } \\
\hline Change in Function & $\begin{array}{c}\text { GMFCS I } \\
\mathrm{N}=24\end{array}$ & $\begin{array}{c}\text { GMFCS II } \\
\mathrm{N}=16\end{array}$ & $\begin{array}{c}\text { GMFCS III, } \\
\text { IV, V } \\
\mathrm{N}=15\end{array}$ & $\begin{array}{c}\text { Significance } \\
\text { Level }\end{array}$ \\
\hline Same=17 & $\begin{array}{c}\text { Same=13 } \\
\text { Improve=7 }\end{array}$ & $\begin{array}{c}\text { Decline=2 } \\
\text { Same=13 }\end{array}$ & $p=.017$ \\
\hline Pain & $1.34(.96)$ & $1.50(.63)$ & $1.60(.74)$ & $p=.484$ \\
\hline Fatigue & $1.88(1.02)$ & $1.84(.67)$ & $2.20(1.21)$ & $p=.577$ \\
\hline Depression & $2.20(.81)$ & $2.09(.54)$ & $2.07(.88)$ & $p=.969$ \\
\hline
\end{tabular}

TABLE 3: PHYSICAL IMPAIRMENTS BY FUNCTIONAL MOTOR CLASSIFICATION Means (standard deviations) 


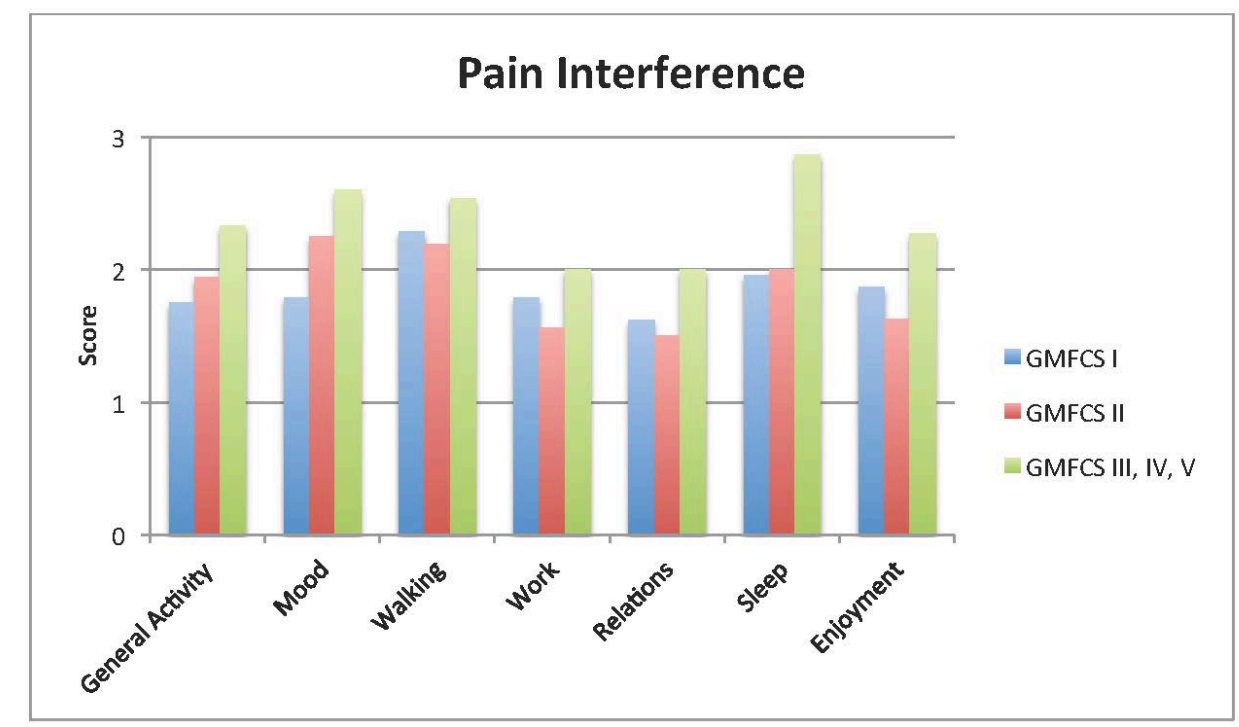

FIGURE 3: MAGNITUDE OF THE INTERFERENCE OF PAIN ON SPECIFIC ACTIVITIES BY FUNCTIONAL MOTOR CLASSIFICATION

All young adults with CP reported greater internal than external locus of control, indicating that they perceived that they were responsible for their own health. There were no significant differences among motor function levels for internal $(p=.021)$ or external $(p=.14)$ locus of control (Figure 4).

Overall, $73 \%$ of young adults with $\mathrm{CP}$ reported that they received the emotional support they needed usually or always. No difference in the amount of emotional support was found among functional levels, $p=.351$. 

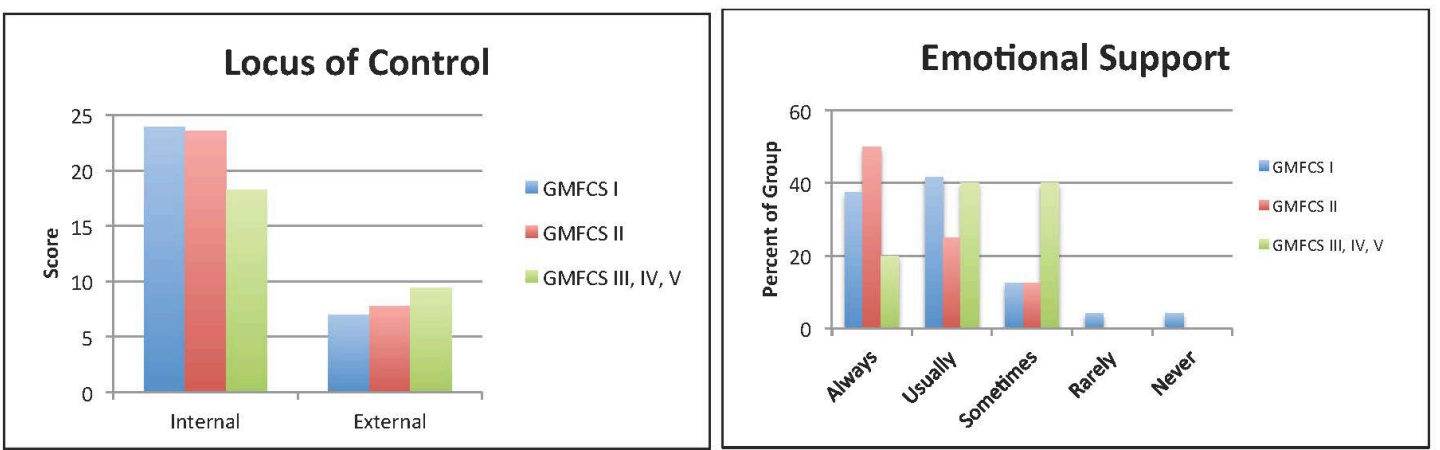

FIGURE 4: HEALTH LOCUS OF CONTROL AND EMOTIONAL SUPPORT BY FUNCTIONAL MOTOR CLASSIFICATION

\section{HEALTH AND WELL-BEING}

Health status was rated as good to excellent in $94 \%$ of young adults with $\mathrm{CP}$, with no significant differences found among functional levels $(p=.839)$ (Figure 5). Significant positive relationships were found between health status and emotional support $(r=.350)$, pain interference $(r=.514)$, fatigue $(r=.401)$ and depression $(r=.349)$ and therefore these variables were used in the regression. While gender $(p=.503)$, pain interference $(p<.01)$, fatigue $(p=.706)$, depression $(p=.427)$ and emotional support $(p=.184$ accounted for $33.8 \%$ of the explained variance in health status, $F(5,48)=4.894, p<.001$, only pain interference significantly contributed to the variance in health status. 


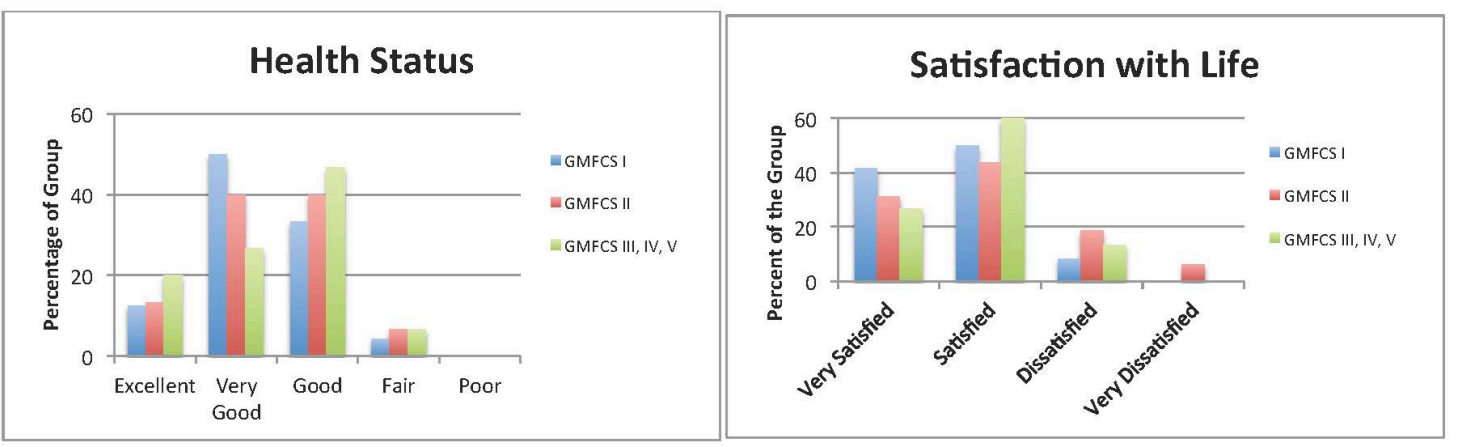

Figure 5: Health Status and SATISFAction With Life by functional category

Overall, $85 \%$ of young adults in this sample reported satisfaction with life. No differences in satisfaction with life were found among functional levels ( $p=.434)$. Satisfaction with life was significantly positively associated with emotional support $(r=.418)$, depression $(r=.405)$ and overall health status $(r=.392)$ and thus these variables were used in the regression. Gender $(p=.539)$, depression $(p=.087)$, overall health status $(p=.142)$ and emotional support $(p<.01$, accounted for $31.9 \%$ of the explained variance in satisfaction with life, $F(3,49)=5.739, p<.001$; however, only emotional support significantly contributed to the variance in satisfaction with life.

\section{Discussion}

The results of this study indicate that ambulatory decline, pain, fatigue and depression reported in adults with $\mathrm{CP}$, also are present in young adults with $\mathrm{CP}$ between the ages of 18-30 years. Although functional motor ability has been reported to discriminate among health outcomes in adults with $\mathrm{CP},{ }^{20 ; 21}$ this was not found in this group of young adults with CP for the physical, psychological and social factors evaluated. This study found Chapter 3: Article 1 
improvements in gross motor function in $18 \%$ of the young adults with CP and declines in only $3.6 \%$, with ambulatory decline occurring in young adults with less functional abilities. These findings are consistent with those in the literature that report improvement in ambulatory function between the ages of $15-24,{ }^{67}$ and ambulatory declines at an average age of 28 years. ${ }^{29 ; 64}$ Similar to reports in the literature ambulatory ability continues to change during adolescence and young adulthood. The ambulatory ability of young adults with CP continues to change between the ages of 1830 years. As $73 \%$ of the young adults in this study were GMFCS level I or II, the absence of any significant ambulatory declines corroborates the findings of Day et al, who found that individuals at GMFCS level II or above rarely loose ambulatory ability. ${ }^{75}$

The prevalence of pain in young adults with $\mathrm{CP}$ has been reported to be as low as $18 \%{ }^{76}$ or as high of $84 \%,{ }^{77 ; 34 ; 35 ; 31}$ with the intensity of pain increasing with age. ${ }^{33}$ This study found that most young adults with $\mathrm{CP}$ report pain, with many reporting moderate to severe pain. This increase in pain found in adults with CP has been associated with a higher prevalence of fatigue and depressive symptoms than their peers. ${ }^{31}$ Mental health is an important concern in this age group of young adults, with depression reported in $10 \%$ of young adults with $\mathrm{CP}^{68}$ and $15.4 \%$ reported for age-matched peers. ${ }^{78}$ While many young adults in this study reported depression and some reported attempted suicide, only a small percentage reported treatment with counseling or medication. This discrepancy between symptoms and treatment may indicate a gap between assessing 
and treating the mental health of young adults with CP. Identifying whether factors related to $\mathrm{CP}$ such as pain and fatigue contribute to the depression, or whether other mental health issues contribute to the depression is important for identifying the appropriate treatment regime for this group of young adults with CP.

Consistent with the findings in the literature, most of young adults with $\mathrm{CP}$ in this study reported their health status as good to excellent, despite physical impairments. ${ }^{35 ; 79}$ As young adults with CP transition into adulthood they begin to take responsibility for addressing their own health and well-being. While not statistically significant, internal locus of control was associated with improved health status in this group of young adults with CP. These results are similar to those in the literature that report that the ability to have control over health choices impacts overall health status. ${ }^{80}$ Similar to the young adults with $\mathrm{CP}$ in this study, Turk reported that self-perceived health ratings and life satisfaction were related to the presence of pain and functional changes over time, but not to the severity of impairment. ${ }^{35}$ Pain and pain intensity have been reported to correlate with reduced physical health-related quality of life rather than psychological health-related quality of life. ${ }^{81}$ In this study, emotional support was associated with improved health status and greater satisfaction with life. It has been proposed that receiving the emotional support one needs leads to the development or maintenance of self-esteem, and thereby better coping or resilience ${ }^{82}$ which are important constructs for improved health status and satisfaction with life. ${ }^{83}$ While not all areas of the ICF 
were examined in this study, the contributions of physical impairments, social and psychological factors to health status and satisfaction with life demonstrate that a multidimensional framework is needed to understand the health and well-being of young adults with $\mathrm{CP}$.

The generalizability of these results to other young adults with CP is limited by the geographical mailing restrictions and the small sample size. As the goal of this study was to obtain a holistic view of health using the ICF model, this required using several instruments to address all of levels of the model. The length of the survey and the amount of time to complete the survey and the lack of current residential information may have significantly impacted the response rate. Furthermore, while statistical significance was set conservatively, Bonferroni corrections were not employed. As multiple tests were conducted this could increase the chance of a Type I error. Despite the limitations identified, this exploratory study offers insight into the factors that impact the health and well-being of young adults with CP.

\section{Conclusions}

The findings of this study have implications for assessment, teaching and interventions in both the pediatric and adult health care systems. Traditionally, the focus of health care for children with $\mathrm{CP}$ is on diminishing motor impairments to enhance functional ability; however the large percentage of young adults in this study reporting pain, 
fatigue and depression indicates that the onset of these impairments may begin at an earlier age. Determination of reliable, age-appropriate and easy-to use screening tools that accurately assess the intensity and location of pain, magnitude of fatigue and the presence of depression should be incorporated into both pediatric and adult clinics that treat individuals with $\mathrm{CP}$ to ensure that these physical and psychological aspects are not overlooked and are addressed with appropriate support and medical intervention. ${ }^{84}$ Additionally, research should examine the complex relationship among pain, fatigue and depression in order to develop preventive measures and more effective interventions to manage the impairments that impact the health and well-being of individuals with CP as they age. $^{31}$

In preparation for their transition to the adult health care system, adolescents and young adults with $\mathrm{CP}$ should be encouraged to communicate their health concerns to medical professionals and to advocate for appropriate and timely interventions prior to their departure from the pediatric health care system. These skills may enhance locus of control and the development of self-esteem, leading to an improvement in health and well-being as they age. In order to provide optimal care and a holistic approach to health, pediatric and adult clinicians should be educated about the prevalence and onset of physical impairments and the role psychological (i.e. locus of control) and social factors (i.e. emotional support) have on the health and well-being of individuals with CP. 
As the provision of emotional support played a significant role in both health and wellbeing of young adults with $\mathrm{CP}$, determining alternative strategies to providing support such as peer support groups, mentors or adult role models, in addition to family support, may be beneficial to improving the health status and satisfaction with life in young adults with CP. Since emotional support incorporates many constructs, future studies should examine which elements of emotional support play a role in improving health status and satisfaction with life, leading to strategies for interventions. As the health and well-being of young adults with $\mathrm{CP}$ is a complex multidimensional concept, future studies should incorporate the framework of the ICF in order to identify the factors that influence health to ascertain potential targets for system changes. 


\section{Chapter 4: Article 2}

PARTICIPATION IN PHYSICAL ACTIVITY AND RECREATION IN YOUNG ADULTS WITH

CEREBRAL PALSY: AN EXPLORATORY STUDY INTO THE ROLE OF FUNCTIONAL MOTOR IMPAIRMENT AND ENVIRONMENTAL BARRIERS

Physical activity is defined as "any body movement that requires more energy than resting" and includes sports, physical exercise and other leisure or recreational activities. ${ }^{85}$ During childhood and adolescence, parents, therapists, and educators of youth with cerebral palsy (CP) assume the primary role of promoting and facilitating participation in physical exercise and recreational activities. As adolescents with $\mathrm{CP}$ transition into adulthood, recreation and leisure activities expand beyond those provided by school and family, potentially limiting participation. Participation in physical activity including recreational activities is influenced by the complex interactions between personal factors (functional motor level, age, and gender) ${ }^{86}$ and environmental barriers. ${ }^{87 ; 88}$ As young adults with CP become autonomous for their health choices, the extent to which their parents mediate the environmental barriers to recreation and leisure changes, leading to a perceived increase in these barriers by the young adult. ${ }^{89}$ Barriers such as cost, proximity and accessibility of fitness and community centers, need for assistance, lack of unisex changing rooms, and transportation have been reported to contribute to both the ability and opportunity to participate in physical activity in the community. ${ }^{90 ; 91 ; 36 ; 43}$ In addition, attitudes, lack of knowledge, and lack of energy and 
fatigue are also reported to contribute to a decreased participation in health promotion activities by adults with childhood onset disabilities. ${ }^{92 ;} 91$

Recent studies report that children and young adults with CP are less active than their typically developing peers, have higher rates of sedentary behaviors, engage in slower tempo activities, and overall participate in a smaller variety of physical activities. ${ }^{86 ; 93-95}$ For individuals with $\mathrm{CP}$, low levels of physical activity cause a cycle of deconditioning, resulting from decreased aerobic capacity, flexibility, muscular strength and endurance. and increased fatigue. This cycle leads to an increased risk for chronic disease and secondary conditions. ${ }^{39 ; 30 ; 40 ; 41}$ Despite recommendations that active participation in regular exercise is effective in controlling obesity, improving cardiovascular fitness, reducing pain, and minimizing the development of secondary conditions, $96 ; 42 ; 97 ; 92 ; 43 ; 41$ most adults with $\mathrm{CP}$ do not adhere to a regular exercise program of stretching, strengthening, and aerobics. ${ }^{32}$ Only $46 \%$ report being physically active for at least one hour per week. ${ }^{98}$

While current health promotion guidelines suggest that interventions with a focus on physical activity and an active lifestyle are important to improve and maintain the health of young adults with $\mathrm{CP},{ }^{99}$ minimal information exists about the role functional motor impairment and environmental barriers have on participation in physical activity. As adolescents with CP transition to adulthood and become more autonomous for their 
health choices, it is important to identify factors which impact their participation in physical activity in order to provide recommendations for change. The purpose of this exploratory study was to examine the role functional motor level alone, and in combination with, environmental barriers has on participation in physical activity and recreation in young adults with $\mathrm{CP}$ transitioning into adulthood. By identifying the factors that impact participation and reducing the environmental barriers associated with physical activity, young adults with CP transitioning could reap the benefits of lifelong participation in physical activity including the maintenance of functional independence, opportunity for leisure and enjoyment and enhancement in overall quality of life. ${ }^{92}$

\section{Method}

\section{PARTICIPANTS}

A convenience sample of young adults with $\mathrm{CP}$ was recruited from the databases of Shriners Hospitals for Children-Portland (SHC-P) and the Child Development and Rehabilitation Center (CDRC) of Oregon Health and Sciences University, Institute on Development \& Disability. Inclusion criteria were: 1) diagnosis of $\mathrm{CP}, 2$ ) between the ages of 18-30 years, and 3) last known address in Oregon or Washington, while living in a foster home was an exclusion factor. 688 potential subjects were identified; 58 subjects were ineligible, as they did not have a diagnosis of CP or lived in foster home, yielding 610 eligible subjects. Ethical approval for this study was obtained from the Portland State University, Human Subjects Research Review Committee (HSRRC). 


\section{PROCEDURES}

The International Classification of Functioning, Disability and Health (ICF), ${ }^{6}$ a multidimensional framework published by the World Health Organization in 2001, was used in this cross-sectional survey approach to examine the complex interactions among the health condition of $\mathrm{CP}$, impairments, activity limitations, participation restrictions, and the personal and environmental factors that influence personal health and wellbeing. Survey packages incorporating questionnaires from all dimensions of the ICF were mailed to 610 potential subjects. Young adults were instructed to complete and return the surveys in the stamped, self-addressed envelope. Subjects were encouraged to self-report; however they could solicit assistance in completing the questionnaires. While self-report is considered the "gold standard," individuals with CP and impairments that prevented them from completing the survey independently could have a proxy complete it on their behalf. Individuals who completed and returned the surveys were sent a \$5 gift card. Follow-up reminder cards were sent three and six weeks later to encourage return of the survey. A repeat mailing of the survey package was sent to nonresponders two months following the initial mailing. Of the 610 potential subjects, 153 surveys were returned as unable to deliver and 15 subjects had died. Of the remaining 442 surveys, a total of 95 surveys were returned, yielding a $21.5 \%$ response rate. Fiftyfive participants self-reported, while forty surveys were completed by a proxy respondent. 
The ICF framework was used to inform the focused examination of the role motor function level alone, and in combination with environmental barriers (physical/structural, work/school, attitudes/support, services/support and policies) has on the magnitude and amount of time individuals participate in physical activity and recreation. ${ }^{8}$ Research shows that the level of gross motor function has been reported to influence participation in physical activity, ${ }^{86}$ thus the Gross Motor Function Classification System (Expanded and Revised)-GMFCS (E\&R)- Self-Report Questionnaire for Young People Aged 12-18 years ${ }^{46}$ was used as the classification system for motor function level. The GMFCS is a 5 level classification system that distinguishes among levels of motor function that are clinically meaningful. ${ }^{47 ; 18}$ Individuals classified as GMFCS level I walk without limitations; GMFCS level II walk with limitations; GMFCS level III walk using a hand-held mobility device; GMFCS level IV possess self-mobility with limitations and may use powered mobility, and GMFCS level V are transported in a manual wheelchair. ${ }^{46}$ It has been shown that adults with CP can accurately self-report their level of function. ${ }^{20}$

The Craig Hospital Inventory of Environmental Factors (CHIEF) ${ }^{57 ; 58}$ was used to examine the role environmental barriers have on participating in physical activity. The self-report questionnaire consists of 25 questions that are divided into five subscales: 1) physical and structural, 2) work and school, 3) attitudes and support, 4) services and 5) support 
and policies. ${ }^{58}$ Each question has two types of response scales: one for the frequency that the identified barrier occurs and one for the magnitude of the barrier as a problem. ${ }^{58}$ The frequency scale uses a 5-point Likert scale ranging from never to daily, while the magnitude scale is dichotomized as either a big problem or little problem. ${ }^{58}$ The CHIEF has good test-retest reliability and evidence of content, construct, and discriminant validity. ${ }^{59}$ As the work/school subscale of the CHIEF was not related to participation in fitness and recreation, it was not included in this study.

Participation in physical activity was assessed with the Physical Activity Scale for Individuals with Physical Disabilities (PASIPD). ${ }^{53 ; 41}$ The PASIPD is a 7-day physical activity recall questionnaire designed to evaluate physical activity levels in persons with disabilities. ${ }^{41}$ The PASIPD consists of 13 items that assess leisure, household and work activities. Only the six leisure time activity items were assessed: 1) stationary activity, 2) walking and wheeling outside, 3) light sport, 4) moderate sport, 5) strenuous sport and 6) exercises to increase muscle strength and endurance. ${ }^{41}$ The metabolic equivalent (MET) value for each activity is created by multiplying the average hours per day (based on the number of days per week and the number of hours per day they report participating in the activity) by a MET value associated with the intensity of the activity. The summation of the five activity items created the PASIPD score. ${ }^{41}$ The PASIPD has been shown to have strong construct and criterion validity for individuals with $\mathrm{CP} .{ }^{54}$ 
The recreation category of the Assessment of Life Habits (LIFE- $\mathrm{H})^{55}$ was used as the measure of participation in physical activity and recreation. The LIFE-H (short form) has 69 items in 12 categories: nutrition, fitness, personal care, communication, housing, mobility, responsibilities, interpersonal relationships, community life, education, employment and recreation. ${ }^{55}$ The LIFE-H evaluates the level of participation by considering both the degree of difficulty and the type of assistance used on a scale of 09 , where 0 indicates total handicap and 9 indicates optimal participation. ${ }^{55}$ Specifically, the recreation category includes 7 questions related to physical activity and recreation including items such as, participating in sporting and recreational activities, taking part in outdoor activities and using neighborhood recreational services. The Life-H has been shown to have good test-retest reliability. ${ }^{55}$

\section{Statistical Analysis}

Due to the potential bias in perceptions of environmental barriers between self and proxy report, ${ }^{58}$ only responses from individuals who self-reported were analyzed in this study. SPSS, version 21 (Chicago, IL) was used for statistical analysis. Data were evaluated for normality, linearity and equality of variance prior to performing statistical analysis and the appropriate parametric or non-parametric statistics were used in the analysis. Categorical variables were expressed as frequencies or percentages, while means and standard deviations were used for continuous variables. One-way ANOVA's 
were used to determine differences among the groups, for physical activity, fitness and recreation.

Linear regression $(\mathrm{N}=55)$ was used to examine the role that functional motor ability and environmental barriers have on participation in recreational activities. Only the CHIEF subscales of services/assistance, attitudes/support, policies and physical structure were included. As this study is exploratory, significance was set conservatively at $p<.01$ to account for multiple comparisons. Six open-ended questions asked about facilitators and barriers to participating in fitness and recreation and the type of fitness and recreational activities young adults with $\mathrm{CP}$ choose to participate in.

\section{Results}

\section{GROUP CHARACTERSITICS}

The mean age of the 55 participants who self-reported was 24.23 years ( \pm 3.61 years) with females representing $62 \%$ of the sample. The majority $(96.4 \%)$ of the participants were Caucasian and only $4.6 \%$ were Hispanic. Due to the small sample size and the limited number of individuals in GMFCS levels III $(\mathrm{N}=7)$ IV $(\mathrm{N}=7$ and $\mathrm{V}(\mathrm{N}=1)$, the group was divided into three subgroups according to functional motor ability. These groupings were chosen to provide similar subject numbers in each group. Individuals classified as GMFCS levels I $(\mathrm{N}=24)$ and II $(\mathrm{N}=16)$ were considered separate groups, while individuals classified as GMFCS levels III, IV, and V $(\mathrm{N}=15)$ were grouped together. 
PHYSICAL ACTIVITY AND ENVIRONMENTAL BARRIERS

No differences in physical activity MET-hours per day or the average amount of hours of activity per day as measured by the PASIPD were found by functional level A significant difference among functional motor subgroups was found for participation in recreation (Table 4). Significant differences in participation in recreational activities were noted between all motor function classification groups, with individuals in GMFCS level I having the highest participation in recreational activities.

\begin{tabular}{|l|c|c|c|c|}
\hline \multicolumn{5}{|c|}{ Physical Activity, Fitness and Recreation } \\
\hline & $\begin{array}{c}\text { GMFCS I } \\
\mathrm{N}=24\end{array}$ & $\begin{array}{c}\text { GMFCS II } \\
\mathrm{N}=16\end{array}$ & $\begin{array}{c}\text { GMFCS III, } \\
\text { IV, V } \\
\mathrm{N}=15\end{array}$ & $\begin{array}{c}\text { Significance } \\
\text { Level }\end{array}$ \\
\hline $\begin{array}{l}\text { PASIPD (MET-hours per } \\
\text { day) }\end{array}$ & $12.43(7.75)$ & $9.24(8.37)$ & $10.37(8.49)$ & $\mathrm{p}=.459$ \\
\hline PASIPD (hours activity) & $3.47(1.92)$ & $2.66(1.92)$ & $2.97(1.98)$ & $\mathrm{p}=.418$ \\
\hline Life-H-Recreation & $9.35(1.21)$ & $7.06(2.55)$ & $4.57(2.32)$ & $\mathrm{p}<.001$ \\
\hline
\end{tabular}

TABLE 4: TIME AND MAGNITUDE OF PHYSICAL ACTIVITY AND PARTICIPATION IN FITNESS AND RECREATIONAL ACTIVITIES

Means (standard deviations)

Overall, the majority of young adults with $\mathrm{CP}$ reported spending more time in stationary activities than in active activities (Figure 1). As the intensity level of the activity increased from stationary to strenuous, less time per day was spent participating in the activity. Greater than $50 \%$ of the young adults with CP reported that they never participate in moderate or strenuous sport activities or strengthening (Figure 6). 


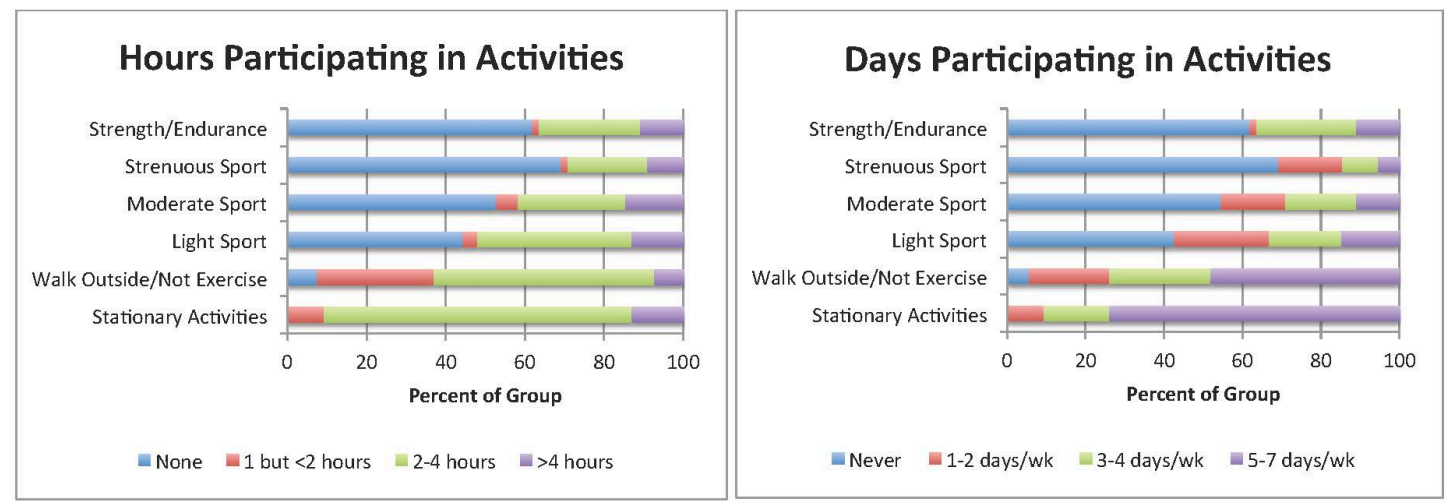

FIGURE 6: NUMBER OF HOURS PER DAY AND NUMBER OF DAYS PER WEEK SPENT PARTICIPATING IN ACTIVITIES

Significant differences across functional levels were found for all the environmental barriers: policies, physical/structural barrier, attitudes/support and the services/assistance barriers (Table 5). Young adults with CP in GMFCS levels I and II, reported fewer physical/structural, and policy barriers than young adults in GMFCS levels III, IV and V. Additionally, young adults with CP in GMFCS level I reported significantly fewer barriers than young adults in GMFCS levels III, IV and V in the services/assistance and attitudes/support barriers. For young adults in GMFCS level II, the services/assistance subscale, which included items such as support and attitudes in the home and community and discrimination, represented the greatest barriers. In contrast, for young adults in GMFCS levels III, IV and V the policies barrier subscale, which included items such as: governmental and business policies in addition to services in the community, represented the area with the greatest barriers. Functional level $(p=.001)$, and the CHIEF subscales of services/assistance $(p=.686)$, attitudes/support $(p=.387)$, policies $(p=.015)$ and physical structure barriers $(p=.637)$ accounted for $62.2 \%$ Chapter 4: Article 2 
of the explained variance in participation recreation, $F(5,53)=15.80, p<.001$; yet only functional level contributed significantly to the model.

\begin{tabular}{|l|c|c|c|c|}
\hline \multicolumn{5}{|c|}{ CHIEF- Environmental Barriers } \\
\hline & $\begin{array}{c}\text { GMFCS I } \\
\mathrm{N}=24\end{array}$ & $\begin{array}{c}\text { GMFCS II } \\
\mathrm{N}=16\end{array}$ & $\begin{array}{c}\text { GMFCS III, IV, V } \\
\mathrm{N}=15\end{array}$ & $\begin{array}{c}\text { Significance } \\
\text { Level }\end{array}$ \\
\hline Physical/ Structural Subscale & $.37(.57)$ & $.60(.66)$ & $1.78(1.61)$ & $\mathrm{p}<.001$ \\
\hline Services/ Assistance Subscale & $.24(.35)$ & $.79(.59)$ & $1.13(1.34)$ & $\mathrm{p}<.01$ \\
\hline Policies Subscale & $.09(.24)$ & $.61(.76)$ & $2.17(2.16)$ & $\mathrm{p}<.001$ \\
\hline Attitudes/Support Subscale & $.24(.52)$ & $.33(.42)$ & $.88(.86)$ & $\mathrm{p}<.01$ \\
\hline
\end{tabular}

TABLE 5: ENVIRONMENTAL BARRIERS BY FUNCTIONAL LEVEL Means (standard deviations)

The majority of young adults with $\mathrm{CP}(72 \%)$ in this study reported not having a membership to a health club. Major barriers included cost, transportation, accessibility of the club and equipment, and availability of health clubs in their area. Other reported barriers were time, no one to go with, feeling self-conscious and not being motivated. Most young adults with health club memberships reported participating in strengthening activities (free or machine weights) and aerobic activities (stationary bike, elliptical, treadmill, Zumba, basketball, racquetball, and swimming).

While recreational activities referred to any activity done during free time, $30 \%$ of young adults with $\mathrm{CP}$ reported that they did not participate in recreational activities. The main reasons for not participating in recreational activities were: time, physical impairments and the inability to find a recreational activity that they enjoy. Young adults with $\mathrm{CP}$ who participated in recreational activities reported a large variety including bicycling, 
walking/hiking/running, bowling, camping, swimming, yoga, music, golf, basketball, ATV or dirt bike riding and softball.

\section{Discussion}

The results of this study are consistent with findings in the literature that report young adults with $\mathrm{CP}$ are less active, have higher rates of sedentary behaviors, engage in slower tempo activities, and overall, participate in a smaller variety of physical activities. ${ }^{86 ; 93-95}$ Participation in physical activity and resistive exercises is vital for adults with $\mathrm{CP}$ in order to minimize secondary muscle pathology and cardiovascular comorbidity that result from aging with $\mathrm{CP} .{ }^{100}$ It has been shown that individuals with $\mathrm{CP}$ can improve muscle strength and cardiovascular fitness through participation in physical activities, ${ }^{99}$ yet greater than $60 \%$ of the young adults with $\mathrm{CP}$ in this study reported never participating in strengthening activities and $50-70 \%$ reported never participating in moderate or strenuous physical activity. The low levels of participation in both moderate and strenuous physical activities reported in this study may play a role in the development of obesity and increased cardiovascular risk during adulthood. ${ }^{101 ; 96 ; 100}$ In order to be successful in participating in higher intensity activities during adulthood, children with CP should be exposed to a variety of different activities early so that they may find activities that they enjoy and can participate in as they transition into adulthood. As young adults with CP begin to choose fitness and recreational activities to participate in, enjoyment and the integration of the activity into daily life have been reported to impact participation in physical activity in adults with $\mathrm{CP} .{ }^{90}$ While Chapter 4: Article 2 
rehabilitation services during adolescence are usually not sought or provided, the provision of physical therapy services would be beneficial to teach young adults with $\mathrm{CP}$ specific activities and strategies for incorporating higher intensity activities, in addition to strengthening and stretching activities, into their daily lives. This could facilitate their lifelong participation in physical activity and help minimize the secondary conditions that arise from aging with $\mathrm{CP} .{ }^{99}$

For individuals with physical disabilities, participation in health promotion activities is related to barriers such as lack of architectural accessibility, discrimination and social attitudes. ${ }^{88}$ In this study, physical and structural barriers such as access to athletic facilities and the exercise equipment and services and assistance barriers such as cost and transportation were major obstacles to participation in physical activity. In addition to the support and guidance offered by parents and schools to promote active participation in physical activity, the combined efforts of physical, occupational and recreational therapy therapists could help the young adult with CP identify potential physical and recreational activities, develop strategies for adapting the environment and provide adaptive equipment to assist with the participation in physical activities.

The open-ended questions identified additional emotional/psychological and resource availability barriers not included in the CHIEF. Buffart reported that young adults with physical disabilities identified psychological barriers such as feeling uncomfortable or 
ashamed, in addition to motivational barriers, such as lack of time and other priorities as reasons not to engage in physical activity. ${ }^{102 ; 103}$ Many young adults with $\mathrm{CP}$ in this study reported not having anyone to work out with or feeling self-conscious about participating in physical activity at a health club. It is well known in the health behavior literature that social support provides solutions to problems, reduces the perceived importance or threat, provides a distraction from the problem and facilitates health coping behaviors such as encouragement, modeling and companionship. ${ }^{104}$ In addition to helping families incorporate a variety of activities into their fitness repertoire, developing opportunities to partner young adults with CP with a peer (either disabled or non-disabled) or peer group may enhance their experience participating in physical activity and promote continued participation during adulthood.

One limitation of this study is the use of a questionnaire to measure the amount of time and intensity of physical activity in young adults with CP. The young adults with CP in this study reported similar physical activity intensities to ambulatory adults with CP reported in the literature $\left(11.8^{105}-14.8^{106}\right.$ MET-hours per day); however, these results should be interpreted with caution. It has been shown that recall questionnaires tend to overestimate the amount of time spent participating in physical activity, ${ }^{96 ; 86}$ which may be reflected in the differences in reported hours of physical activity in this study to that found in the literature using direct measurement of activity. ${ }^{107 ; 108}$ While direct measurement of physical activity is optimal, it is difficult to do for a large population 
group and therefore the use of the PAISID provides valuable insight into the intensity and time young adults with CP engage in physical activity.

The inclusion criteria, lack of a population-based sample, survey tools utilized and the small sample size limit the generalizability of these results to other young adults with CP. The goal of this study was to obtain a multidimensional view of health and well-being, requiring the use of a large number of instruments to address all of levels of the ICF model. As the length of the questionnaire and the amount of time to complete the survey have been found to influence the response rate, ${ }^{109}$ survey length may have adversely impacted participation in this study.

\section{Conclusions}

Similar to the findings of Shikako-Thomas et al., ${ }^{110}$ the results of this study indicate the combination of functional level and environmental barriers impacted participation in fitness and recreational activities. Environmental barriers play a role in participation in both physical activity and recreation for individuals with $\mathrm{CP}$, minimizing the gap between the individuals' functional abilities and the demands of the social and physical environment. The use of physical and occupational services during adolescence may enhance participation in physical activity during adulthood. More study is needed to assess effective ways of supporting physical activities that children with CP can continue into adulthood. Given the many health benefits (physical, social and psychological) associated with physical activity, educating young adults, their families and fitness Chapter 4: Article 2 
professionals about alternative activities for physical activity, in addition to traditional fitness and recreation options, may enhance the participation of individuals with $\mathrm{CP}$ throughout adulthood. 


\section{Chapter 5: Article 3}

THE ROLE OF FUNCTIONAL MOTOR LEVEL AND ENVIRONMENTAL BARRIERS ON

PARTICIPATION AND SATISFACTION WITH LIFE IN YOUNG ADULTS WITH CEREBRAL

PALSY: AN EXPLORATORY ANALYSIS

Cerebral Palsy (CP) is the most common cause of physical disability in childhood

affecting 2.0-2.5 children per 1000 live births. ${ }^{12}$ Defined as "a group of permanent disorders of the development of movement and posture, causing activity limitation, that are attributed to non-progressive disturbances that occurred in the developing fetal or infant brain." ${ }^{11}$ Motor impairments associated with CP have been found to impact the ability to participate in daily activities and social roles to varying degrees. ${ }^{111 ; 112}$ The World Health Organization defines participation as the "involvement in a life situation," and is a key component of the International Classification of Functioning, Disability and Health (ICF). ${ }^{6}$ Participation includes education, employment, civic, social and leisure activities, as well as family roles. ${ }^{113}$

Adults with CP experience participation restrictions in independent day-to-day living, employment, and social and leisure activities. ${ }^{28 ; 114 ; 115 ; 40}$ As adolescents with CP transition into adulthood, autonomy from parents is usually sought and they begin to take steps toward independence such as graduating from high school, pursuing post secondary education, leaving the parents' home, forming intimate partnerships, getting Chapter 5: Article 3 
a job and becoming financially independent. ${ }^{116 ; 117}$ While research in children with CP has shown that restrictions in participation are impacted by motor function, ${ }^{111 ; 112}$ environmental factors (physical and social) may also impact participation. ${ }^{118 ;} 55$ To date, minimal information exists regarding the role functional motor impairment has on the acquisition of adult social roles and the extent to which functional motor impairment alone, or in combination with, environmental barriers affects the ability of young adults with CP to participate in life.

Objective measurement of participation and subjective measurement of quality of life have been proposed as key outcomes for individuals with disabilities in both epidemiological studies and intervention studies. ${ }^{119}$ In addition, restrictions in participation and environmental factors may play a role in the satisfaction with life in adults with physical disabilities. ${ }^{120}$ As young adults with $\mathrm{CP}$ take steps toward independence, the extent to which they are able to participate and the magnitude of environmental barriers they encounter may influence their satisfaction with life. The purpose of this exploratory study was to: 1) to examine the role functional motor level and environmental factors have on participation in daily activities and social roles 2) to examine the role functional motor impairment has on the acquisition of adult social roles and 3) to examine the role environmental barriers and participation in daily activities and social roles have on the satisfaction with life of young adults with CP. 
Method

\section{PARTICIPANTS}

Young adults were recruited from the databases of Shriners Hospitals for ChildrenPortland (SHC-P) and the Child Development and Rehabilitation Center (CDRC) of Oregon Health and Sciences University Institute on Development \& Disability. Inclusion criteria included: 1) diagnosis of $\mathrm{CP}, 2$ ) between 18 -30 years of age, and 3) last known address in Oregon or Washington. Young adults living in a foster home were excluded from participation. 688 potential subjects were identified, 58 subjects were ineligible, as they did not have a diagnosis of CP or lived in foster home, yielding 610 eligible subjects. The Portland State University, Human Subjects Research Review Committee (HSRRC) approved this study.

\section{PROCEDURES}

The multidimensional framework of the $\mathrm{ICF}^{6}$ was used in this cross-sectional survey approach. Survey packages incorporating questionnaires from all dimensions of the ICF were mailed to 610 potential subjects. Young adults were instructed to complete and return the surveys in the stamped, self-addressed envelope. Subjects were encouraged to self-report, however could solicit assistance to complete the survey. While self-report is considered the "gold standard," individuals with CP and impairments that prevented them from completing the survey independently, could engage a proxy to complete it on their behalf. Individuals who completed and returned the surveys were sent a \$5 gift 
card. Follow-up reminder cards were sent three and six weeks later. A repeat mailing of the survey package was sent to non-responders two months following the initial mailing. Of the 610 potential subjects, parents reported that 15 subjects had died and 153 surveys were returned as undeliverable. A total of 95 surveys out of 442 surveys were returned, yielding a $21.5 \%$ response rate. Fifty-five participants self-reported, while forty surveys were completed by a proxy respondent.

For young adults with $\mathrm{CP}$, participation encompasses both activities of daily living and social roles. In addition to normative social roles, the acquisition of adult social roles is important as young adults with CP transition into adulthood. For this study, participation was measured by the by the level of participation in daily activities and social roles in addition to the achievement of adult social roles. The Assessment of Life Habits (LIFE-H) ${ }^{55}$ was used to evaluate the level of participation in daily activities and social roles. The Life-H was developed to evaluate the social participation of people with disabilities, regardless of the type of underlying impairments. ${ }^{56}$ The LIFE-H (short form) has 69 items in 12 categories: 1) nutrition, 20 fitness, 3) personal care, 4) communication, 5) housing, 6) mobility, 7) responsibilities, 8) interpersonal relationships, 9) community life, 10) education, 11) employment and 12) recreation. ${ }^{55}$ The LIFE-H evaluates the level of participation in daily activities and social roles by considering both the degree of difficulty and the type of assistance used on a scale of $0-9$, where 0 indicates total handicap and 9 indicates optimal participation. ${ }^{55}$ Scores for both the 
accomplishment and satisfaction scales are calculated for each of the 12 categories. While each category can be examined independently, overall participation in daily activities includes the categories of nutrition, fitness, personal care, communication, housing, and mobility, while participation in social roles includes responsibilities, interpersonal relationships, community life, education, employment, and recreation. The Life-H has been shown to have good test-retest reliability in older adults with disabilities. $^{56 ; 55}$

Three adult social roles were used as markers of transition into adult roles: residential status, financial independence and education and employment status (Table 6). Residential status was classified as dependent or independent. Financial independence was based on income and classified into 3 distinct categories. The pursuit of higher education and employment status were grouped into four mutually exclusive categories.

\begin{tabular}{|l|l|}
\hline \multirow{4}{*}{ Residential Status } & Category \\
\hline \multirow{4}{*}{ Financial Independence } & $\begin{array}{l}\text { Dependent- Living in the parental home or adult care } \\
\text { center }\end{array}$ \\
\cline { 2 - 2 } & $\begin{array}{l}\text { Independent- Living independently alone or with a } \\
\text { spouse, partner of friend }\end{array}$ \\
\cline { 2 - 2 } Status & Income between $\$ 0-10,000$ \\
\cline { 2 - 2 } & Income between $\$ 10,000-34,999$ \\
\hline Income greater than 35,000 \\
\cline { 2 - 2 } & Not working or going to school \\
\cline { 2 - 2 } & Volunteering or working in a sheltered workshop \\
\cline { 2 - 2 } & Student only (high school or post secondary) \\
\cline { 2 - 2 } & $\begin{array}{l}\text { Working (full time or part time) or working part time and } \\
\text { pursuing secondary education }\end{array}$ \\
\hline
\end{tabular}

TABLE 6: CLASSIFICATION OF ADULT SOCIAL ROLES 
The Craig Hospital Inventory of Environmental Factors (CHIEF) $)^{57 ; 58}$ was used to examine the role environmental barriers have on participation. The questionnaire consists of 25 questions that are divided into five subscales: 1) physical and structural, 2)work and school, 3) attitudes and support, 4) services and support and 5) policies. ${ }^{58}$ Each question has two types of response scales: one for the frequency that the identified barrier occurs and one for the magnitude of the barrier as a problem. ${ }^{58}$ The frequency scale uses a 5-point Likert scale ranging from never to daily, while the magnitude scale was dichotomized as either a big problem or little problem. ${ }^{58} \mathrm{~A}$ magnitude frequency product score is computed to indicate the overall impact of the barrier, with higher scores indicating greater barriers. While the five subscales can be examined separately to determine the role of a specific type of barriers has on participation, a total CHIEF score can be used to examine the role of all environmental barriers evaluated by the CHIEF. The CHIEF has good test-retest reliability and evidence of content, construct, and discriminant validity. ${ }^{59}$

Differences in functional motor ability have been reported to discriminate between health outcomes in adults with CP. ${ }^{20 ; 21}$ The Gross Motor Function Classification System (Expanded and Revised)-GMFCS (E\&R)- Self-Report Questionnaire for Young People Aged $12-18$ years $^{46}$ was used as a classification system to discriminate among functional levels. The GMFCS is a five level classification system that distinguishes among levels of 
motor function that are clinically meaningful. ${ }^{47 ; 18}$ Individuals classified as GMFCS level I, walk without limitations; GMFCS level II walk with limitations; GMFCS level III walk using a hand-held mobility device; GMFCS level IV posses self-mobility with limitations and may use powered mobility, and GMFCS level V are transported in a manual wheelchair. ${ }^{46}$ It has been shown that adults with cerebral palsy can accurately selfreport their level of function. ${ }^{20}$

Satisfaction with life was assessed with a single question from the 2011 Behavioral Risk Factor Surveillance System (BRFSS) Questionnaire ${ }^{50}$ using a four-point scale, with a score of 0 indicating very satisfied and a score of three indicating very dissatisfied. ${ }^{50}$

\section{Statistical Analysis}

Due to the potential bias between self and proxy report for subjective assessments of quality of life ${ }^{70-73}$ and perceptions of environmental barriers, ${ }^{121 ; 58}$ only young adults who self-reported were included in the analyses. Statistical analysis of the data was carried out with SPSS, version 21 (Chicago, IL). Data were evaluated for normality, linearity and equality of variance and the appropriate parametric or non-parametric statistics were used in the analysis. Categorical variables are expressed as frequencies or percentages, while means and standard deviations were used for continuous variables. One-way ANOVA's were used to examine the impact of functional motor level on environmental barriers and participation in daily activities and social roles. 
Hierarchical linear regression $(\mathrm{N}=55)$ was used to examine the role functional motor level and environmental barriers have on participation in daily activities and social roles above and beyond functional level. Linear regression was also used to examine the combined role environmental barriers and participation in daily activities and social roles have on satisfaction with life. As this study is exploratory, significance was set conservatively at $\mathrm{p}<.01$ to account for multiple comparisons.

\section{Results}

\section{GROUP CHARACTERISTICS}

The mean age of the 55 participants was 24.23 years ( \pm 3.61 years) with females representing $62 \%$ of the sample. Only $4.6 \%$ of the participants were Hispanic, and the majority (96.4\%) were Caucasian. Due to the small sample size, the impact of functional level could not be examined using all five levels of the GMFCS, thus, the 55 subjects were divided into three subgroups according to functional ability. In order to provide similar subject numbers in each group, young adults classified as GMFCS I ( $N=24)$ and GMFCS II ( $\mathrm{N}=16)$ were considered separate groups, while individuals classified as GMFCS levels III, IV, and V ( $\mathrm{N}=15)$ were considered one group.

\section{PARTICIPATION IN DAILY ACTIVITIES AND SOCIAL ROLES}

The Life-H demonstrated significant difference among motor function levels in all life habits categories, except responsibilities (Figure 7). Young adults in GMFCS level I 
demonstrated greater accomplishment in all the remaining life habits when compared to young adults in GMFCS levels III, IV and V. Young adults in GMFCS level I also demonstrated higher accomplishment scores than young adults in GMFCS level II for the daily activities of housing and mobility and the social roles of community life, employment, and recreation.

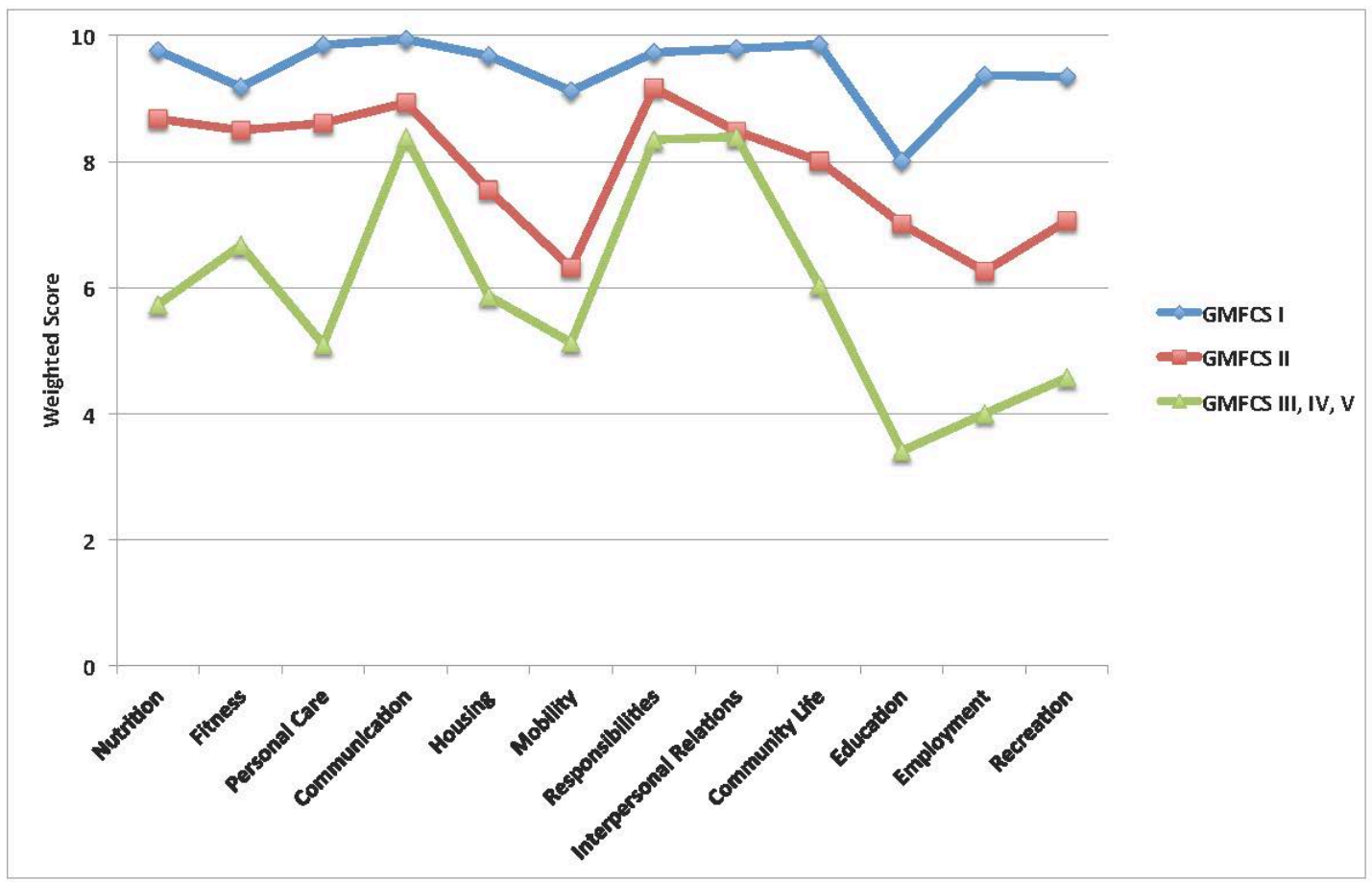

FIGURE 7: LIFE-H PARTICIPATION IN DAILY ACTIVITIES AND SOCIAL ROLES BY FUNCTIONAL LEVEL

\section{ACQUISITION OF ADULT SOCIAL ROLES}

Thirty-six percent of the young adults with CP lived independently (5\% spouse, $11 \%$ partner, $11 \%$ friends and $9 \%$ alone). $63 \%$ of the young adults were enrolled or had completed post-secondary education, with $16 \%$ reporting completion of graduate Chapter 5: Article 3 
education. Further, $43.6 \%$ of young adults with CP were competitively employed either part or full-time. Significant differences were found among motor function levels for all adult social roles (Figure 8). Young adults in GMFCS level I were more often employed $(p=.005)$, had a higher income level $(p=.005)$ and lived independently $(p=.007)$, than those in GMFCS level II followed by those classified as GMFCS level III, IV, and V.

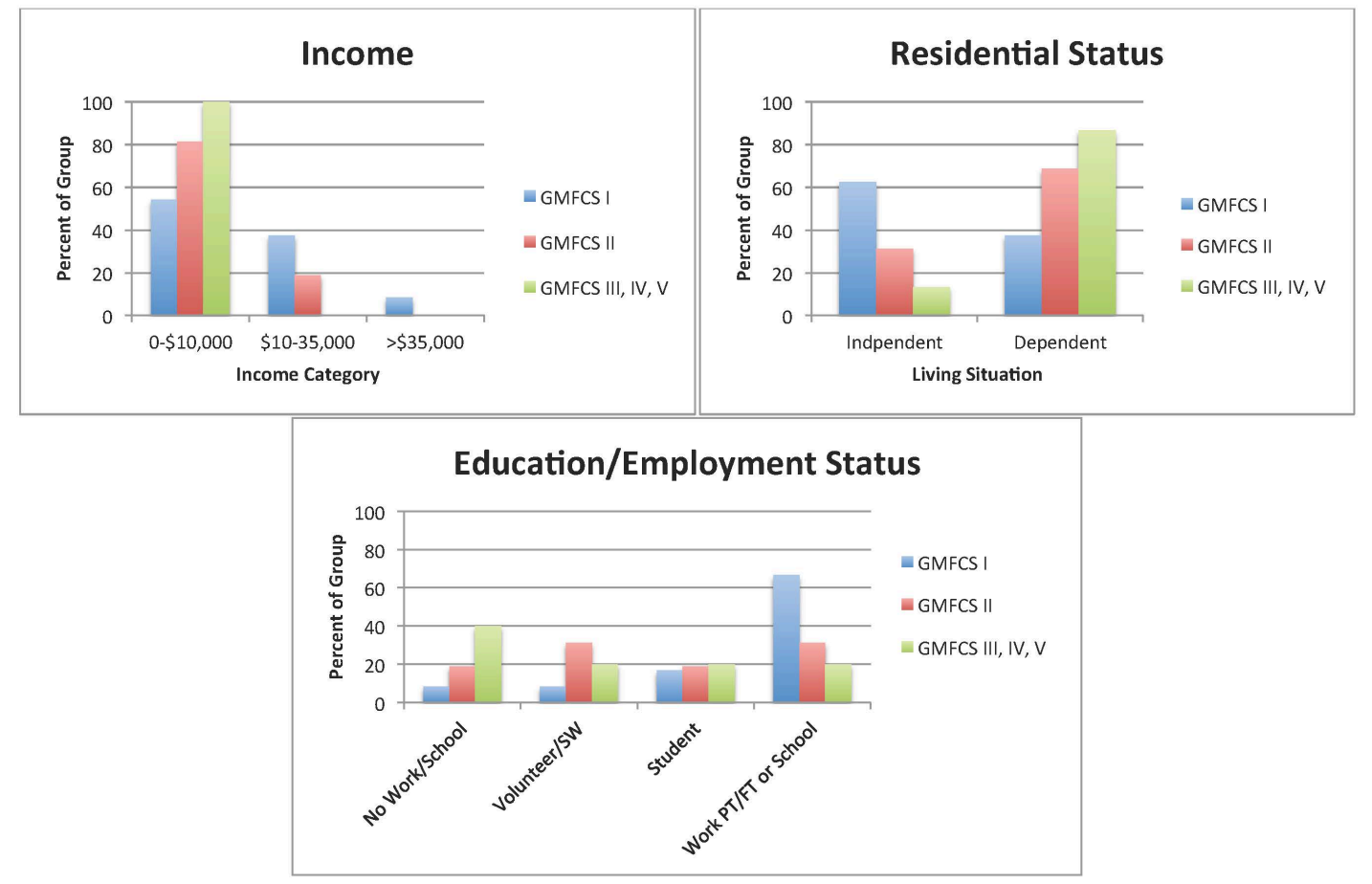

FiguRE 8: AdULT SOCIAL ROLES BY FUNCTIONAL LEVEL $\mathrm{SW}=$ Sheltered workshop, $\mathrm{PT}=$ part-time, $\mathrm{FT}=$ full-time.

\section{BARRIERS TO PARTICIPATION}

A significant difference among motor function levels was found for the summation of all environmental barriers (CHIEF total), with individuals classified as GMFCS level I and II experiencing fewer environmental barriers than individuals classified as GMFCS levels III, Chapter 5: Article 3 
IV and V (Table 7). Significant differences were found among functional levels for all of subscales of the CHIEF except work/school. Young adults in GMFCS level III, IV and V experienced greater barriers than young adults in GMFCS levels I or II on all other subscales.

\begin{tabular}{|l|c|c|c|c|}
\hline \multicolumn{5}{|c|}{ CHIEF-Environmental Barriers } \\
\hline Subscales & $\begin{array}{c}\text { GMFCS I } \\
\mathrm{N}=24\end{array}$ & $\begin{array}{c}\text { GMFCS II } \\
\mathrm{N}=16\end{array}$ & $\begin{array}{c}\text { GMFCS III, IV, V } \\
\mathrm{N}=15\end{array}$ & Significance \\
\hline Physical/ Structural & $.37(.57)$ & $.60(.66)$ & $1.78(1.61)$ & $\mathrm{p}<.001$ \\
\hline Services/ Assistance & $.24(.35)$ & $.79(.59)$ & $1.13(1.34)$ & $\mathrm{p}<.001$ \\
\hline Policies & $.09(.24)$ & $.61(.76)$ & $2.17(2.16)$ & $\mathrm{p}<.001$ \\
\hline Work/School & $.35(.69)$ & $.33(.50)$ & $.55(1.0)$ & $\mathrm{P}=.639$ \\
\hline Attitudes/Support & $.24(.52)$ & $.33(.42)$ & $.88(.86)$ & $\mathrm{p}<.01$ \\
\hline CHIEF Total & $.26(.28)$ & $.57(.47)$ & $1.33(1.08)$ & $\mathrm{p}<.001$ \\
\hline \multicolumn{5}{|c|}{ Life-H Domains } \\
\hline Daily Activities & $9.59(.53)$ & $8.10(1.37)$ & $6.15(1.58)$ & $\mathrm{p}<.001$ \\
\hline Social Roles & $9.35(1.03)$ & $7.67(1.74)$ & $5.79(1.68)$ & $\mathrm{p}<.001$ \\
\hline
\end{tabular}

TABLE 7: ENVIRONMENTAL BARRIERS AND LIFE-H DOMAINS BY FUNCTIONAL LEVEL Means (standard deviation)

\section{FACTORS ASSOCIATED WITH PARTICIPATION AND SATISFACTION WITH LIFE}

Functional level accounted for a significant amount of variance in participation in daily activities $\left(\mathrm{R}^{2}=.61, \mathrm{p}<.001\right)$. The addition of the environmental barriers resulted in a significant increase in the amount of variance explained $\left(R^{2}=.79, F_{\text {inc }}(3,53)=44.63\right.$, $\mathrm{p}<.001)$. Functional level, physical/structural, attitudes/support and services/assistance barriers accounted for $79 \%$ of the explained variance in participation in daily activities, yet only functional level $(p<.001)$ significantly contributed to participation in daily activities. 
Examining the factors associated with participation in social roles, functional level accounted for a significant amount of variance in participation in social roles $\left(R^{2}=.51\right.$, $p<.001)$. The addition of the environmental barriers resulted in a significant increase in the amount of variance explained $\left(R^{2}=.65, F_{i n c}(6,53)=14.36, p<.01\right)$. Together, functional level and all CHIEF barrier subscales accounted for $64.7 \%$ of the explained variance in participation in social roles. Only functional level $(p<.001)$ and policy barriers $(p<.01)$ significantly contributed to participation in social roles. Environmental barriers and participation did not significantly $(F(3,53)=2.436, p=.076)$ explain the variance $(13 \%)$ of the variance in satisfaction with life.

\section{Discussion}

Similar to the results previously reported in the literature for children with $\mathrm{CP}$, severity of motor impairment was a key predictor of participation; however, the combination of motor impairment and environmental barriers played a greater role. ${ }^{122 ; 123 ; 111 ; 124 ; 112 ; 118}$ Overall, young adults in GMFCS level I actively participated in daily activities and social roles, as reflected by their mean score 9.59 out of 10 for daily activities and 9.35 out of 10 for social roles. The ambulatory difficulties experienced by young adults in GMFCS level II impacted their ability to move around their home and community. For young adults in GMFCS levels III, IV and V, the use of an assistive device may have decreased their ability to participate in activities related to meals, personal care, housing and mobility without difficulty and assistance. As young adults with CP take steps toward independence, the provision of adaptive equipment and training by physical, Chapter 5: Article 3 
occupational and vocational rehabilitation therapists, in addition to more innovative therapeutic approaches (assistive technology), will provide the young adult with CP with the skills, resources and adaptations of the environment needed to participate in all areas of life with reduced or no assistance.

All groups demonstrated lower scores for participation in social roles than participation in daily activities. The categories of education, employment and recreation demonstrated the lowest participation scores, especially for young adults in GMFCS level III, IV and V. As young adults with CP transition into adulthood, the financial independence, social participation and personal fulfillment resulting from the pursuit of education and the achievement of employment are important factors for young adults with $\mathrm{CP} .{ }^{125}$ While the acquisition of adult social roles is on a continuum for young adults with and without disabilities, there is significant variability in the accomplishment of these roles in young adults with CP. While a large percentage (63\%) of the young adults in this study were enrolled or had completed post-secondary education, most were in GMFCS level I. The cost of education is a significant deterrent to attending college for many young adults; educating young adult with CP and their families, and high school and college counselors, about potential opportunities for scholarships, service organizations and disability services may enhance their participation in educational activities. The provision of advanced education facilitates employment and financial 
independence. Future studies should focus on determining the factors that prevent more young adults with CP from pursuing advanced education.

As more young adults with CP transition into adulthood, their ability to participate in employment activities is of major importance to achieving financial independence.

While, $43.6 \%$ of the young adults in this study were competitively employed either part or full-time, most had an income of less than $\$ 10,000$. As this level of income is below the current poverty level, ${ }^{126}$ many young adults with CP needed to continue to live with their parents as they could not afford to live independently. Employment provides financial independence and promotes psychological well-being, ${ }^{127}$ and thus the provision of therapy services specifically directed toward employment in addition to vocational services may improve the employment opportunities for young adults with $\mathrm{CP}$. Recently, there has been a significant focus in the literature regarding potential interventions $s^{127}$ and vocational rehabilitation services ${ }^{128 ; 129}$ to improve employment outcomes for young adults with physical disabilities. It is necessary to continue to investigate potential interventions and services that could enhance employment opportunities for young adults with CP. While minimal research has been reported in this area, through the combining of rehabilitation and vocational services, several new interventions for improving employment outcomes including: interview training, "role" models, on-the-job training, job placement assistance, on-the-job support, maintenance 
services; and rehabilitation technology. ${ }^{128 ; 127}$ These interventions may facilitate employment opportunities for young adults with CP.

In addition to level of impairment, environmental barriers have been reported to impact the ability to participate. While young adults in GMFCS level I reported scores for all CHIEF subscales similar to their non-disabled peers $(0.41),{ }^{59}$ young adults in GMFCS level II, III, IV and V encounter barriers from policies, the physical and structural environment and from the services or assistance provided were greatest. Similar to the results from children with cerebral palsy, participation in daily activities for individuals in GMFCS levels III, IV and V, was associated with the magnitude of barriers encountered from the physical environment. ${ }^{130}$ While functional impairment impacted participation to a greater extent than environmental barriers, finding mechanisms to reduce the physical/structural and services/assistance barriers through therapeutic adaptations and interventions could reduce barriers and enhance participation.

Although environmental barriers were found to be a contributing factors to participation in both physical activities and social roles, the combination of environmental barriers and participation in daily activities and social roles did not contribute significantly to the satisfaction with life in young adults with $\mathrm{CP}$. The results of this study indicate that in order to provide a holistic understanding of the factors contributing to the satisfaction with life in young adults with $\mathrm{CP}$, a multidimensional 
approach is needed. Since the magnitude of environmental barriers encountered and the ability to participate in daily activities and social roles only partially explained satisfaction with life, all dimensions of the $\mathrm{ICF}^{6}$ framework should be examined in order to provide a thorough understanding of the complex interactions among the factors that impact the satisfaction with life for young adults with CP.

The generalizability of these results to other young adults with CP is limited by the lack of a population-based sample, geographical mailing restrictions and the small sample size. There are several factors that may have influenced the response rate: the use of a postal survey, the length of the questionnaire and the transient nature of individuals between the ages of 18-30 years. Reducing the length of the survey and determining alternative strategies to ensure receipt and completion of the surveys may increase the response rate in future studies. Although statistical significance was set conservatively, Bonferroni corrections were not employed. Since multiple tests were conducted, this may increase the chances of a Type I error.

As this study focused on the role functional level and environmental barriers had on participation, the role of pain, fatigue and depression were not included. As these impairments are known to influence participation, future studies with larger populations should consider their incorporation using complex modeling techniques to provide a comprehensive understanding of the factors that influence participation. Additionally, 
this study focused on the barriers or factors restricting participation. Future studies should evaluate facilitators such as emotional support and rehabilitation training, in addition to the barriers, to determine their combined role in improving participation.

\section{Conclusions}

The results of this study indicate that both functional motor impairment and environmental barriers impacted participation in activities and adult roles. While the provision of occupational and physical therapy services would enhance participation in daily activities, the services of school counselors and vocational services may improve participation in social roles. Acquiring the necessary skills to assume adult social roles requires a coordinated effort by both the rehabilitation and school systems in order to plan and prepare the young adult with CP for future independent living, education and employment. Similar to their able-bodied peers, facilitating education and employment will serve to enhance independence, increase participation and potentially enhance the satisfaction with life of young adults with CP. 


\section{Chapter 6: Article 4}

PROXY REPORT OF FUNCTIONAL IMPAIRMENTS, ACTIVITY LIMITATIONS AND

PARTICIPATION RESTRICTIONS IN YOUNG ADULTS WITH CEREBRAL PALSY: AN

EXPLORATORY STUDY OF THE ROLE OF FUNCTIONAL MOTOR LEVEL AND

\section{ENVIRONMENTAL BARRIERS}

Cerebral Palsy (CP) is defined as "a group of permanent disorders of the development of movement and posture, causing activity limitation, that are attributed to nonprogressive disturbances that occurred in the developing fetal or infant brain. The motor disorders of $\mathrm{CP}$ are often accompanied by disturbances in sensation, perception, cognition, communication, and behavior; by epilepsy, and by secondary musculoskeletal problems." ${ }^{11}$ The manifestation of the motor disorders and the consequences of the additional disturbances vary across the spectrum of condition. It has been reported that between $25-80 \%$ of individuals with CP have additional impairments, with a large proportion reporting some level of cognitive impairment. ${ }^{131}$ Although the perspective of the young adult with $\mathrm{CP}$ is desired, the presence of additional physical, cognitive or communication impairments may prevent them from being able to self-report their impairments, activity limitations and participation restrictions. It has been suggested that the use of proxy respondents is a reasonable approach for obtaining information about health outcomes when self-reporting is not possible. ${ }^{132}$ While it has been reported that concordance between an individual and their parent is greater for 
observable or overt behaviors (physical functioning) than for internal behaviors such perception of pain, fatigue and depression, ${ }^{133}$ utilization of proxy reporting provides broader inclusion and a more representative sample across the spectrum of CP. As this group of adolescents with CP and additional impairments transition into adulthood, it is crucial to provide them with a voice in order to understand the issues impacting their health and well-being in order to identify services that may reduce the barriers, increase activity and enhance participation.

In 2001, the World Health Organization approved the International Classification of Functioning, Disability and Health (ICF), ${ }^{6}$ a multidimensional framework to examine the complex interactions among the health condition, impairments, activity limitations, participation restrictions and the personal and environmental factors that influence personal health and well-being. ${ }^{62 ; 6}$ As more children with CP survive into adulthood, health and social impairments that arise with aging are now being recognized as barriers to participation, impacting both the health and well-being of adults with $\mathrm{CP} .{ }^{117}$ The purpose of this exploratory study was twofold: 1) to examine how proxies perceive functional motor ability impacts physical impairments (change in functional ability, pain, fatigue and depression), activity and participation (daily activities and social roles) in young adults with $\mathrm{CP}$ and 2 ) to examine how proxies perceive environmental barriers impact participation in daily activities and social roles. Through a comprehensive understanding of the complex interactions that impact the health and well-being of 
young adults with $\mathrm{CP}$, strategies and services can be identified and provided to enhance participation.

Method

\section{PARTICIPANTS}

Young adults were recruited from the databases of Shriners Hospitals for ChildrenPortland (SHC-P) and the Child Development and Rehabilitation Center (CDRC) of Oregon Health and Sciences University Institute on Development \& Disability. Inclusion criteria included: 1) diagnosis of $\mathrm{CP}, 2$ ) between $18-30$ years of age and 3) last known address in Oregon or Washington. Young adults living in a foster home were excluded from participation. 688 potential subjects were identified, 58 subjects were ineligible, as they did not have a diagnosis of CP or lived in foster home, yielding 610 eligible subjects. Approval for this study was obtained from the Portland State University, Human Subjects Research Review Committee (HSRRC).

Survey packages were addressed and mailed to 610 young adults. Potential subjects were instructed to complete and return the surveys in the stamped, self-addressed envelope. Individuals who returned the surveys were sent a $\$ 5$ gift card for completing the survey. Subjects were encouraged to self-report; however could solicit assistance in completing the questionnaires, if necessary. While self-report is considered the "gold standard", specifically for subjective measures, i.e. pain, fatigue, and depression, proxy reporting was permitted for individuals with $\mathrm{CP}$ and impairments that prevented them Chapter 6: Article 4 
from completing the survey independently. Follow-up reminder cards were sent three and six weeks later to encourage return of the survey. A repeat mailing of the survey package was sent to non-responders two months following the initial mailing.

Of the 610 potential subjects, parents reported that 15 subjects had died and 153 surveys were returned as undeliverable. A total of 95 surveys out of 442 surveys were returned, yielding a $21.5 \%$ response rate. Fifty-five participants self-reported, while forty surveys were completed by a proxy respondent. In addition to a diagnosis of $\mathrm{CP}$, all proxies reported the presence of an additional impairment or combination of impairments, vision, cognition, or communication that prevented the young adult with $\mathrm{CP}$ from being able to self-report, even with assistance. Due to the potential bias between self and proxy report for assessments of pain ${ }^{69}$ and perceptions of environmental barriers, ${ }^{121 ; 58}$ and the potential impact of the additional impairments on activity limitation and participation restrictions, only the responses by the proxy were included in the analyses. Self-report findings are reported elsewhere.

\section{PROCEDURES}

In order to assess all factors that impact the health and well-being of young adults with $\mathrm{CP}$, a cross-sectional, multidimensional survey approach was used. Although all components of the ICF were examined in the complete survey, only environmental barriers and the functional dimensions of body functions and structure, activities, and 
participation will be reported in this study. Recently differences in functional motor ability have been reported to discriminate between health outcomes in adults with $\mathrm{CP},{ }^{20 ; 21}$ and therefore the Gross Motor Function Classification System (Expanded and Revised)-GMFCS (E\&R)- Self-Report Questionnaire for Young People Aged 12-18 years ${ }^{46}$ was used both as a classification system and a measure of deterioration in motor ability between childhood and young adulthood. The GMFCS is a five level classification system that distinguishes among levels of motor function that are clinically meaningful. ${ }^{47 ; 18}$ Individuals classified as GMFCS level I walk without limitations; GMFCS level II walk with limitations; GMFCS level III walk using a hand-held mobility device; GMFCS level IV posses self-mobility with limitations and may use powered mobility, and GMFCS level V are transported in a manual wheelchair. ${ }^{46}$ In this study, deterioration in ambulatory ability was assessed by the change in GMFCS rating from age 12 to current.

In addition to the deterioration of functional mobility, pain, fatigue and depression are associated with aging with $\mathrm{CP} .{ }^{37 ; 31}$ The magnitude of pain and the interference of pain on activities were assessed with the pain question from the 2011 Behavioral Risk Factor Surveillance System (BRFSS) ${ }^{48}$ and the impact of pain on functioning and Well-being Scale of the Brief Pain Inventory (BPI). ${ }^{49}$ The BRFSS pain question assesses the level of bodily pain present on a five-point scale ranging from none to very severe. ${ }^{50}$ The pain interference scale of the $\mathrm{BPI}^{49}$ uses a five-point scale ranging from none to extremely to measure the extent to which pain interferes with general activity, mood, walking ability, 
normal work, relations with people, sleep and enjoyment in life. Scores from the specific activities can be evaluated independently or summed to yield a total pain interference score.

Fatigue was assessed with Fatigue Assessment Scale (FAS), ${ }^{51}$ a 10 -item selfadministered questionnaire designed to measure chronic fatigue. Fatigue is rated on a five-point scale ranging from 1 , never, to 5 , always. ${ }^{51}$ The FAS has been shown to have high internal consistency and correlates strongly with other fatigue scales. ${ }^{51}$ The presence and severity of depression were assessed with the Patient Health Questionnaire-9 (PHQ-9). ${ }^{52}$ The PHQ-9 is a brief self-report questionnaire that assesses the levels of depression on the nine key symptoms. The amount to which each symptom bothers the individual is rated on a scale from not at all to nearly every day. ${ }^{52}$ Five distinct categories of depression severity are determined based on the total score, ranging from a score of 0-5 indicating no depression to a score of 20 or greater indicating severe depression. $^{52}$

Participation in physical activity was assessed with the Physical Activity Scale for Individuals with Physical Disabilities (PASIPD). ${ }^{53 ; 41}$ The PASIPD is a 7-day physical activity recall questionnaire designed to evaluate physical activity levels in persons with disabilities. ${ }^{41}$ The PASIPD consists of 13 items that assess leisure, household and work activities. Only the six leisure time activity items were assessed: 1) stationary activity, 2) 
walking and wheeling outside, 3) light sport, 4) moderate sport, 5) strenuous sport and 6) exercises to increase muscle strength and endurance. ${ }^{41}$ The MET value for each activity is created by multiplying the average hours per day (based on the number of days per week and the number of hours per day they report participating in the activity) by a metabolic equivalent (MET) value associated with the intensity of the activity. The summation of the five activity items created the PASIPD score. ${ }^{41}$ The PASIPD has been shown to have strong construct and criterion validity for individuals with $\mathrm{CP}{ }^{54}$

For young adults with CP, participation encompasses both activities of daily living and social roles. In addition to normative social roles, the acquisition of adult social roles is important as young adults with CP transition into adulthood. For this study, participation was measured by the by the level of participation in daily activities and social roles, in addition to the achievement of adult social roles. The Assessment of Life Habits (LIFE-H) ${ }^{55}$ was used to evaluate the level of participation in daily activities and social roles. The Life-H was developed to evaluate the social participation of people with disabilities, regardless of the type of underlying impairments. ${ }^{56}$ The LIFE-H (short form) has 69 items in 12 categories: 1) nutrition, 20 fitness, 3) personal care, 4) communication, 5) housing, 6) mobility, 7) responsibilities, 8) interpersonal relationships, 9) community life, 10) education, 11) employment and 12) recreation. ${ }^{55}$ The LIFE-H evaluates the level of participation in daily activities and social roles by considering both the degree of difficulty and the type of assistance used on a scale of 0-9, where 0 
indicates total handicap and 9 indicates optimal participation. ${ }^{55}$ Scores for both the accomplishment and satisfaction scales are calculated for each of the 12 categories. While each category can be examined independently, overall participation in daily activities includes the categories of nutrition, fitness, personal care, communication, housing, and mobility, while participation in social roles includes responsibilities, interpersonal relationships, community life, education, employment, and recreation. The Life-H has been shown to have good test-retest reliability in older adults with disabilities. $^{56 ; 55}$

In order to assess transition into adult roles, three adult social roles were used:

residential status, financial independence, and education and employment status (Table 8). Residential status was classified as dependent or independent. Financial independence was based on income and classified into 3 distinct categories. The pursuit of higher education and employment status were grouped into four mutually exclusive categories. 


\begin{tabular}{|c|c|}
\hline & Category \\
\hline \multirow[t]{2}{*}{ Residential Status } & $\begin{array}{l}\text { Dependent- Living in the parental home or adult care } \\
\text { center }\end{array}$ \\
\hline & $\begin{array}{l}\text { Independent- Living independently alone or with a } \\
\text { spouse, partner of friend }\end{array}$ \\
\hline \multirow[t]{3}{*}{ Financial Independence } & Income between $\$ 0-10,000$ \\
\hline & Income between $\$ 10,000-34,999$ \\
\hline & Income greater than 35,000 \\
\hline \multirow{4}{*}{$\begin{array}{l}\text { Education/Employment } \\
\text { Status }\end{array}$} & Not working or going to school \\
\hline & Volunteering or working in a sheltered workshop \\
\hline & Student only (high school or post secondary) \\
\hline & $\begin{array}{l}\text { Working (full time or part time) or working part time and } \\
\text { pursuing secondary education }\end{array}$ \\
\hline
\end{tabular}

TABLE 8: CLASSIFICATION OF ADULT SOCIAL ROLES

The Craig Hospital Inventory of Environmental Factors (CHIEF) $)^{57} 58$ was used to examine the role environmental barriers have on participation. The questionnaire consists of 25 questions that are divided into five subscales: physical and structural, work and school, attitudes and support, services and support and policies. ${ }^{58}$ Each question has two types of response scales: one for the frequency that the identified barrier occurs and one for the magnitude of the barrier as a problem. ${ }^{58}$ The frequency scale uses a 5-point Likert scale ranging from never to daily, while the magnitude scale was dichotomized as either a big problem or little problem. ${ }^{58}$ A magnitude frequency product score is computed to indicate the overall impact of the barrier, with higher scores indicating greater barriers. While the five subscales can be examined separately to determine the role of a specific type of barriers has on participation, a total CHIEF score can be used to examine the role of all environmental barriers evaluated by the CHIEF. The CHIEF has good test-retest 
reliability and evidence of content, construct and discriminant validity. ${ }^{59}$ The CHIEF has a reported ICC of .618 for subject-proxy agreement. ${ }^{58}$

\section{Statistical Analysis}

Statistical analysis of the data was carried out with SPSS, version 21 (Chicago, IL). Data were evaluated for normality, linearity and equality of variance and the appropriate parametric or non-parametric statistics were used in the analysis. Categorical variables are expressed as frequencies or percentages, while means and standard deviations were used for continuous variables. One-way ANOVA's were used to determine differences among the functional levels for impairments, activity limitations, participation restrictions and environmental barriers. Pearson correlations were used to examine the relationship between environmental barriers and participation in daily activities and social roles. As this study is exploratory, significance was set conservatively at $p<.01$ to account for multiple comparisons.

\section{Results}

\section{GROUP CHARACTERISTICS}

The mean age of the 40 participants was 23.19 years ( \pm 3.49 years) with males representing $60 \%$ of the sample. $82.5 \%$ of the sample was Caucasian and $22.5 \%$ were Hispanic. Due to modest sample size, the impact of functional level could not be examined across all five levels of the GMFCS; the 40 subjects were divided into three 
subgroups according to functional ability. These groupings were chosen to provide similar subject numbers each group. Young adults classified as GMFCS level I, II and III $(\mathrm{N}=9)$ were considered one group, while young adults classified as GMFCS level IV $(\mathrm{N}=14)$ or $\mathrm{V}(\mathrm{N}=17)$ were each considered separate groups.

\section{BODY STRUCTURE AND FUNCTION, ACTIVITY, PARTICIPATION}

No significant differences among functional levels were found for pain, pain interference, fatigue or depression (Table 9). Overall, $67 \%$ of proxy's reported that their young adult experienced some pain, with $36 \%$ reporting greater than moderate pain. Proxies reported that $51.5 \%$ of the sample experienced fatigue sometimes, with $17.5 \%$ reporting fatigue regularly. While proxies reported that $69 \%$ of young adults with CP had no depression, mild depression was recognized in $12 \%$ of the young adults, with moderate (16\%) and severe depression (3\%) reported in the remainder of the young adults. 


\begin{tabular}{|c|c|c|c|c|}
\hline \multicolumn{5}{|c|}{ Impairments of Structure and Function } \\
\hline & $\begin{array}{c}\text { GMFCS I, II, III } \\
\mathrm{N}=9\end{array}$ & $\begin{array}{c}\text { GMFCS IV } \\
N=14\end{array}$ & $\begin{array}{c}\text { GMFCS V } \\
\mathrm{N}=17\end{array}$ & $\begin{array}{c}\text { Significance } \\
\text { Level }\end{array}$ \\
\hline Change in Function & $\begin{array}{c}\text { Same }=6 \\
\text { Improve }=3\end{array}$ & $\begin{array}{c}\text { Same=13 } \\
\text { Improve=1 }\end{array}$ & $\begin{array}{l}\text { Decline }=2 \\
\text { Same }=15\end{array}$ & \\
\hline Pain & $1.22(1.30)$ & $.73(.91)$ & $1.54(1.13)$ & $p=.219$ \\
\hline Pain Interference & $1.78(1.09)$ & $1.28(.71)$ & $2.31(1.26)$ & $p=.061$ \\
\hline Fatigue & $2.48(.92)$ & $2.27(.77)$ & $2.64(.95)$ & $p=.606$ \\
\hline Depression & $.89(.93)$ & $.42(.90)$ & $.36(.81)$ & $p=.363$ \\
\hline \multicolumn{5}{|c|}{ Activity } \\
\hline $\begin{array}{l}\text { PASIPD (MET-hours/ } \\
\text { day) }\end{array}$ & $6.42(4.88)$ & $9.86(5.84)$ & $4.60(3.66)$ & $p=.016$ \\
\hline PASIPD (hours activity) & $1.98(1.27)$ & $3.05(1.70)$ & $1.59(1.28)$ & $p=.025$ \\
\hline \multicolumn{5}{|c|}{ Participation } \\
\hline Life-H-Daily Activities & $6.63(1.38)$ & $3.62(1.71)$ & $2.03(1.39)$ & $p<.001$ \\
\hline Life-H-Social Roles & $4.82(1.78)$ & $2.83(1.28)$ & $2.30(1.51)$ & $p<.01$ \\
\hline
\end{tabular}

TABLE 9: IMPAIRMENTS, ACTIVITIES AND PARTICIPATION BY FUNCTIONAL LEVEL (PROXY-REPORT) Means (standard deviation)

There were no differences by functional motor level in the magnitude of physical activity as measured by the PASIPD MET-hours per day or the average amount of activity hours; however there was a trend for individuals in GMFCS level IV to report higher MET hours per day and greater activity hours than both the young adults in GMFCS I, II and III and GMFCS level V (Table 9). For the majority of young adults with CP, more time was spent participating in stationary activities than active activities (Figure 9). As the intensity level of the activity increased from stationary to strenuous, less time per day was spent participating in the activity. Greater than $65 \%$ of the proxies reported that young adults with CP never participated in moderate or strenuous sport activities or strengthening activities (Figure 9). 


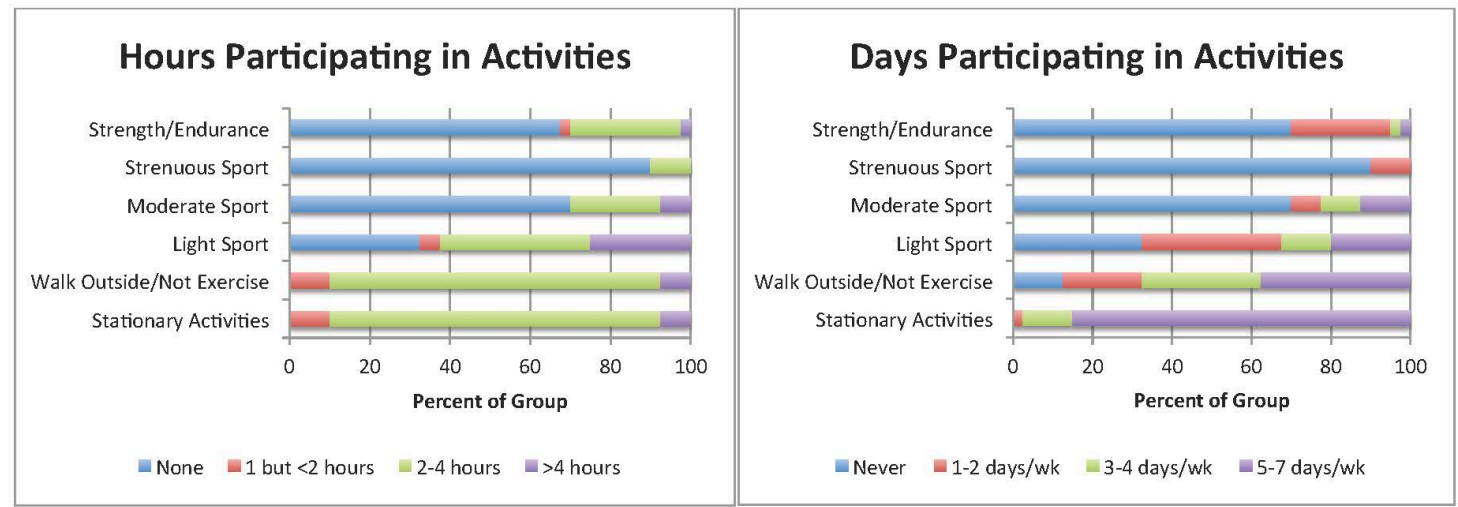

FIGURE 9: NUMBER OF HOURS PER DAY AND DAYS PER WEEK SPENT PARTICIPATING IN ACTIVITIES (PROXYREPORT)

Proxies reported that in addition to cost, the major reason for not joining a health club was the inability to utilize any of the equipment or services provided by the club. For those with a club membership, only swimming, stretching and weights were reported as activities that the young adults participated in. While physical and cognitive impairments were identified as factors limiting active participation in fitness and recreation, the presence of seizures was also a major contributing factor.

There was limited variety in the acquisition of adult social roles, as all young adults with CP in GMFCS levels IV or V had reported incomes of less than $\$ 10,000$ and lived with their parents. $70 \%$ of young adults in GMFCS level V and $50 \%$ of individuals In GMFCS level IV were neither employed nor going to school, while the remainder of the young adults with CP were volunteering or attending school. For young adults in GMFCS levels I, II and III, only one individual had a reported income of greater than $\$ 10,000$ and 2 (22\%) reported living independently with friends. As the mean age of the young adults in 
GMFCS levels I, II, and III was 20 years of age, it is not surprising that $56 \%$ of the group were still students and $95 \%$ lived with their parents. There were no differences in income $(p=.179)$, education/employment status $(p=.160)$ or in residential status $(p=.029)$ by functional level.

Proxies reported that young adults in GMFCS levels I, II and III had significantly greater participation in daily activities and social roles than young adults in GMFCS levels IV and V(

\begin{tabular}{|c|c|c|c|c|}
\hline \multicolumn{5}{|c|}{ Impairments of Structure and Function } \\
\hline & $\begin{array}{c}\text { GMFCS I, II, III } \\
N=9\end{array}$ & $\begin{array}{c}\text { GMFCS IV } \\
N=14\end{array}$ & $\begin{array}{c}\text { GMFCS V } \\
N=17\end{array}$ & $\begin{array}{c}\text { Significance } \\
\text { Level }\end{array}$ \\
\hline Change in Function & $\begin{array}{c}\text { Same }=6 \\
\text { Improve=3 }\end{array}$ & $\begin{array}{c}\text { Same=13 } \\
\text { Improve=1 }\end{array}$ & $\begin{array}{l}\text { Decline }=2 \\
\text { Same }=15\end{array}$ & \\
\hline Pain & $1.22(1.30)$ & $.73(.91)$ & $1.54(1.13)$ & $p=.219$ \\
\hline Pain Interference & $1.78(1.09)$ & $1.28(.71)$ & $2.31(1.26)$ & $p=.061$ \\
\hline Fatigue & $2.48(.92)$ & $2.27(.77)$ & $2.64(.95)$ & $p=.606$ \\
\hline Depression & $.89(.93)$ & $.42(.90)$ & $.36(.81)$ & $p=.363$ \\
\hline \multicolumn{5}{|c|}{ Activity } \\
\hline $\begin{array}{l}\text { PASIPD (MET-hours/ } \\
\text { day) }\end{array}$ & $6.42(4.88)$ & $9.86(5.84)$ & $4.60(3.66)$ & $p=.016$ \\
\hline PASIPD (hours activity) & $1.98(1.27)$ & $3.05(1.70)$ & $1.59(1.28)$ & $p=.025$ \\
\hline \multicolumn{5}{|c|}{ Participation } \\
\hline Life-H-Daily Activities & $6.63(1.38)$ & $3.62(1.71)$ & $2.03(1.39)$ & $p<.001$ \\
\hline Life-H-Social Roles & $4.82(1.78)$ & $2.83(1.28)$ & $2.30(1.51)$ & $p<.01$ \\
\hline
\end{tabular}

Table 9). Within the daily activities categories, for young adults in GMFCS levels I, II and

III the proxies reported significantly greater participation for all activities, except communication (Figure 10). In contrast, within the social roles categories, the proxies 
reported significant greater participation by young adults in GMFCS levels I, II and III, for the categories of community life and recreation only.

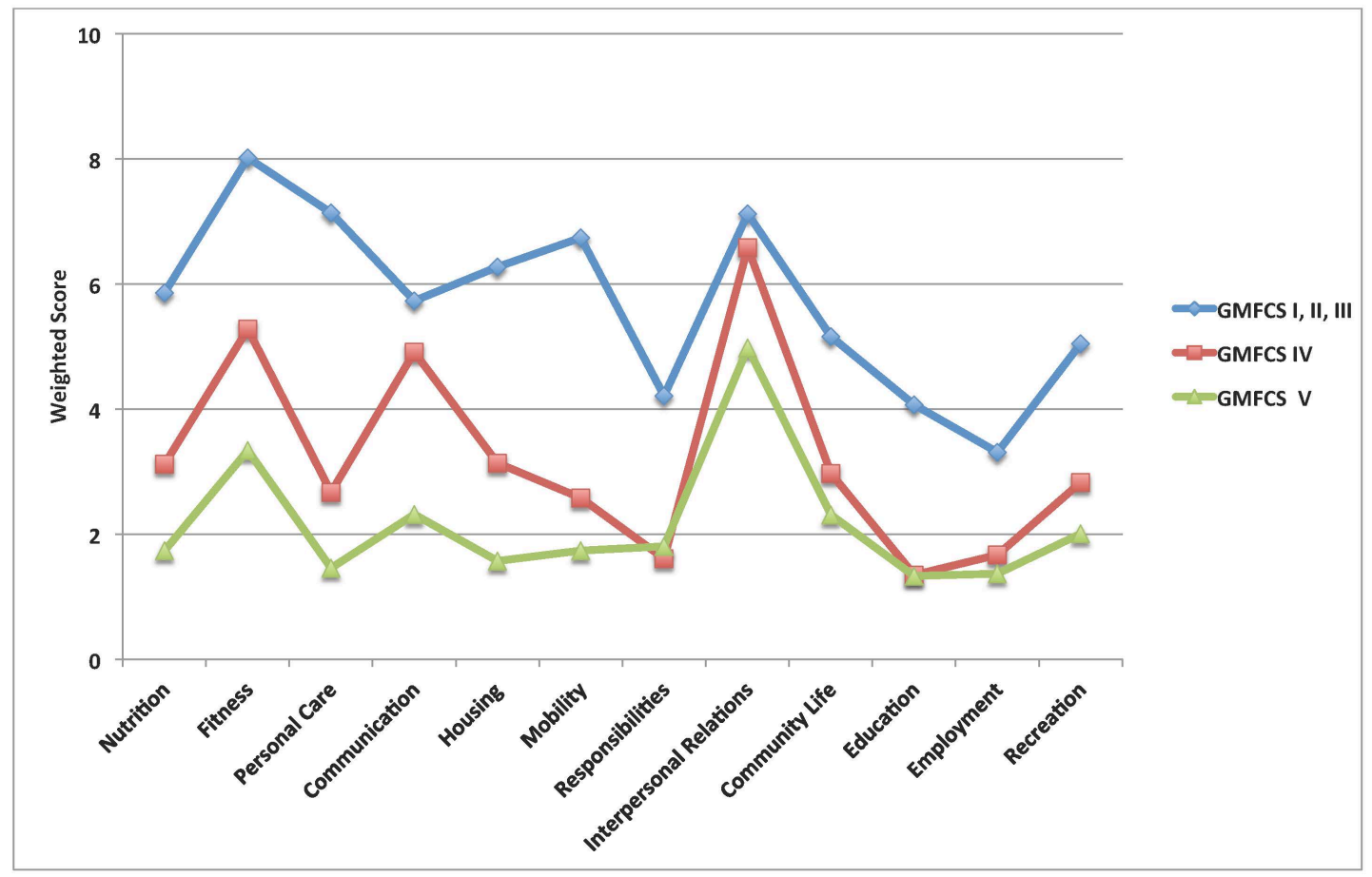

FiguRE 10: LIFE-H CATEGORIES BY FUNCTIONAL LEVEL (PROXY-REPORT)

\section{BARRIERS TO PARTICIPATION}

There were no statistically significant differences among functional levels in the barrier subscales of physical and structural, policy, work/school (or services/assistance (Table 10). Only attitudes/support barriers demonstrated significant differences by functional level $(F(2,37)=6.136, p<.01)$, with young adults in GMFCS level IV reporting fewer barriers than young adults in GMFCS levels I, II, III. Physical/structural, services/assistance and policies subscales were greater than two times the reported mean frequency magnitude product score of .41 reported for a non-disabled individual, 
for all functional levels. ${ }^{59}$ None of the environmental barrier subscales identified in the CHIEF were associated with the participation in daily activities or social roles.

\begin{tabular}{|c|c|c|c|c|c|}
\hline \multicolumn{6}{|c|}{ Environmental Barriers } \\
\hline CHIEF & \multicolumn{2}{|c|}{$\begin{array}{l}\text { GMFCS I, II, III } \\
N=9\end{array}$} & $\begin{array}{c}\text { GMFCS IV } \\
\mathrm{N}=14\end{array}$ & $\begin{array}{c}\text { GMFCS V } \\
N=17\end{array}$ & $\begin{array}{c}\text { Significance } \\
\text { Level }\end{array}$ \\
\hline $\begin{array}{l}\text { Physical/ Structural } \\
\text { Subscale }\end{array}$ & \multicolumn{2}{|c|}{$1.33(2.04)$} & $1.00(.83)$ & $2.03(1.65)$ & $p=.173$ \\
\hline $\begin{array}{l}\text { Services/ Assistance } \\
\text { Subscale }\end{array}$ & \multicolumn{2}{|c|}{$1.51(1.64)$} & $.79(.78)$ & $1.38(1.04)$ & $p=.236$ \\
\hline Policies Subscale & \multicolumn{2}{|c|}{$1.31(2.12)$} & $1.59(2.03)$ & $1.50(2.11)$ & $p=.950$ \\
\hline $\begin{array}{l}\text { Attitudes/Support } \\
\text { Subscale }\end{array}$ & \multicolumn{2}{|c|}{$1.69(1.63)$} & $.30(.60)$ & $.55(.72)$ & $p<.01$ \\
\hline Work/School Subscale & 1.44 & $.91)$ & $.42(.55)$ & $1.27(2.28)$ & $p=.309$ \\
\hline \multicolumn{6}{|c|}{ Associations between environmental barriers and participation } \\
\hline & $\begin{array}{l}\text { Physical/ } \\
\text { Structure }\end{array}$ & $\begin{array}{l}\text { Work/ } \\
\text { School }\end{array}$ & \begin{tabular}{|c|} 
Attitudes/ \\
Support
\end{tabular} & $\begin{array}{c}\text { Services/ } \\
\text { Assistance }\end{array}$ & Policies \\
\hline Daily Activities & -.167 & .103 & .370 & .016 & .026 \\
\hline Social Roles & -.207 & -.075 & .173 & -.115 & -.209 \\
\hline
\end{tabular}

TABLE 10: ENVIRONMENTAL BARRIERS BY FUNCTIONAL LEVEL AND ASSOCIATIONS (PEARSON CORRELATION COEFFICIENTS) AMONG ENVIRONMENTAL BARRIERS AND PARTICIPATION IN DAILY ACTIVITIES AND SOCIAL ROLES (PROXY-REPORT)

Means (standard deviation)

\section{Discussion}

The parental proxies in this study perceived that a large percentage of young adults with $\mathrm{CP}$ and additional physical, cognitive or communication impairments experience both pain and fatigue and that the magnitude was similar amongst individuals with differing degrees of impairment. Additionally, some parents also perceived that their young adult with CP suffered from depression; however only $3 \%$ of parents reported seeking medication for their young adult with $\mathrm{CP}$ to address the depression. These findings are consistent with those in the literature from young adults who self-reported, ${ }^{38 ; 37 ; 31}$ indicating pain, fatigue and depression are present in a large percentage of individuals Chapter 6: Article 4 
with CP starting at an early age. The responses from this study were ascertained from the parent-proxy; attention should be given to determining the appropriate methodology for accurately assessing and addressing these issues in adults with CP with physical, cognitive and communication impairments, in order to ensure that pain, fatigue and depression are addressed with appropriate medical interventions.

Similar to the findings in the literature, functional ability and the presence of additional physical, cognitive or communication impairments played a significant role in whether young adults with CP participated in physical activities. As participation in physical activity required the assistance or presence of another individual, this limited both the opportunities and magnitude of participation in physical activity. The increase in MET hours/day and number of hours participating in activities seen in the young adults in GMFCS level IV resulted from the significant efforts of a few parents to obtain physical therapy primarily for stretching, and to incorporate swimming and group exercise classes into their daily routine. One parent reported that, "I do everything I can to find opportunities to participate in physical activity and recreation as I am aware of the longterm benefits on health both physically and mentally." Knowledge and resource availability have been reported as barriers to participation in physical activity. ${ }^{88}$ Parents reported the lack of information regarding available programs and accessible facilities in the community. This lack of information in addition to the knowledge gaps of fitness professionals about adaptive recreation options, may hamper the ability of this group of 
young adults with CP to be involved in physical activities. As physical activity is important for all individuals with CP to control obesity, improve cardiovascular fitness, reduce pain and minimize the development of secondary conditions, ${ }^{39 ; 30 ; 108}$ rehabilitation specialists can assist parents and caregivers in identifying alternative activities and adaptations for involvement in physical activity in order to reduce the health risks that come with aging with $\mathrm{CP}$.

Participation in both daily activities and social roles was significantly restricted in this group of young adults with CP. As functional ability decreased, participation also decreased. Similar to the reports of children with $\mathrm{CP},{ }^{134}$ participation in "relationships" was the least disrupted area of everyday life for all functional levels, while education and employment were the most disrupted. Since functional ability has been shown to be a prognostic factor for restrictions in daily activities, and cognitive ability has been shown to contribute to restrictions in education and social relations, ${ }^{122}$ young adults with $\mathrm{CP}$ and with additional physical, cognitive or communication impairments may experience participation restrictions in both daily activities and social roles. Significantly lower participation in both employment and education may reflect the transitional state of this group of young adults. As many young adults with CP and additional impairments transition out of the educational system at the age of 21 years, this is a time when alternatives such as vocational education, volunteering or employment are sought. The lack of participation in these adult social roles may be indicative of the lack of 
opportunities available to young adults with CP with additional physical, cognitive or communication impairments. While restrictions in participation were found for both daily activities and social roles, participation in social roles was significantly compromised. Transition for young adults with CP requires a coordinated effort by both the rehabilitation and school systems to identify opportunities for young adults with CP to acquire skills to pursue education and seek employment, as well as housing alternatives that may lead to increased independence as they transition into adulthood.

While significant barriers were found for all subscales of the CHIEF, differences were not found among individuals with different degrees of impairment. The lack of difference in environmental barriers and the absence of a relationship between environmental barriers and participation may be reflective of the role the parent plays in negotiating the barriers encountered at all levels. Many parents reported that although numerous barriers were encountered during this transitional time, that continual appeal (sometimes lasting years) of insurance decisions regarding assistive devices, augmentative communication, therapeutic interventions and environmental adaptations ultimately provided the needed services or equipment, subsequently reducing the negative impact of these barriers on the participation of the young adult with CP. Allowing proxies to respond on behalf of the young adult with CP provides insight into the impact of caring for a young adult with CP as all proxies responding to this survey reported that they provided all the day-to-day care needs for the young 
adult with CP. Given the current age and health of the proxy, it may be possible to meet the current needs of the young adult with $\mathrm{CP}$; however, this may be problematic in the future when the proxy is not able to physically provide care or negotiate barriers on behalf of the individual with CP. As more adolescents with CP transition into adulthood it is important to identify alternatives for the provision of care in the future when parents may not be able to accomplish this task anymore.

The generalizability of these results to other young adults with CP with additional physical, cognitive or communication impairments is limited by the lack of a populationbased sample, geographical mailing restrictions, survey tools utilized and the small sample size. The goal of this study was to obtain a multidimensional view of health and well-being, requiring the use of a large number of instruments to address all of levels of the ICF paradigm. It has been reported in the literature that a low response rate by proxy responders for young adults with $\mathrm{CP}$ with additional physical, cognitive or communication impairments may be related to the increased burden of completing the survey perceived by the proxy. ${ }^{73}$ The survey required between 1-2 hours to complete, so completion of the survey may have placed an increased burden on the proxy, in addition to caring for their young adult with $\mathrm{CP}$. Reducing the length of the survey and determining alternative strategies to facilitate receipt and completion of the surveys may increase the sample size in future studies. While statistical significance was set 
conservatively, Bonferroni corrections were not employed, which may increase the chances of a Type I error since multiple tests were conducted.

The results of this study should be interpreted with caution as proxy response only provides an indirect account of the individuals well-being. ${ }^{72 ; 73}$ The responses provided by the proxy reflect their perception of magnitude and may incorrectly estimate the individual's perception of subjective health variables, activity, participation and environmental barriers. ${ }^{135}$ Additionally, while the proxies reported that they completed the survey, it is not possible to determine whether the young adult with CP provided any input on the responses or whether the response was only the perception of the parent. It has been reported that concordance between an individual and their parent is greater for observable or overt behaviors (physical functioning) than for internal behaviors such perception of pain, fatigue and depression. ${ }^{133}$ Approximately $25 \%$ $(10 / 40)$ of the proxy reporters in this study did not complete the impairment section of the survey, expressing that they could not make a judgment about the young adult's level of pain, fatigue and especially depression. While future studies should incorporate adaptations and modified assessment procedures to enable more youth with significant motor, cognitive and communication impairments to participate in research, it is also important to solicit responses from their parent or caregiver to provide their perspective on the health and well-being of individuals with CP. 


\section{Conclusions}

This study utilized the ICF framework to identify the impairments, activity limitations and participation restrictions in young adults with $\mathrm{CP}$ and additional physical, cognitive or communication impairments and the role of environmental barriers. While the responses from the parent responders should be viewed with caution, the responses provide perspective on the health and well-being of individuals with $\mathrm{CP}$ across the spectrum. Determining opportunities for young adults with CP to acquire vocational skills to seek a level of paid employment may not provide financial independence, but may decrease daily demands on the parent and enhance social interactions for the young adult with CP. Additionally, identifying opportunities to increase involvement in physical activity and improve participation will enhance the health and well-being of this subgroup of young adults with CP. For young adults with CP and additional physical, cognitive or communication impairments, parents play a substantial role in providing care, facilitating activity and participation and negotiating barriers. As parents and their young adult with CP continue to age, identifying alternatives for care and housing is necessary in order to be prepared for when the parent is no longer able to assume this significant role. 


\section{Chapter 7: Methodological Considerations and Potential limitations GENERALIZABILITY}

Comparison of the results from this study with other studies is limited because of the different selection criteria (ages and geographical limitation), use of different measurement instruments, cultural and economic differences (most studies have been performed on European samples) and the lack of controls using these tools. In this study, the sample was limited to young adults between the ages of $18-30$ years with a last known address in Oregon or Washington. Eligible participants were recruited using addresses from the patient databases of SHC-P and CDRC. Most of the individuals who were mailed survey packages were no longer followed clinically at SHC-P or CDRC and as such, the addresses utilized for mailing may not reflect their current residential status and surveys may have not reached the potential participant, contributing to the small sample size.

Further limitations to the generalizability of the results stem from the criteria used for inclusion in the study, specifically age, geographical restrictions and limitation to recruitment from one primary center. In order to gain insight into the functional impairments, activity limitations and participation restrictions of young adults with $\mathrm{CP}$, as they transition into adulthood, the maximum age for inclusion was 30 years, limiting the generalizability to all adults with CP. Additionally, as access to health care services 
and geographic location have a role in activity and participation, ${ }^{136}$ recruitment was limited to prospective subjects living in Oregon and Washington who had received care primarily by one institution. This regionalization limits the generalizability of the results to young adults from the Pacific Northwest.

\section{DESIGN OF THE STUDY}

For this study mail surveys were chosen as the optimal methodology to sample a large volume of subjects. While postal surveys are often utilized in health research due to their low cost and efficient, unobtrusive way to reach a large number of subjects, ${ }^{109}$ this may not have been the best method to obtain the complex information requested in the survey booklets. As this study asked questions at multiple levels, this may have been too overwhelming and mad it difficult for the young adults with CP to understand what was being asked in each survey. While the instructions for each survey tool were included in the comprehensive survey, the instructions may not have been clear enough, especially for the questionnaires that required several levels of responses.

Since length of the questionnaire has been found to influence the response rate ${ }^{109}$ this may have significantly impacted participation. In the present study the survey package was 24 pages, with an anticipated completion time, depending on reading and functional ability, between 1-2 hours. This volume of pages and the length of time to involved may have made completion of the survey overwhelming and time-consuming for the participants. 
Numerous methodologies were incorporated into the design of this study to maximize the response rate including, the provision of an incentive, developing an appealing survey pack, personally addressing the survey pack, sending two reminder cards, sending a second copy of the survey package and offering to assist with a phone interview. The return rate for the survey was low considering these methods.

Additionally, sending a second copy of the survey package has been shown to increase the odds of response by $60 \%$ in comparison to sending a reminder card only; ${ }^{109}$ however, sending a second copy of the survey pack only yielded five more completed surveys, a response rate of $3.8 \%$. Many parents called to say that they were very interested in the study and anticipated that their young adult would complete the survey; however, as they could only encourage completion of the survey, actual completion and return of the survey, often did not occur. While several ideas are offered to understand the lack of response on behalf of the young adults with $\mathrm{CP}$, it is not possible to know why they did not return the survey. Understanding why surveys were not returned, what incentives could be provided to enhance the return, and whether utilizing a mailed survey is the best method to obtain this data from this population group would be beneficial for future studies.

This study permitted a proxy to complete the survey on behalf of the young adult with $\mathrm{CP}$. One short-coming of the survey design was that it did not inquire why the young 
adult did not complete the survey independently or with assistance. Despite this, all parents reported that they completed the survey because of significant physical, cognitive or communication impairments. This information may inform future studies regarding adaptations or alternative methods (such as computer based studies) that could be employed to maximize participation. In addition, data from proxy respondents should be interpreted with caution, especially for subjective measures such as pain, fatigue and depression; ${ }^{133 ; 137 ; 72}$ as responses by the proxy reflect their perception of magnitude ${ }^{135}$ and may incorrectly estimate the individual's perception of subjective health variables and quality of life. As many proxy-respondents expressed difficulty completing the questions on subjective measures such as pain, depression, fatigue and quality of life, this reflects a need to determine survey tools or alternative testing methods to obtain this information directly from the young adult with CP.

Although contact information was provided should an individual require assistance with the survey for any reason (reading, physical ability, or language), this option was not pursued by any of the participants. Therefore it is difficult to ascertain whether the inability to read or read English prevented completion of the survey. The demographics of the respondents in this study may indicate a response bias. Although $12 \%$ of the participants were Hispanic, which is consistent with the 2012 reports from the census bureau for the populations of Oregon and Washington, ${ }^{138} 53 \%$ of the respondents were female, which is contrary to the reports in the literature which find that $\mathrm{CP}$ is more 
common in males than in females. ${ }^{139}$ Finding methods to ensure that the sample is representative of the population of individuals with $\mathrm{CP}$ would enhance the generalizability of the results.

During statistical analysis it is important to limit both the Type I (concluding there is an effect or difference, when there is none) and Type II (concluding there is no effect or difference, when there actually is one) errors. At a given sample size, Type I and Type II errors are inversely related and as such the goal is to find a reasonable balance between the two. When sample size is small and multiple comparisons are performed, it has been suggested that a Bonferroni correction (dividing the criterion $p$-value by the number of planned pairwise tests, producing a smaller $p$-value) be used to reduce the chance of making a Type I error. Recently the use of Bonferroni corrections has come under question, as it has been shown that this methodology reduces the power (increasing the Type II error). ${ }^{140}$ In this study, statistical significance was set conservatively $(p<.01)$ to account for the small sample size (self-report, $\mathrm{N}=55$, proxy-report, $\mathrm{N}=40$ ) and multiple comparisons. This adjustment of the $p$-value was judged the optimal balance of Type I and Type II errors. In addition to using statistical significance, the effect sizes (correlations) and the confidence intervals of the effect sizes were used to corroborate the findings. 


\section{OUTCOME TOOLS}

As the goal of this study was to obtain a holistic view of health and well-being using the ICF model, this required the use of a large number of instruments to address all of levels of the paradigm. The comprehensive nature of the study limited the ability to utilize outcome tools that thoroughly assess each component of the model. In order to decrease the length of the survey booklets, short forms of survey tools or single questions were used to evaluate complex concepts such as pain, health status and quality of life. While the results provide a general understanding of the areas assessed in this study, it may limit the interpretation of results. Although a comprehensive study of health and well-being has merit, it may be beneficial for future studies to focus on one component at a time, in order to allow thorough investigation with possibly a shorter assessment tool.

Recall bias could influence the accuracy or completeness of the data as time frame for each of the assessments varied from a minimum of one week for the physical activity scale to many years for the GMFCS classification. The differing time references and the extent of time to recall could impact the accuracy of the data. Additionally, the PASIPD required the individual to recall the amount of time, type of activity and the number of days per week they participated in the activity, which may significantly impact the findings. It has been shown that recall questionnaires for the assessment of physical activity tend to overestimate the amount of time spent that individuals actually do 
participate in physical activity. ${ }^{96 ; 86}$ While direct measurement of physical activity is optimal, it is difficult to do for studies recruiting a large number of subjects and therefore this study found that the use of the PAISID provided valuable insight into the intensity and time young adults with CP engage in physical activity.

Overall, the survey instruments used in this study provided the information sought for this study. While some difficulty in completing the surveys was expressed by the participants, especially for surveys with multiple levels of responses, such as the PASIPD, the CHIEF, and the Life-H, this did not prevent the surveys from being completed. Missing data was only encountered for proxy respondents who felt uncomfortable determining the level of pain and depression, satisfaction with life and satisfaction with life habits. 


\section{Chapter 8: Synthesis and Discussion}

\section{SYNTHESIS}

More individuals with $\mathrm{CP}$ are now surviving into adulthood, with a life span approaching that of the general population. While CP is considered a static condition, deterioration in function and evolving medical co-morbidities such as pain and fatigue have been reported to impact activity and participation of adults with CP. As a result, it is important to expand the research focus beyond the functional impairments, activity limitations and participation restrictions found in childhood and adolescence. To date, the consequences of aging with $\mathrm{CP}$ and the role impairments, activity limitations and participation restrictions have on health and well-being of adults with CP are poorly understood. This exploratory study used survey methodology to examine the complex relationships among the impairments in body structure and function, activity limitations, participation restrictions, personal factors and environmental barriers and to determine the impact they have on the health and well-being of young adults with CP as they transition into adulthood.

\section{MAIN FINDINGS}

Although functional motor ability has been reported to discriminate among health

outcomes in adults with $\mathrm{CP},{ }^{20 ; 21}$ there were no differences with respect to the impairments of body structure and function (change in motor level, pain, fatigue and depression) by functional motor classification. Traditionally, the focus of health care for 
children with $\mathrm{CP}$ is on diminishing motor impairments to enhance functional ability; however the large percentage of young adults in this study reporting pain, fatigue and depression indicates that the onset of these impairments is prevalent in this group of young adults with $\mathrm{CP}$ and that these impairments may begin at an earlier age. For young adults with $\mathrm{CP}$ in the self-report group, the provision of emotional support decreased the impact of pain, fatigue and depression on overall health status and satisfaction with life indicating that the provision of emotional support by parents, peers, and medical professionals is important to health and well-being in this group of young adults with CP.

The results of this study also demonstrate that although the diagnostic categorization of $\mathrm{CP}$ is homogenous, differences in functional motor ability in addition to the presence of additional impairments (physical, cognitive and communication), contribute to the heterogeneity found in the barriers encountered and level of participation in daily activities and social roles. For the group of young adults in GMFCS level I who selfreported, the magnitude of barriers and the level of participation in both daily activities and social roles was similar to that of the abled-bodied peers. As functional motor ability decreased (increasing the GMFCS classification), the magnitude of barriers increased and the level of participation decreased. For the self-report group, physical and structural barriers, services and assistance barriers and policy barriers had the greatest impact on participation in daily activities and social roles. Reports by the proxies indicate that although a significant magnitude of barriers are encountered, their impact 
on participation was minimal, as the proxy reported finding ways to negotiate many of the barriers encountered on behalf of the young adult with CP. Reports by the proxies also indicate that functional motor level impacts the ability to participate in daily activities and social roles.

The results from the self-report group indicate that, similar to their able-bodied peers the acquisition of adult social roles is on a continuum as indicated by the significant variability found in this group of young adults with CP. In contrast, proxies reported minimal variability in the acquisition of social roles as the majority of the young adults with CP lived with their parents, were not attending school, were not employed and had a current income less than $\$ 10,000$. The discrepancy between the self-report and proxyreport groups of young adults with $\mathrm{CP}$ in the acquisition of social roles indicates that the presence of additional impairments may limit the ability to transition into normative adult roles.

The health and well-being of young adults with CP is a complex multidimensional concept. The utilization of ICF framework has facilitated an understanding of the complex interactions that influence the health and well-being of young adults with $\mathrm{CP}$, including the factors that either constrain or enhance functional possibilities. Similar to a "dynamic system," the changes in one area have an impact on other areas. As the magnitude of environmental barriers impacts levels of participation, reducing these 
barriers could enhance activity and participation. Similarly, as the impairments in body structure and function increased, overall health status and satisfaction with life decreased. Thus determining mechanisms to minimize impairments, increase activity and improve participation could enhance overall health status and satisfaction with life in young adults with $\mathrm{CP}$.

\section{CLINICAL IMPLICATIONS}

Although this study was exploratory in nature, the results provide insight into the complex relationships that exist among the factors impacting the health and well-being of young adults with CP. Although these results are preliminary, they can highlight potential areas for improved coordination among professionals/providers, services/service centers, developers/companies and families (Figure 11) to enhance the health and well-being of young adults with $\mathrm{CP}$ and to identify areas for future research. 


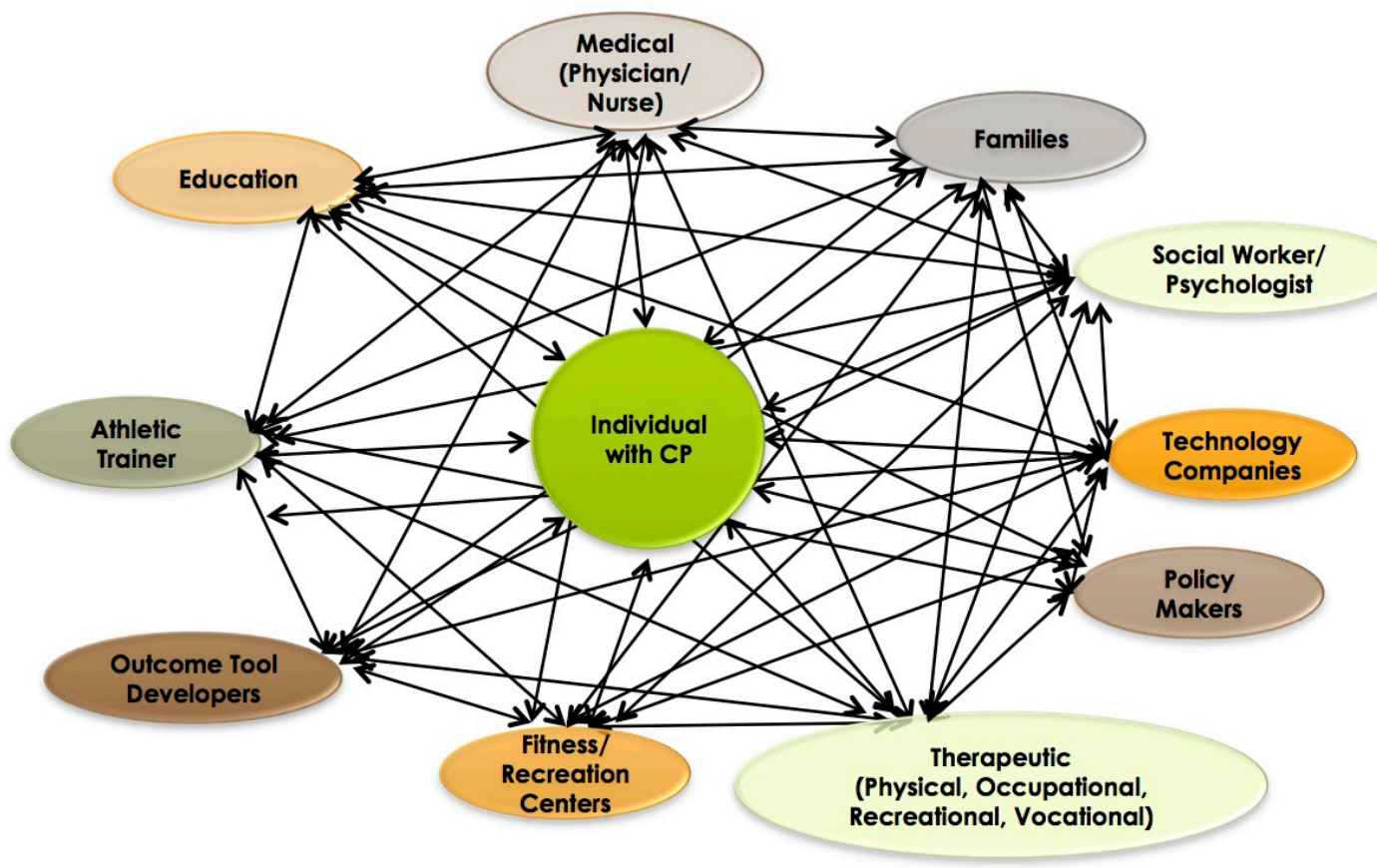

Figure 11: Representation of the Complex Relationships that exist among Professionals, SERVICES, COMPANIES, AND FAMILIES, WHICH IMPACT THE HEALTH AND WELL-BEING OF YOUNG ADULTS WITH CP

Coordination among medical professionals, services, companies, families and young

adults with $\mathrm{CP}$ to address impairments in body structure and function

Engagement of adolescents in their health care is an important factor for successful transition from the pediatric to adult health care systems. In order to prepare the adolescent with CP for the transition into adult healthcare, it is necessary to begin the process early. This could be done through the establishment of multidisciplinary transition clinics that could coordinate the services provided by the physicians, nurse, therapists, psychologists and social workers in order provide comprehensive care and ensure that medical needs and appropriate environmental adaptations are provided. 
Since the presence of pain, fatigue and depression are recognized as factors impacting the health and well-being of adults with $\mathrm{CP}$, clinics should incorporate the use of reliable, age-appropriate and easy-to use screening tools that accurately assess the intensity and location of pain, magnitude of fatigue and the presence of depression. In addition to addressing the primary impairments related to $\mathrm{CP}$, identification of secondary impairments would help ensure that these physical and psychological aspects are not overlooked and are addressed with appropriate multidisciplinary support and medical intervention. ${ }^{84}$ As a transition clinic could serve as the link between the pediatric and adult health care systems, enhancing the education of health care providers treating individuals with $\mathrm{CP}$ on issues related to aging with $\mathrm{CP}$ and the development of secondary conditions, sexuality, pregnancy, relationships, substance abuse, mental health, and recreational activities in order to provide continuity of care between the two systems.

Environmental barriers play a role in participation in both daily activities and social roles; minimizing the gap between the individuals' functional abilities and the demands of the social and physical environment could occur with adaptations to the environment and the provision of assistive technology and augmentative communication. Coordination of services including equipment vendors and technology companies could adapt the home and school environment. Appropriate training on equipment use by physical and occupational therapists could facilitate independence in both daily activities and social roles as adolescents transition into young adulthood. 
Transition programs could incorporate self-reporting by the adolescents with $\mathrm{CP}$ whenever possible to promote autonomy, improve self-confidence and provide young adults with $\mathrm{CP}$ the knowledge and skills required to negotiate the adult health care system independently. As the provision of emotional support played a significant role in the health and well-being of young adults with $\mathrm{CP}$, transition clinics could incorporate alternative strategies, such as peer support groups, mentors or adult role models to augment the family support. This could be beneficial in improving the health status and satisfaction with life in young adults with CP. Planning ahead for long term needs and promoting acquisition of developmentally appropriate self-management skills and competencies teach young adults with $\mathrm{CP}$ that leaving the pediatric care system is not a precursor for drastic declines in health. ${ }^{141}$

Coordination among medical professionals, services, companies, families and young adults with $\mathrm{CP}$ to address activity limitations

Individuals with CP are often perceived to be in poor health due to the presence of physical impairments or deficits and therefore are often excluded from health promotion efforts. ${ }^{1}$ This study found that many young adults with CP did not participate in moderate to high intensity physical activity or stretching and strengthening programs. Given the many health benefits (physical, social and psychological) associated with physical activity, physical and occupational therapists could coordinate instruction and training for these activities into their rehabilitation programs during adolescence as a Chapter 8 
mechanism to incorporate physical activity into the daily routines of young adults with $\mathrm{CP}$ once they transition out of the pediatric system. Physical, occupational and recreational therapists could also coordinate with fitness professionals in local communities to identify potential fitness activities and environmental adaptations that would provide young adults with CP access to local fitness and recreation programs. Additionally, since feeling self-conscious and not having anyone to work out with were given as reasons for not participating in fitness, establishing mechanisms at fitness clubs or recreational centers for providing exercise mentors or partners may enhance participation of the young adult with CP in physical activity.

Coordination among medical professionals, services, companies, families and young adults with CP to address participation restrictions

The results of this study demonstrate that participation in daily activities and social roles is based on the level of functional impairment and the presence of additional impairments. Coordination among many professionals and services is needed to improve participation in daily activities and social roles. The services of occupational and physical therapists, the provision of assistive devices and adaptations to home environment would enhance participation in daily activities. Additionally, the coordination of services among physical, occupational and recreational therapists, as well as school and vocational counselors would improve participation in social roles, especially with the provision of assistive devices, augmentative communication and environmental adaptations. Acquiring the necessary skills to assume adult social roles Chapter 8 
requires a coordinated effort by both the rehabilitation and school systems in order to plan and prepare the young adult with CP for future independent living, education and employment. Similar to their able-bodied peers, obtaining advanced education facilitates employment and will serve to enhance independence, increase participation and potentially enhance satisfaction with life for young adults with CP. While not all young adults with CP are able to advance their education beyond high school due to physical, cognitive and communication impairments, coordination between physical, occupational and vocational therapists could identify opportunities and provide necessary environmental adaptations for young adults with $\mathrm{CP}$ to acquire vocational skills to seek employment, decreasing the daily demands on the parent, and enhancing social interactions for the young adult with $\mathrm{CP}$.

\section{General Summary}

One area that is significantly lacking in the Unites States is the development and utilization of registries. In the Europe and Australia, registries have been developed to document the incidence of specific conditions, in addition to tracking treatments and outcomes over time. The development of a registry in the United States would enhance our understanding of the factors that impact the health of young adults with $\mathrm{CP}$, in order to identify areas for change.

It is hoped that by linking young adults with CP and their families with the appropriate health care professionals and services, increasing access to physical activity programs 
and facilities, reducing environmental barriers, providing vocational training and empowering youth to take control of their lives, we can enhance participation and improve the health and well-being of young adults with $\mathrm{CP}$.

\section{RECOMMENDATIONS FOR FUTURE RESEARCH}

Research to reduce the impact of impairments in body and structure

This study found that the presence of pain, fatigue and depression were prominent in this population of young adults with CP. Future research should examine the complex relationship among these factors in order to determine areas for intervention. In order to focus treatment interventions for young adults with $\mathrm{CP}$, future studies should examine whether contextual factors (family patterns, socioeconomic status, individual experience), adolescent developmental variables related to transitioning to adulthood or factors related to their disability (pain, fatigue, loss of function and/or decreased physical activity and participation) impact depression in young adults with CP.

\section{Research to improve physical activity}

The results of this study found that participation in moderate to high intensity physical activity was limited in young adults with CP. Future research should examine whether incorporating activities at various intensity levels during childhood and adolescence when parents are available to assist and encourage participation, facilitates continued participation in physical activity during young adulthood. While Healthy People 2020 provides national objectives for improving the health of all Americans, ${ }^{113}$ research 
should determine whether the recommended guidelines for physical activity are appropriate for all individuals with $\mathrm{CP}$, or whether they should be adjusted based on gross motor function level. For able-bodied individuals, the fitness benefits for the various levels (low, moderate and high intensity) and types (aerobic, strengthening and stretching) are well established. Future research should investigate the impact of different activities at varying levels of intensity on fitness in order to determine the health benefits of specific activities for individuals with $\mathrm{CP}$, and to make specific recommendations regarding physical activities for individuals with CP across the lifespan. The results of this study also found that environmental barriers impacted participation in physical activity and recreation. Investigation of the role environmental adaptations have on reducing these barriers could improve participation of physical activity during adulthood.

\section{Research to enhance participation}

This study found that all types of environmental barriers (physical/ structural, work/school, attitudes/support, services/assistance and policies) impacted participation of young adults with CP in daily activities and social roles. Future research should specifically evaluate each of the subdomains of the CHIEF to identify potential areas of the environment that could be changed to reduce the barriers for all individuals with $\mathrm{CP}$ regardless of the functional abilities. Advanced education facilitates employment and financial independence; future studies should focus on determining the factors that prevent more young adults with CP from pursuing advanced education. Additionally, as 
the use of technology increases, future studies should determine how these advancements in technology could enhance independence and opportunities for acquisition of adult social roles.

Recently, research has been focused toward identifying potential interventions ${ }^{127}$ and vocational rehabilitation services ${ }^{128 ; 129}$ to improve employment outcomes for young adults with physical disabilities. Since the acquisition of adult social roles is extremely important in facilitating independence, future research should continue to investigate potential interventions and services, such as interview training, "role" models, on-thejob training, job placement assistance, on-the-job support, maintenance services, and rehabilitation technology ${ }^{128 ; 127}$ that could enhance employment opportunities for young adults with $\mathrm{CP}$.

\section{General research ideas}

To date, many of the large studies evaluating impairments, activity limitations and participation restrictions have been performed in Europe and Australia. Expanding a survey similar to the present study to a larger group of individuals across the entire United States would provide enhanced understanding of the issues impacting young adults with $\mathrm{CP}$ and would help identify areas for intervention, specifically at the national policy level. 
Lincoln and Guba, 1985, proposed that the purpose of research inquiry is to "resolve" the problem or question by accumulating sufficient knowledge to lead to an enhanced understanding or explanation. ${ }^{142}$ As this study utilized quantitative survey methodology only, it is important that future studies incorporate mixed methodology to gain a thorough understanding of the comprehensive factors that impact health and wellbeing. Integrating data from both quantitative and qualitative methods will enhance understanding of the factors that impact the health and well-being of young adults with $\mathrm{CP}$ that may not have been uncovered when using a single methodology. 


\section{References}

1 Kim K, Fox M. (2006) Moving to a holistic model of health among persons with mobility disabilities. Qual Soc Work 5: 470-88.

2 Putnam M, Geenen S, Powers L, Saxton M, Finney S, Dautel P. (2003) Health and wellness: people with disabilities discuss barriers and facilitators to well being. J Rehabil 69: 37-45.

3 Becker $\mathrm{H}$, Schaller J. (1995) Perceived health and self-efficacy among adults with cerebral palsy. J Rehabil April/May/June: 36-42.

$4 \quad$ Becker $\mathrm{H}$, Schaller J. (1995) Perceived health and self-efficacy among adults wtih cerebral palsy. J Rehabil April/May/June: 36-42.

$5 \quad$ Merriam-Webster. Merriam-Webster's Online Dictionary.

6 WHO. (2001) International Classification of Functioning, Disability and Health. Geneva: World Health Organization.

7 Rosenbaum P, Rosenbloom L. (2012) Cerebral Palsy from diagnosis to adult life. London: MacKetih Press.

8 Rimmer J. (2006) Use of the ICF in identifying factors that impact participation in physical activity/rehabilitation among people with disabilities. Disabil and Rehabil 28: 1087-95.

9 Majnemer A. (2012) The purpose and framework for this text. In: A Majnemer editor. Measures for children with Developmental Disabilities An ICY-CY approach London: Mac Keith Press. p 10-5.

10 Ramstad K, Jahnsen R, Skjeldal OH, Diseth TH. (2012) Parent-reported participation in children with cerebral palsy: the contribution of recurrent musculoskeletal pain and child mental health problems. Dev Med Child Neurol 54: 82935.

11 Rosenbaum P, Paneth N, Leviton A, Goldstein M, Bax M, Damiano D, Dan B, Jacobsson B. (2007) A report: the definition and classification of cerebral palsy April 2006. Dev Med Child Neurol Suppl 109: 8-14.

12 Doralp S, Bartlett D. (2010) The prevalence, distribution, and effect of pain among adolescents with cerebral palsy. Pediatr Phys Ther 22: 26-33.

13 Paneth N, Hong T, Korzeniewski S. (2006) The descriptive epidemiology of cerebral palsy. Clin Perinatol 33: 251-67.

14 Cox D, Weze C, Lewis C. (2005) Cerebral palsy and ageing: a systematic review. London. p 1-81.

15 Strauss D, Brooks J, Rosenbloom L, Shavelle R. (2008) Life expectency in cerebral palsy: an update. Dev Med Child Neurol 50: 487-93.

16 Strauss D, Shavelle R, Reynolds R, Rosenbloom L, Day S. (2007) Survival in cerebral palsy in the last 20 years: signs of improvement. Dev Med Child Neurol 49: 8692.

17 Murphy K. (2010) The adult with cerebral palsy. Orthop Clin N Am 41: 595-605. 
18 Palisano R, Rosenbaum P, Walter S, Russell D, Wood E, Galuppi B. (1997) Gross Motor Function Classification System for Cerebral Palsy. Dev Med Child Neurol 39: 21423.

19 Palisano RJ, Cameron D, Rosenbaum PL, Walter SD, Russell D. (2006) Stability of the gross motor function classification system. Dev Med Child Neurol 48: 424-8.

20 Jahnsen R, Aamodt G, Rosembaum P. (2006) Gross motor function classification system used in adults with cerebral palsy: agreement of self-reported versus professional rating. Dev Med Child Neurol 48: 734-8.

21 Sandstrom K, Alinder J, Oberg B. (2004) Descriptions of functioning and health and relations to a gross motor classification in adults with cerebral palsy. Disabil Rehabil 26: 1023-31.

22 McDonagh J, Kelly D. (2010) The challenges and opportunities for transitional care research. Pediatr Transplantation 14: 688-700.

23 Stewart D, Freeman M, Law M, Healy H, Burke-Geffney J, Forhan M, Young N, Guenther S. (2010) The transition to adulthood for youth with disabilities:evidence from the literature. Int Encyclo Rehabil Buffalo: Center for International Rehabilitation Research Information and Exchange. p 1-25.

24 Gleason B, Palmer J, Bhagat S, Reiss J. (2009) Enhancing health care transition for youth and young adults living with chronic medical conditions and disabilities.

25 McCormick A, Brien M, Plourde J, Wood E, Rosenbaum P, McLean J. (2007)

Stability of the Gross Motor Function Classification System in adults with cerebral palsy. Dev Med Child Neurol 49: 265-9.

26 Bell L, Sawyer S. (2010) Transition of care to adult services for pediatric solidorgan transplant recipients. Pediatr Clin N Am 57: 593-610.

27 While A, Forbes A, Ullman R, Lewis S, Mathes L, Griffiths P. (2004) Good practices that address continuity during transition from child to adult care: synthesis of the evidence. Child: Care, Health \& Development 30: 439-52.

28 Andersson C, Mattsson E. (2001) Adults with cerebral palsy: a survey describing problems, needs, and resources, with special emphasis on locomotion. Dev Med Child Neurol 43: 76-82.

29 Bottos M, Feliciangeli A, Sciuto L, Gericke C, Vianello A. (2001) Functional status of adults with cerebral palsy and implications for treatment of children. Dev Med Child Neurol 43: 516-28.

30 Tosi LL, Maher N, Moore DW, Goldstein M, Aisen ML. (2009) Adults with cerebral palsy: a workshop to define the challenges of treating and preventing secondary musculoskeletal and neuromuscular complications in this rapidly growing population. Dev Med Child Neurol 51 Suppl 4: 2-11.

31 van der Slot WMA, Nieuwenhuijsen C, VanDenBerg-Emons R, Bergen $M$, Hilberink S, Stam H, Roebroeck M. (2012) Chronic pain, fatigue, and depressive symptoms in adults with spastic bilateral cerebral palsy. Dev Med Child Neurol 54: 83642. 
32 Gajdosik CG, Cicirello N. (2001) Secondary conditions of the musculoskeletal system in adolescents and adults with cerebral palsy. Phys Occup Ther Pediatr 21: 49-68. 33 Murphy KP, Molnar GE, Lankasky K. (1995) Medical and functional status of adults with cerebral palsy. Dev Med Child Neurol 37: 1075-84.

34 Schwartz L, Engel JM, Jensen MP. (1999) Pain in persons with cerebral palsy. Arch Phys Med Rehabil 80: 1243-6.

35 Turk MA. (2009) Health, mortality, and wellness issues in adults with cerebral palsy. Dev Med Child Neurol 51 Suppl 4: 24-9.

36 Turk MA, Geremski CA, Rosenbaum PF, Weber RJ. (1997) The health status of women with cerebral palsy. Arch Phys Med Rehabil 78: S10-7.

37 Opheim A, Jahnsen R, Olsson E, Stangelle J. (2009) Walking function, pain, and fatigue in adults with cerebral palsy: a 7-year follow-up study. Dev Med Child Neurol 51: 381-8.

38 Liptak G. (2008) Health and well being of adults with cerebral palsy. Curr Opin Neurol 21: 136-42.

39 Hombergen SP, Huisstede BM, Streur MF, Stam HJ, Slaman J, Bussmann JB, van den Berg-Emons RJ. (2012) Impact of cerebral palsy on health-related physical fitness in adults: systematic review. Arch Phys Med Rehabil 93: 871-81.

40 van der Slot WM, Nieuwenhuijsen C, van den Berg-Emons RJ, Wensink-Boonstra AE, Stam HJ, Roebroeck ME. (2010) Participation and health-related quality of life in adults with spastic bilateral cerebral palsy and the role of self-efficacy. J Rehabil Med 42: 528-35.

41 Washburn RA, Zhu W, McAuley E, Frogley M, Figoni SF. (2002) The physical activity scale for individuals with physical disabilities: development and evaluation. Arch Phys Med Rehabil 83: 193-200.

42 Lollar D. (2001) Public health trends in disability. In: G Albrecht, K Sleeman, M Bury editors. Handbook of disability studies London: Sage Publications. p 754-71.

43 Vogtle LK. (2009) Pain in adults with cerebral palsy: impact and solutions. Dev Med Child Neurol 51 Suppl 4: 113-21.

44 van der Dussen L, Nieuwstraten W, Roebroeck M, Stam HJ. (2001) Functional level of young adults with cerebral palsy. Clin Rehabil 15: 84-91.

45 Matlow A, Wright J, Zimmerman B, Thomson K, Valente M. (2006) How can the principles of complexity science be applied to improve the coodination of care for complex pediatric patients? Qual Saf Health Care 15: 85-8.

46 Palisano RJ, Rosenbaum P, Bartlett D, Livingston MH. (2008) Content validity of the expanded and revised Gross Motor Function Classification System. Dev Med Child Neurol 50: 744-50.

47 Palisano R, Rosenbaum P, Walter S, Russell D, Wood E, Galuppi B. (1997)

Development of a system to classify gross motor function in children with cerebral palsy. Dev Med Child Neurol 39: 214-23.

48 (2011) Behavioral Risk Factor Surveillance System Questionnaire. In: HaH Services editor. Atlanta, Georgia: Centers for Disease Control and Prevention (CDC).

References 
49 Keller S, Bann C, Dodd S, Schein J, Mendoza T, Cleeland C. (2004) Validity of the Brief Pain Inventory for use in documenting the outcomes of patients with noncancer pain. Clin J Pain 20: 309-18.

50 CDC. (2011) Centers for Disease Control and Prevention (CDC). Behavioral Risk Factor Surveillance System Survey Questionnaire. In: CfDCaP Department of Health and Human Services editor. Atlanta, Georgia: U.S.

51 Michielsen HJ, De Vries J, Van Heck GL. (2003) Psychometric qualities of a brief self-rated fatigue measure: The Fatigue Assessment Scale. J Psychosom Res 54: 345-52.

52 Zuithoff NP, Vergouwe Y, King M, Nazareth I, van Wezep MJ, Moons KG, Geerlings MI. (2010) The Patient Health Questionnaire-9 for detection of major depressive disorder in primary care: consequences of current thresholds in a crosssectional study. BMC family practice 11: 98.

53 van der Ploeg HP, Streppel KR, van der Beek AJ, van der Woude LH, VollenbroekHutten M, van Mechelen W. (2007) The Physical Activity Scale for Individuals with Physical Disabilities: test-retest reliability and comparison with an accelerometer. J Phys Act Health 4: 96-100.

54 van den Berg-Emons RJ, L'Ortye A, Buffard L, Nieuwenhuijsen C, Nooijen C, Bergen M, Stam HJ, Bussmann J. (2011) Validation of the physical activity scale for individuals with physical disabilities. Arch Phys Med Rehabil 92: 923-8.

55 Poulin V, Desrosiers J. (2009) Reliability of the LIFE-H satisfaction scale and the relationship between participation and satisfaction of older adults with disabilities. Disabil and Rehabil 31: 1311-7.

56 Noreau L, Desrosiers J, Robichaud L, Fougeyrollas P, Rochette A, Viscogliosi C. (2004) Measuring social participation: reliability of the LIFE-H in older adults with disabilities. Disabil Rehabil 26: 346-52.

57 Department CHR. (2001) Craig Hospital Inventory of Environmental Factors (CHIEF). Englewood, CO: Craig Hospital.

58 Whiteneck G, Brooks C, Charlifue S, Gerhart K, Mellick D, Overholser D, Richardson G. (2001) Craig Hospical Inventory of Environmental Factors (CHIEF) Manual. 59 Whiteneck GG, Harrison-Felix CL, Mellick DC, Brooks CA, Charlifue SB, Gerhart KA. (2004) Quantifying environmental factors: a measure of physical, attitudinal, service, productivity, and policy barriers. Arch Phys Med Rehabil 85: 1324-35.

60 Wallston KA. (2005) The validity of the multidimensional health locus of control scales. J Health Psychol 10: 623-31.

61 Wallston KA, Stein MJ, Smith CA. (1994) Form C of the MHLC Scales: A ConditionSpecific Measure of Locus of Control. J Personality Assess 63: 534-53.

62 Frisch D, Msall ME. (2013) Health, functioning, and participation of adolescents and adults with cerebral palsy: a review of outcomes research. Develop Disabil Res Reviews 18: 84-94.

63 Ando N, Ueda S. (2000) Functional deterioration in adults with cerebral palsy. Clin Rehabil 14: 300-6. 
64 Furukawa A, Iwatsuki H, Nishiyana M, Nii E, Uchida A. (2001) A study on the subjective well-being of adult patients with cerebral palsy. J Phys Ther Sci 13: 31-5.

65 Jahnsen R, Villien L, Stanghelle JK, Holm I. (2003) Fatigue in adults with cerebral palsy in Norway compared with the general population. Dev Med Child Neurol 45: 296303.

66 Jensen MP, Engel JM, Schwartz L. (2006) Coping with cerebral palsy pain: a preliminary longitudinal study. Pain Med 7: 30-7.

67 Jahnsen R, Villien L, Egeland T, Stanghelle JK, Holm I. (2004) Locomotion skills in adults with cerebral palsy. Clin Rehabil 18: 309-16.

68 Krakovsky G, Huth MM, Lin L, Levin RS. (2007) Functional changes in children, adolescents, and young adults with cerebral palsy. Research in developmental disabilities 28: 331-40.

69 Ramstad K, Jahnsen R, Skjeldal OH, Diseth TH. (2011) Characteristics of recurrent musculoskeletal pain in children with cerebral palsy aged 8 to 18 years. Dev Med Child Neurol 53: 1013-8.

70 Livingston MH, Rosembaum PL, Russell DJ, Palisano RJ. (2007) Quality of life among adolescents with cerebral palsy: what does the literature tell us? Dev Med Child Neurol 49: 225-31.

71 Vargus-Adams J. (2005) Health-related quality of life in childhood cerebral palsy. Arch Phys Med Rehabil 86: 940-5.

72 White-Koning M, Arnaud C, Bourdet-Loubere S, Bazex H, Colver A, Grandjean H. (2005) Subjective quality of life in children with intellectual impairment--how can it be assessed? Dev Med Child Neurol 47: 281-5.

73 White-Koning M, Grandjean H, Colver A, Arnaud C. (2008) Parent and professional reports of the quality of life of children with cerebral palsy and associated intellectual impairment. Dev Med Child Neurol 50: 618-24.

74 Jensen MP, Kuehn CM, Amtmann D, Cardenas DD. (2007) Symptom burden in persons with spinal cord injury. Arch Phys Med Rehabil 88: 638-45.

75 Day SM, Wu YW, Strauss DJ, Shavelle RM, Reynolds RJ. (2007) Change in ambulatory ability of adolescents and young adults with cerebral palsy. Dev Med Child Neurol 49: 647-53.

76 Jahnsen R, Villien L, Aamodt G, Stanghelle J, Holm I. (2004) Musculoskeletal pain in adulsts with cerebral palsy compared with the general population. J Rehabil Med 37: 78-84.

77 Hirsh AT, Gallegos JC, Gertz KJ, Engel JM, Jensen MP. (2010) Symptom burden in individuals with cerebral palsy. JRRD 47: 863-76.

78 Park MJ, Paul Mulye T, Adams SH, Brindis CD, Irwin CE, Jr. (2006) The health status of young adults in the United States. J Adolesc Health 39: 305-17.

79 Young N, Rochon T, McCormick A, Law M, Hedge J, Fehlings D. (2010) The health and quality of life outcomes among youth and young adults with cerebral palsy. Arch Phys Med Rehabil 90: 143-8. 
80 Becker H, Schaller J. (1995) Perceived health and self-efficacy among adults with cerebral palsy. J Rehabilit April/May/June: 36-42.

81 Opheim A, Jahnsen R, Olsson E, Stanghelle JK. (2011) Physical and mental components of health-related quality of life and musculoskeletal pain sites over seven years in adults with spastic cerebral palsy. J Rehabil Med 43: 382-7.

82 King G, Willoughby C, Specht JA, Brown E. (2006) Social support processes and the adaptation of individuals with chronic disabilities. Qual Health Res 16: 902-25.

83 Horsman M, Suto M, Dudgeon B, Harris SR. (2010) Ageing with cerebral palsy: psychosocial issues. Age Ageing 39: 294-9.

84 Parkes J, White-Koning M, Dickinson HO, Thyen U, Arnaud C, Beckung E, Fauconnier J, Marcelli M, McManus V, Michelsen SI, Parkinson K, Colver A. (2008)

Psychological problems in children with cerebral palsy: a cross-sectional European study. Journal of child psychology and psychiatry, and allied disciplines 49: 405-13.

85 Li C, Chen S. (2012) Exploring experiences of physical activity in special school students with cerebral palsy: a qualitative perspective. EUJAPA 5: 7-17.

86 Maher CA, Williams MT, Olds T, Lane AE. (2007) Physical and sedentary activity in adolescents with cerebral palsy. Dev Med Child Neurol 49: 450-7.

87 Boucher N, Dumas F, Maltais DB, Richards CL. (2010) The influence of selected personal and environmental factors on leisure activities in adults with cerebral palsy. Disabil Rehabil 32: 1328-38.

88 Rimmer JH, Riley B, Wang E, Rauworth A, Jurkowski J. (2004) Physical activity participation among persons with disabilities Barriers and Facilitators. Am J Prev Med 26: 419-25.

89 Law M, Petrenchik T, King G, Hurley P. (2007) Perceived environmental barriers to recreational, community, and school participation for children and youth with physical disabilities. Arch Phys Med Rehabil 88: 1636-42.

90 Sandstrom K, Samuelsson K, Oberg B. (2009) Prerequisites for carrying out physiotherapy and physical activity - experiences from adults with cerebral palsy. Disabil REhabil 31: 161-9.

91 Specht J, King G, Brown E, Foris C. (2002) The importance of leisure in the lives of persons with congenital physical disabilities. Am J Occup Ther 56: 436-45.

92 Rimmer JH. (1999) Health promotion for people with disabilities: the emerging paradigm shift from disability prevention to prevention of secondary conditions. Phys Ther 79: 495-502.

93 van den Berg-Emons HJ, Saris WH, de Barbanson DC, Westerterp KR, Huson A, van Baak MA. (1995) Daily physical activity of schoolchildren with spastic diplegia and of healthy control subjects. J Pediatr 127: 578-84.

94 van den Berg-Emons RJ, Fc S, de Vos L, Bussman J, Stam HJ. (2007) Impact of chronic pain on everyday physical activity. European Journal of Pain 11: 587-93.

95 van Eck M, Dallmeijer AJ, Beckerman $H$, van den Hoven PA, Voorman JM, Becher JG. (2008) Physical activity level and related factors in adolescents with cerebral palsy. Pediatric exercise science 20: 95-106. 
96 Heller T, Ying Gs GS, Rimmer JH, Marks BA. (2002) Determinants of exercise in adults with cerebral palsy. Public Health Nurs 19: 223-31.

97 Low Choy N, Isles R, Barker R, Nitz J. (2003) The efficacy of a work-station intervention programme to improve functional ability and flexibility in ageing clients with Cerebral Palsy: a pilot study. Disabil REhabil 25: 1201-7.

98 Jahnsen R, Villien L, Aamodt G, Stangelle J, Holm I. (2003) Physiotherapy and physical activity - experiences of adults with cerebral palsy, with implications for children. Advances in Physiotherapy 5: 21-32.

99 Fowler EG, Kolobe TH, Damiano DL, Thorpe DE, Morgan DW, Brunstrom JE, Coster WJ, Henderson RC, Pitetti KH, Rimmer JH, Rose J, Stevenson RD, Section on Pediatrics Research Summit P, Section on Pediatrics Research Committee Task F. (2007) Promotion of physical fitness and prevention of secondary conditions for children with cerebral palsy: section on pediatrics research summit proceedings. Phys Ther 87: 1495510.

100 Peterson M, gordon P, Hurvitz E. (2013) Chronic disease risk among adults with cerebral palsy: the role of premature sarcopoenia, obesity and sedentary behaviour. Obesity Reviews 14: 171-82.

101 Buffart LM, Roebroeck ME, Rol M, Stam HJ, van den Berg-Emons RJ. (2008) Triad of physical activity, aerobic fitness and obesity in adolescents and young adults with myelomeningocele. J Rehabil Med 40: 70-5.

102 Buffart L, Westendorp T, vandenBerg-Emons R, Stam H, Roebroeck M. (2009) Perceived barriers to and facilitators of physical activity in young adults with childhooldonset physical disabilities. J Rehabil Med 41: 881-5.

103 Verschuren O, Wiart L, Hermans D, Ketelaar M. (2012) Identification of facilitators and barriers to phyiscal activity in children and adolescents with cerebral palsy. J Pediatr 161: 488-94.

104 Glanz K, Rimer BK, Viswanath K editors. (2008) Health behvior and health education theory, research and practice. San Francisco: Jossey-Bass.

105 van den Berg-Emons RJ, L'Ortye AA, Buffart LM, Nieuwenhuijsen C, Nooijen CF, Bergen MP, Stam HJ, Bussmann JB. (2011) Validation of the Physical Activity Scale for individuals with physical disabilities. Arch Phys Med Rehabil 92: 923-8.

106 Nieuwenhuijsen C, van der Slot WM, Dallmeijer AJ, Janssens PJ, Stam HJ, Roebroeck ME, van den Berg-Emons HJ, Transition Research Group South West N. (2011) Physical fitness, everyday physical activity, and fatigue in ambulatory adults with bilateral spastic cerebral palsy. Scandinavian journal of medicine \& science in sports 21 : 535-42.

107 Nieuwenhuijsen C, van der Slot WM, Beelen A, Arendzen JH, Roebroeck ME, Stam HJ, van den Berg-Emons RJ. (2009) Inactive lifestyle in adults with bilateral spastic cerebral palsy. J Rehabil Med 41: 375-81.

108 van der Slot WM, Roebroeck ME, Landkroon AP, Terburg M, Berg-Emons RJ, Stam HJ. (2007) Everyday physical activity and community participation of adults with hemiplegic cerebral palsy. Disabil Rehabil 29: 179-89.

References 
109 Sahlqvist S, Song Y, Bull F, Adams E, Preston J, Ogilvie D, consortium i. (2011) Effect of questionnaire length, personalisation and reminder type on the response rate to a complex postal survey: randomised controlled trial. BMC Medical Research Methodology 11: http://www.biomedical central.com/1471-2288/11/62.

110 Shikako-Thomas K, Shevell M, Schmitz N, Lach L, Law M, Poulin C, Majnemer A, Group TQ. (2013) Determinants of participation in leisure activities among adolescents with cerebral palsy. Res Develop Disabilit 34: 2621-34.

111 Kerr C, McDowell B, McDonough S. (2006) The relationship between gross motor function and participation restriction in children with cerebral palsy: an exploratory analysis. Child Care Health Dev 33: 22-7.

112 Mc Manus V, Corcoran P, Perry IJ. (2008) Participation in everyday activities and quality of life in pre-teenage children living with cerebral palsy in South West Ireland. BMC Pediatr 8: 50.

113 (2012) Healthy People 2020. Atlanta, GA: Centers for Disease Control and Prevention.

114 Andren E, Grimby G. (2004) Dependence in daily activities and life satisfaction in adult subjects with cerebral palsy or spina bifida: a follow-up study. Disabil REhabil 26: 528-36.

115 Nieuwenhuijsen C, Donkervoort M, Nieuwstraten W, Stam H, Roebroeck M, Netherlands TRGSW. (2009) Experienced problems of young adults with cerebral palsy: targets for rehabilitation care. Arch Phys Med Rehabil 90: 1891-7.

116 Gorter J, Stewart D, Woodbury-Smith M. (2011) Youth in transition: care, health and development. Child Care Health Dev 37: 757-63.

117 Schulenberg J, Bryant A, O'Malley P. (2004) Taking hold of some kind of life: How developmental tasks relate to trajectories of well-being during the transition to adulthood. Develop Psychopath 16: 119-1140.

118 Morris C, Kurinczak J, Fitzpatrick R, Rosenbaum P. (2006) Do the abilities of children with cerebral palsy explain their activities and participation. Dev Med Child Neurol 48: 954-61.

119 Colver A. (2009) Quality of life and participation. Dev Med Child Neurol 51: 656-9. 120 Levasseur M, Desrosiers J, Noreau L. (2004) Is social participation associated with quality of life of older adults with physical disabilities. Disabil and Rehabil 26: 1206-13. 121 Vogts N, Mackey AH, Ameratunga S, Stott NS. (2010) Parent-perceived barriers to participation in children and adults with cerebral palsy. J Paediatr Child Health 46: 680-5.

122 Beckung E, Hagberg G. (2002) Neuroimpairments, activity limitations, and participation restrictions in children with cerebral palsy. Dev Med Child Neurol 44: 30916.

123 Fauconnier J, Dickinson HO, Beckung E, Marcelli M, McManus V, Michelsen SI, Parkes J, Parkinson KN, Thyen U, Arnaud C, Colver A. (2009) Participation in life situations of 8-12 year old children with cerebral palsy: cross sectional European study. BMJ 338: b1458. 
124 Majnemer A, Shevell M, Law M, Birnbaum R, Chilingaryan G, Rosenbaum P, Poulin C. (2008) Participation and enjoyment of leisure activities in school-aged children with cerebral palsy. Dev Med Child Neurol 50: 751-8.

125 Vogtle LK. (2013) Employment outcomes for adults with cerebral palsy: an issue that needs to be addressed. Dev Med Child Neurol 55: 973.

126 FamiliesUSA. (2013) 2013 Federal Poverty Guidelines. Washington, DC.

127 Verhoef JA, Miedema HS, Van Meeteren J, Stam HJ, Roebroeck ME. (2013) A new intervention to improve work participation of young adults with physical disabilities: a feasibility study. Dev Med Child Neurol 55: 722-8.

128 Huang IC, Holzbauer JJ, Lee EJ, Chronister J, Chan F, O'Neil J. (2013) Vocational rehabilitation services and employment outcomes for adults with cerebral palsy in the United States. Dev Med Child Neurol 55: 1000-8.

129 Huang IC, Wang YT, Chan F. (2013) Employment outcomes of adults with cerebral palsy in Taiwan. Disabil Rehabil 35: 228-35.

130 Colver A, Thyen U, Arnaud C, Beckung E, Fauconnier J, Marcellli M, McMAnus V, Michelsen SI, Parkes J, Parkinson K, Dickinson HO. (2012) Association between participation in life situations of children with cerebral palsy and their physical, social, and attitudinal environment: a cross-sectional multicenter European study. Arch Phys Med Rehabil 93: 2154-64.

131 Odding E, Roebroeck ME, Stam HJ. (2006) The epidemiology of cerebral palsy: incidence, impairments and risk factors. Disabil Rehabil 28: 183-91.

132 Cella D, Hahn EA, Jensen SE, Butt Z, Nowinski CJ, Rothrock N. (2012)

Methodological Issues In The Selection, Administration And Use Of Patient-Reported

Outcomes In Performance Measurement In Health Care Settings. Northwestern University. p 1-63.

133 Cohen LL, Vowles KE, Eccleston C. (2010) Adolescent chronic pain-related functioning: concordance and discordance of mother-proxy and self-report ratings. Eur J Pain 14: 882-6.

134 Parkes J, McCullough N, Madden A. (2010) To what extent do children with cerebal palsy participate in everyday life. Health and Social Care in the Community 18: 304-15.

135 Burns TM, Graham CD, Rose MR, Simmons Z. (2012) Quality of life and measures of quality of life in patients with neuromuscular disorders. Muscle \& nerve 46: 9-25.

136 Colver A, Thyen U, Arnaud C, Beckung E, Fauconnier J, Marcelli M, McManus V, Michelsen SI, Parkes J, Parkinson K, Dickinson HO. (2012) Association between participation in life situations of children with cerebral palsy and their physical, social, and attitudinal environment: a cross-sectional multicenter European study. Arch Phys Med Rehabil 93: 2154-64.

137 Verrips G, Vogels A, denOuden A, Paneth N, Verloove-Vanhorick S. (2000) Measuring health-related quality of life in adolsecents: agreement between raters and between methods of administration. Child Care Health Dev 26: 457-69. 
138 (2012) U.S Census Bureau: State and County QuickFacts. U.S Census Bureau. p Data derived from population estimates, American community survey, Census of population and housing, state and county housing unit estimates, county business patterns, nonemployer statistics, economic census, survey of buisiness owners, building permits.

139 Johnston MV, Hagberg H. (2007) Sex and the pathogenesis of cerebral palsy. Dev Med Child Neurol 49: 74-8.

140 Nakagawa S. (2004) A farewell to Bonferonni: the problems of low statistical power and publication bias. Behavioral Ecology 15: 1044-5.

141 Binks J, Barden W, Burke T, Young N. (2007) What do we really know about the transition to adult-centered health care? A focus on cerebral palsy and spina bifida. Arch Phys Med Rehabil 88: 1064-73.

142 Johnstone P. (2004) Mixed Methods, Mixed Methodology Health Services Research in Practice. Qual Health Res 14: 259-71. 